Geethanjali Chandramouli

Bachelor of Engineering, Visvesvaraya Technological University (2011)

\author{
A project \\ presented to Ryerson University \\ in partial fulfilment of the \\ requirements for the degree of \\ Master of Engineering \\ in the program of \\ Aerospace Engineering
}

Toronto, Ontario, Canada, 2019

(C) Geethanjali Chandramouli 2019 


\section{AUTHOR'S DECLARATION FOR ELECTRONIC SUBMISSION OF A PROJECT}

I hereby declare that I am the sole author of this project. This is a true copy of the project, including any required final revisions, as accepted by my examiners.

I authorize Ryerson University to lend this project to other institutions or individuals for the purpose of scholarly research.

I further authorize Ryerson University to reproduce this project by photocopying or by other means, in total or in part, at the request of other institutions or individuals for the purpose of scholarly research.

I understand that my project may be made electronically available to the public. 


\title{
FINITE ELEMENT MODELING OF 3D PRINTED PARTS WITH DEFECTS
}

Geethanjali Chandramouli

Master of Engineering, Aerospace Engineering, Ryerson University, Toronto (2019)

\begin{abstract}
To manufacture a component, one first needs to assess its structural design performance, damage tolerance, and service experience, and validate them with pertinent test results. Finite Element (FE) modeling can predict mechanical performance, save time and cost by limiting required structural testing. 3D printing is a layer-by-layer manufacturing technology that has been widely used for rapid prototyping applications in product design and development. Recently, there has been a move towards manufacturing functional products using 3D printing, which requires materials mechanical characterization and simulation. Mechanical characterization testing results are available for 3D printed ASTM D638 tensile coupons without defects, i.e. tension along $\left(0^{\circ}\right)$ and transverse $\left(90^{\circ}\right)$ to the printing direction, and a quasiisotropic stacking sequence. In addition, tensile test results of a quasi-isotropic coupon with intentional defects are also available. In this project, FE models of the coupons are created to obtain their tensile strength, modulus, and failure strain. First ply, last ply failure and stiffness reduction iterative approach have been implemented on a 2D shell model. MSC Software is used to simulate the analyses due to its ease of use for composites using $2 \mathrm{~d}$ shell elements. This simulation is then extended to predict strength and stiffness of a quasi-isotropic coupon with defects. The analysis is also extended to implement progressive failure analysis to predict the ultimate strength of the laminate. For coupons without defects, FE models estimated test results of stiffness and strength within $1 \%$ error, while the error for estimating failure strain is higher. For coupons with defects, the error in calculating stiffness and strength is below $8 \%$, while it is higher for failure strain. Although the stress-strain curve from FE simulation looks similar to experimental result, it is found that progressive failure analysis is necessary for obtaining failure strain values with acceptable error percentage.
\end{abstract}




\section{ACKNOWLEDGEMENTS}

Firstly, I would like to thank my supervisors Dr. Kazem Fayazbakhsh of the Department of Aerospace Engineering at Ryerson University. His guidance and support helped me advance my knowledge and understanding in the field of 3D printing technology and Advanced Composite Materials. His constant feedbacks have been very valuable in steering my project work towards the right direction.

I would like to acknowledge Mr. Prashanth Pawar and Jagga Rao from UTC Aerospace Systems for their support in the MSC Software part of my research. Their constant guidance and feedback was instrumental to the knowledge I gained in solving progressive analysis of composites using MSc Software.

Finally, I would like to thank my family for their understanding, support and encouragement throughout this journey 


\section{TABLE OF CONTENTS}

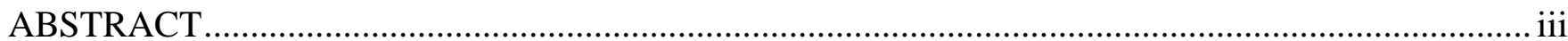

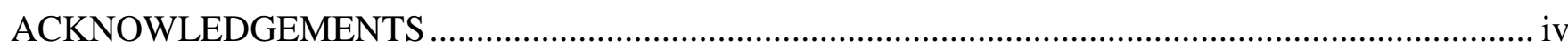

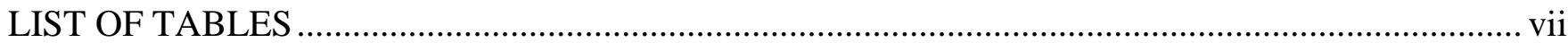

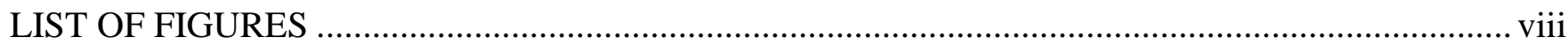

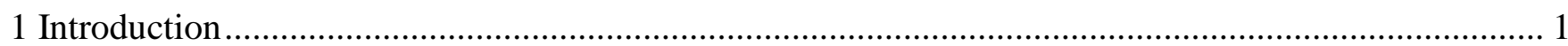

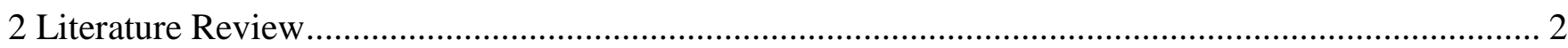

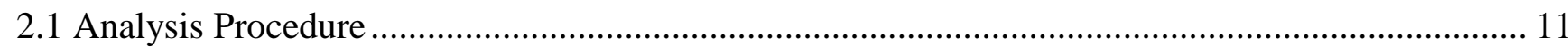

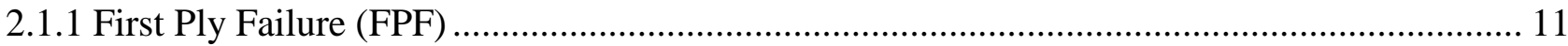

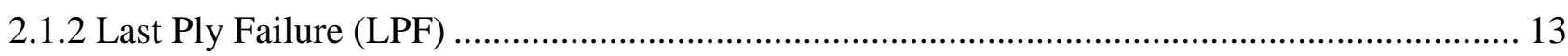

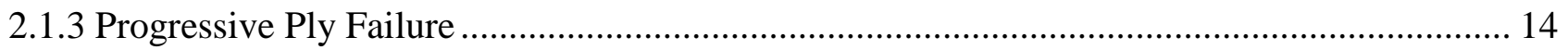

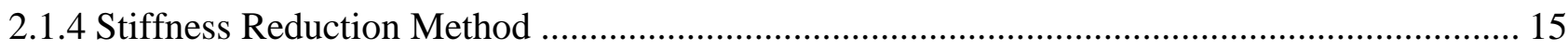

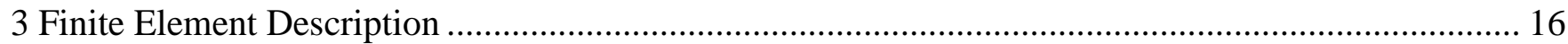

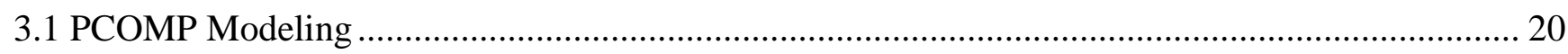

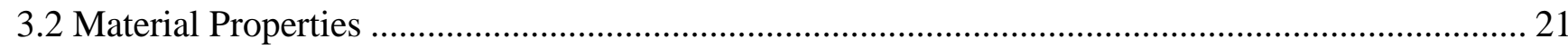

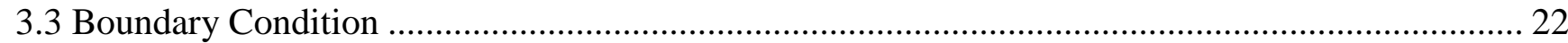

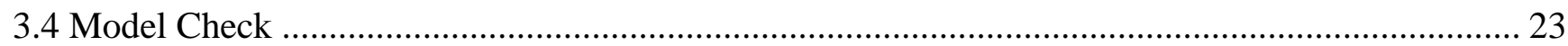

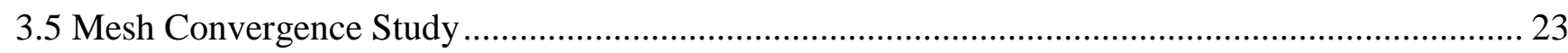

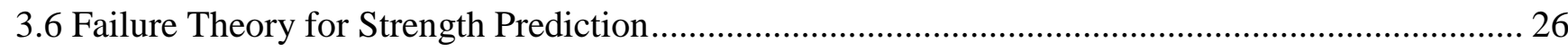

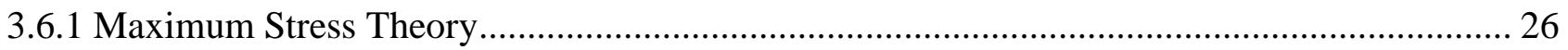

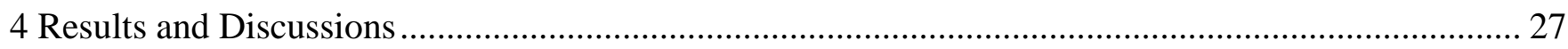

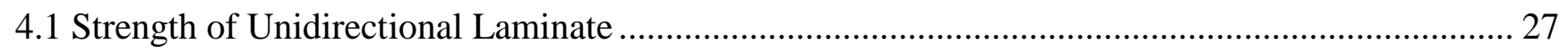

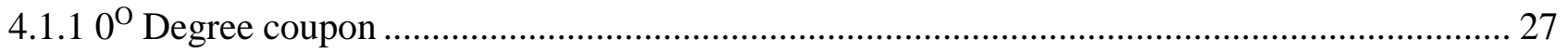




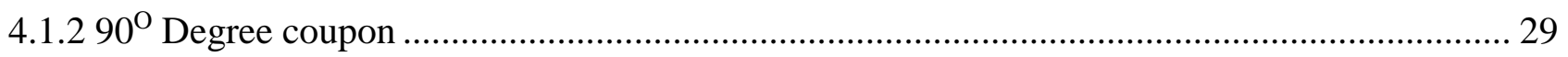

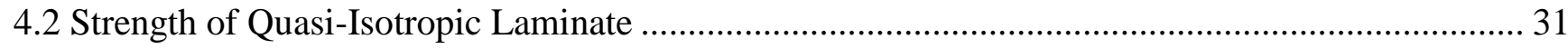

4.3 Strength of Quasi-Isotropic Laminate with Defect ......................................................... 36

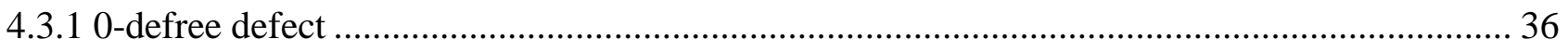

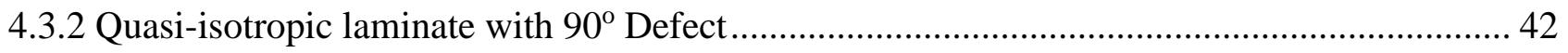

4.3.3 Quasi-isotropic laminate with $0^{\circ}$ and $90^{\circ}$ Defect...................................................... 45

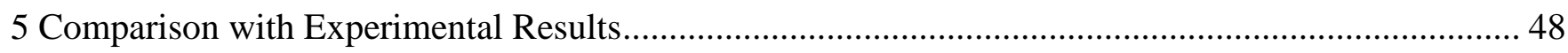

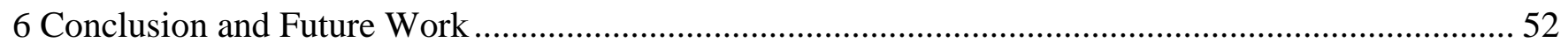

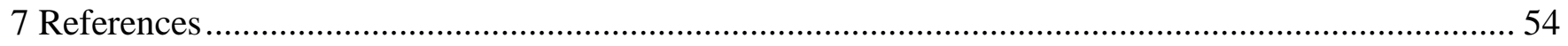

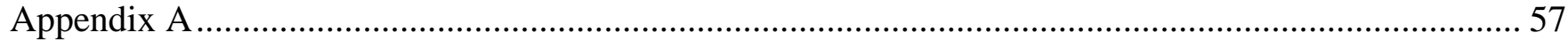




\section{LIST OF TABLES}

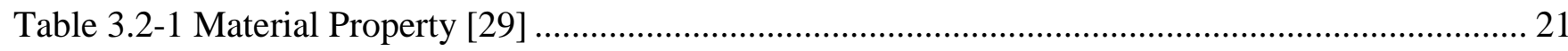

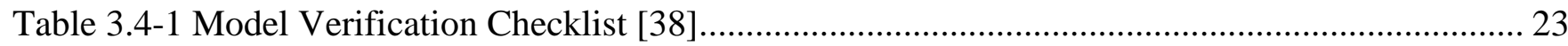

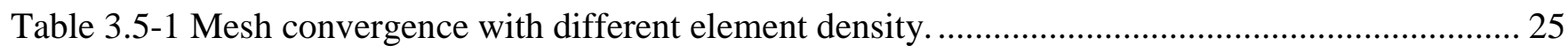

Table 4.1-1 Ply-wise Stresses and their Failure Index for $\left(0^{\circ}\right.$ ply $)$ laminate …….................................... 28

Table 4.1-2 Ply-Wise Stresses and their Failure Index for $\left(90^{\circ}\right.$ ply) laminate.......................................... 30

Table 4.2-1 Ply-Wise Stresses and their Failure Index for quasi-isotropic laminate - FPF. ..................... 32

Table 4.2-2 Ply-wise Stresses and their Failure Index for quasi-isotropic laminate - LPF...................... 34

Table 4.3-1 Ply-Wise Stresses and Failure Index for quasi-isotropic laminate - $0^{\circ}$ Defect, LPF............. 37

Table 4.3-2 Ply-Wise Stresses and their Failure Index for quasi-isotropic laminate - $0^{\circ}$ Defect............. 40

Table 4.3-3 Ply-Wise Stresses and their Failure Index for quasi-isotropic laminate - $90^{\circ}$ Defect........... 43

Table 4.3-4 Ply-Wise Stresses and Failure Index for quasi-isotropic laminate $-0^{\circ}$ and $90^{\circ}$ Defect........ 46

Table 4.3-1 FEA and Experimental Result Comparison- Unidirectional laminate.................................... 48

Table 4.3-2 FEA and Experimental Result Comparison- Unidirectional laminate.................................... 49

Table 4.3-3 FEA and Experimental Result Comparison- Quasi-Isotropic laminate................................ 49

Table 4.3-4 FEA and Experimental Result Comparison- $0^{\circ}$ Defect. ..........................................................5 50

Table 4.3-5 FEA and Experimental Result Comparison-90 Defect. .................................................. 50

Table 4.3-6 FEA and Experimental Result Comparison- $0^{\circ}$ and $90^{\circ}$ Defect. ......................................... 51 


\section{LIST OF FIGURES}

Figure 1-1 Schematic of the FFF process (Carneiro, OS., et al [1]).................................................... 1

Figure 2-1 Transformation of stresses and strains in element to material coordinate system. ................. 11

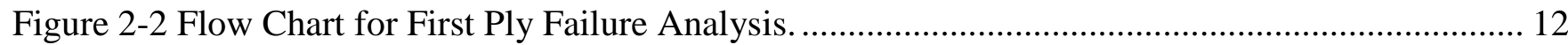

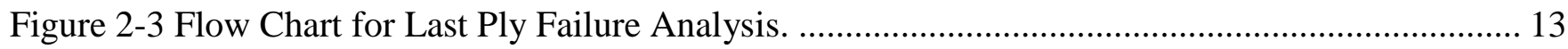

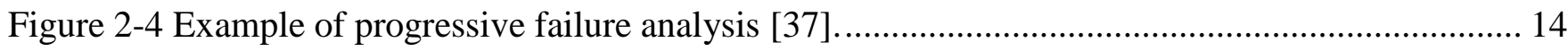

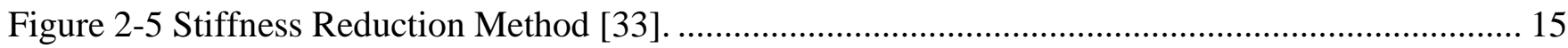

Figure 3-1 Finite element model representation of coupon with ASTM standard test specimen (ASTM

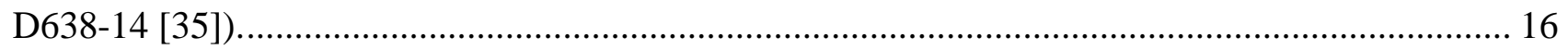

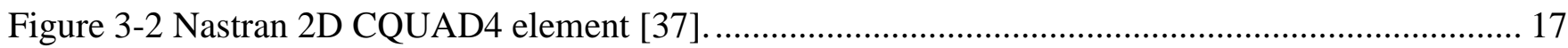

Figure 3-3 CQUAD4 Element Geometry and Coordinate Systems [37]............................................. 18

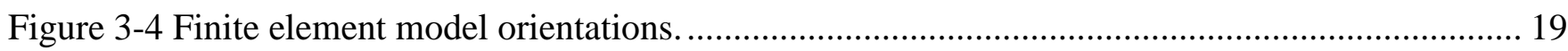

Figure 3-5 Finite element model: Element and Material Orientations. .................................................... 19

Figure 3-6 Finite element model: 2D model and thickness representation. ........................................... 20

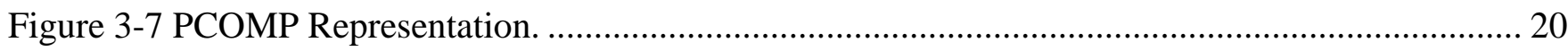

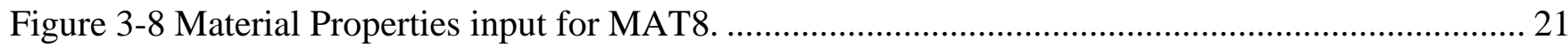

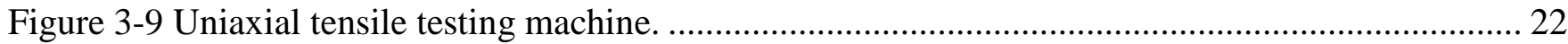

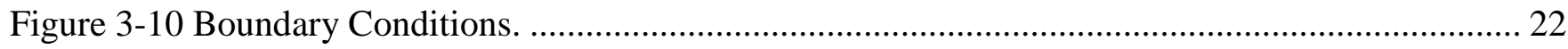

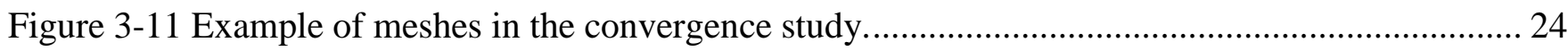

Figure 3-12 A plot of Von Mises stress versus n shows the changes in stress results for the different mesh

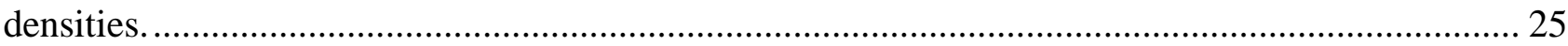

Figure 3-13 Laminae material and element co-ordinate system [34] . ................................................. 26

Figure 4-1 FEA Results - Constraint forces for unidirectional $\left(0^{\circ}\right.$ ply) laminate $(\mathrm{N} / \mathrm{mm})$. ..................... 27

Figure 4-2 FEA Results - Constraint forces for unidirectional $\left(90^{\circ} \mathrm{ply}\right)$ laminate $(\mathrm{N} / \mathrm{mm})$. ................... 29

Figure 4-3 FEA Results - Constraint forces for quasi-isotropic laminate - FPF - (N/mm) ..................... 31

Figure 4-4 Tensile test results: (a) Experimental results for $0^{\circ}, 90^{\circ}$ and quasi-isotropic laminate [29] (b)

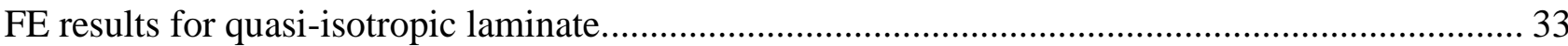

Figure 4-5 FEA Results - Constraint forces for quasi-isotropic laminate - LPF - (N/mm). ................... 33

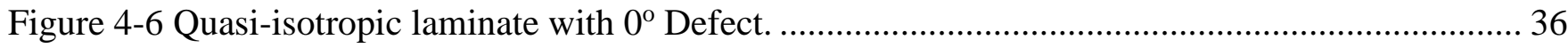

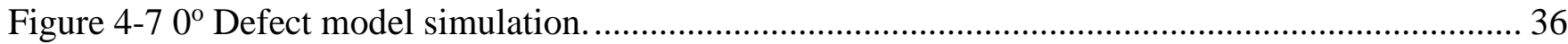

Figure 4-8 FEA Results - Constraint forces for quasi-isotropic laminate $-0^{\circ}$ Defect, LPF - (N/mm) ... 38 
Figure 4-9 FEA Results - Constraint forces for quasi-isotropic laminate - $0^{\circ}$ Defect - (N/mm). 39

Figure 4-10 Load Averaging for $0^{\circ}$ Defect Coupon. ....................................................................... 39

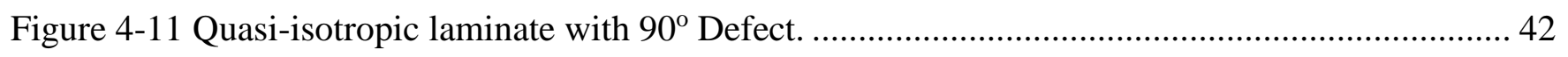

Figure 4-12 FEA Results - Constraint forces for quasi-isotropic laminate - 90 Defect - (N/mm)....... 42

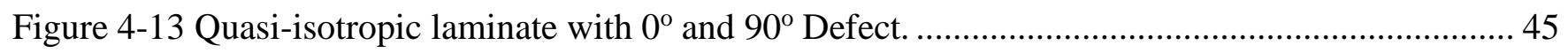

Figure 4-14 FEA Results - Constraint forces for quasi-isotropic laminate $-0^{\circ}$ and $90^{\circ}$ Defect - $(\mathrm{N} / \mathrm{mm})$.

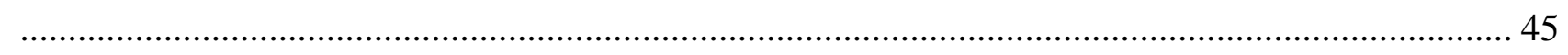

Figure 34 Sign Convention for In-Plane Transformation Angle $\theta$ [34] .......................................... 58

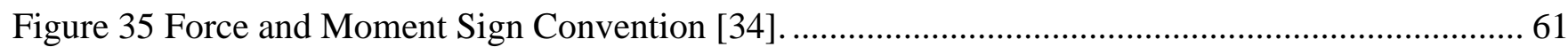

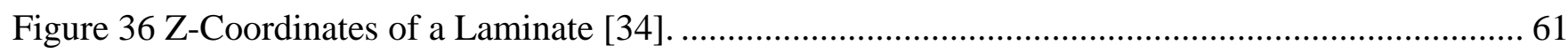




\section{INTRODUCTION}

Fused Filament Fabrication (FFF) 3D printing employs manufacturing parts built on a layer-by-layer basis, through a series of cross-sectional slices. As opposed to subtractive manufacturing techniques, like Computer Numerical Control (CNC) machining, the process of FFF creates a 3D part by adding layers on top of layers. Fused Filament Fabrication is widely used for manufacturing pure plastic and fiber reinforced composite parts. In FFF process, a filament is heated to a molten state inside the liquefier at a temperature above its melting point and is pushed through a nozzle by the still solid upstream filament (Figure 1-1). The extruded material is laid down onto the platform that might be heated as well.

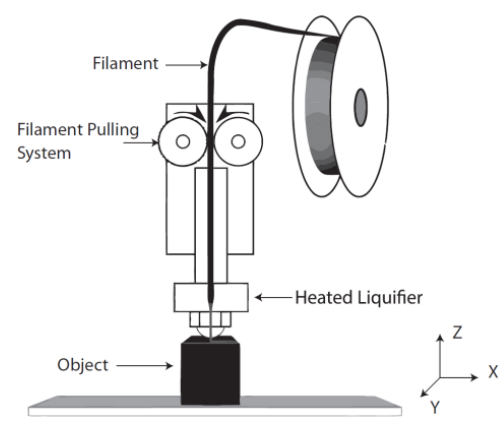

Figure 1-1 Schematic of the FFF process (Carneiro, OS., et al [1]).

3-D printers use slicer software that creates cross-sections (slices) of each part and determines exactly how each layer is to be constructed. In near future, the choice of commercial applications for 3-D printing can skyrocket as new 3-D printers are ready to accommodate larger products and come through bigger levels of accuracy. There ought to likewise be striking decreases in material and apparatus costs as more people and firms receive this 3-D printing. Additionally, the usage of 3-D printing will increase due to the development of materials with greater strength and resistance to heat [2].

When compared to other manufacturing methods, the nature of FFF produced parts is dependent to the specific parameters that affect the mechanical properties of the completed part. As opposed to numerous conventional manufacturing processes, the material experiences a basic phase change amongst the procedure, changing its geometry as well as its mechanical properties. Preparing plan and parameters in FFF assume an increasingly critical job in the basic execution of the part. A similar part geometry fabricated with two distinct arrangements of process parameters will by and large 
outcome in parts with altogether different basic properties. As a result, FFF processes lead to an anisotropic distribution of material properties in the fabricated part, which is usually not represented and accounted for in the part's design model. The accuracy of downstream applications, such as structural analysis, depends on the ability not only to model the geometry of the produced part, but also the mechanical properties of the material. The material properties might be assessed at three scales: material phase change occurring at the micro, meso and macro scale. As FFF process is rapidly evolving from a technology to prototype products in the conceptual design stage into a manufacturing process for the end-use load-bearing functional components, it is imperative to develop a computational infrastructure that allows mechanical analysis to be performed directly on the manufactured part.

\section{LITERATURE REVIEW}

Several studies and approaches have been made by researchers to simulate and reproduce the results from experiments either in analytical models or FEA approach. Huang and Singamneni [3] have discussed the mechanical property such as strength and stiffness of an FFF manufactured part being dependent on the raster angle and thickness for which they have developed a sophisticated analytical model. These analytical models are developed to predict the elastic stress, strain and moduli using the plane stress approach, which takes into consideration of the inter-road coalescence (bonding). Rate of coalescence is also determined based on the analytical model which varies from 0 to 1 mentioned by Frenkel [4] and Eshelby [5]. They have shown how bonding between the extrudates plays a role in influencing the mechanical characterization of the parts produced. Results were validated with experimental data, where samples built with various raster angles showed the ultimate tensile strength gradually decreasing with an increase in raster angle. A good correlation was observed between experimental results and analytical predictions in the case of the ultimate strength, validating the models. The elastic modulus decreased with increasing raster angle and attained a minimum at around $50^{\circ}$ to $60^{\circ}$. The shear modulus remained constant at lower raster angles, but gradually decreased beyond 45 at varying rates depending on the magnitude of coalescence. Analytically, the Poisson's ratio is observed to vary widely with varying coalescence and raster angles. Also, the rotation of individual strands (plastic spin) is found to peak at around 45 raster angle, for different levels of coalescence. 
Similar kind of study was conducted by Bayraktar et al. [6] where the mechanical performance based on raster angle, layer thickness and melt temperature was studied. For analytical simulation, artificial neural networks (ANNs) models are used which incorporates various training algorithms and Analytical simulation for predicting systems performance. ANNs are composed of networks of layers and of interconnecting nodes (also called neurons). It consists of three groups of layers: input layer, hidden layers, and output layer. In the experimental setup, parameters such as, acceleration, bed temperature, infill percentage and printing speed were kept constant. From experimental and analytical models, crisscross $\left(+45^{\circ} / 45^{\circ}\right)$ raster pattern were observed to have the highest tensile strength which is the only paper in the review that discusses this result. At low melt temperatures, low tensile strength values were observed, whereas with rise in melt temperature, tensile strength values of most of the samples were observed to improve. The increase in layer thickness led to a decrease in tensile strength values for the crisscross and the vertical raster patterns, while it led to improved tensile strength values for the horizontal raster pattern. The max of $6.44 \%$ error was observed for experimental to analytical validation for vertical raster pattern. In the crisscross raster pattern the fibers in the material is found to uniformly distribute the stress, preventing stress buildups, due to which the validation resulted in $0 \%$ error.

Liu et al. [7] proposed a new two- stage approach to modeling and estimating the effective elastic properties of parts manufactured by the Fused Filament Fabrication (FFF) process. First, they have constructed an implicit illustration of an effective mesoscale geometry, material model of the printed structure that considers the details of the process and its material information. Then, its homogenized model at macro scale is taken through a solution of an integral equation which is articulated using Green's function. They showed that the integral equation can be transformed into a linear equation system that can be efficiently solved with Fourier transformation. The calculated homogenized properties are then validated both by the finite element method and by experimental results. A voxelized finite element mesh of the mesoscale geometry material printed model was created by every query point within the effective material domain as a linear element with 8 nodes on a dog bone coupon (ASTM D3039). The output of FEA analysis is the nodal displacement field and it is differentiated numerically to derive the strain field. Averaged strain and stress are computed through the displacement and traction on the boundary of the material domain. The predicted effective material properties were found to be in good agreement with known experimental results and with the homogenization results predicted by the finite element method within $10 \%$ error. 
Casavola et al. [9] implemented hand calculation using classical laminate theory to determine the mechanical properties of an FFF manufactured part and later validated the results using experimental data. They investigated and compared Polylactic Acid (PLA) and Acrylonitrile butadiene styrene (ABS) composite material in the paper. The tests on the wire filament show that the PLA has a Young's modulus and UTS values that are about twice the values of ABS, while PLA shows brittle nature. Experimental setup was created with single layer tests and for symmetric, balanced stack sequence $[+30 /-30 / 0 /-30 /+30]$. The single layer tests highlighted the orthotropic behavior of the FFF parts showing a reduction of the mechanical characteristics with an increase in raster angle. The mean reduction in Young's modulus from $0^{\circ}$ to $90^{\circ}$ raster angle was $35.7 \%$ for ABS and $11.1 \%$ for PLA. The mean reduction in UTS was $74.3 \%$ and $55.2 \%$ for ABS and PLA, respectively. The hand calculation results for young's modulus with the use of CLT showed a good capability to predict mechanical properties in both materials with an error of $4.7 \%$ for PLA and $6.6 \%$ for ABS material. Alaimo et al. [10] have investigated how mesostructure impacts macro-scale mechanical properties of ABS experimentally and validated the same with hand calculation. With the studies conducted by various researchers they found it apt to implement CLT with Tsai-hill failure criterion in hand calculation to determine the in-plane stiffness and strength of the specimens with varying thickness and extrudates width. The paper conducts experiment on various raster angles to simulate the behavior for this change in diameter of the filament. Since a detail FEA model has not been used for the study in this paper the error percentages are between $15 \%-20 \%$ in predicting the in-plane stiffness and strength.

Domingo-Espin et al. [8] have studied a 3D FEM model to simulate FFF parts and correlating this finite element analysis simulation with physical testing. They conducted experiments to determine the nine mechanical constants, i.e. three Young's moduli, three Poisson's ratio, and three shear moduli that define the stiffness matrix of an orthotropic material. To obtain nine independent constants values of the stiffness matrix, thirty Polycarbonate samples were built and tested in six different orientations. The stiffness matrix for the orthotropic constitutive model was used to simulate the mechanical response of the parts that were tested. Six different simulations were made, one for each orientation and one model in which isotropic properties are considered. This was used for comparison on how accurate the results would be when considering orthotropic simulation in FEA. The mechanical constants used in the isotropic simulation were obtained using the mean values of elastic modulus, Poisson's ratio and shear in directions 1, 2 and 3. Ansys software is used to simulate the deformation 
of an L-bracket part with combined bending and torsion loading. Since the load is not always applied in the same position due to bending, a contact was set for this area. For finite element modeling, Hexahedral mesh (Solid 185) was used for all the linear and static loading cases. Total element number of 10476 and total node number of 14008 were used in the model. Flexural stiffness coefficient (F/d) was calculated for each model with different raster angles, but with each model the difference was low $(2.1 \%)$ as the effect of orientation did not really matter and the same was observed for experimental data. The paper concluded that anisotropic material properties should be considered when using FEA simulation of FFF parts exceeding the elastic region limit. For elastic deformations, authors proposed that the material can be considered isotropic with the mean values of the mechanical properties, since the results do not show large variation when anisotropic properties are considered.

Researchers have also worked on developing complicated 3D FEA simulation using a representative volume element. Rodríguez et al. [16] have developed 3D FEA computational models to determine stiffness and strength of FFF parts. The FE simulation was obtained from micrographs of the mesostructure part. Effective elastic modulus is obtained using an elastic approach based on asymptotic theory of homogenization mentioned in Nemat-Nasser et al. [17]. In this work, it was assumed that a representative volume element (RVE) can be defined for building the constitutive model. RVE, also called the unit cell, is the smallest volume over which a measurement can be made that will yield a value representative of the whole. Once the RVE was defined, a mathematical homogenization theory was used to transform the constitutive characteristics of heterogeneous composite material to that of a homogeneous material with effective properties that result in equivalent average macroscopic response. FE with RVE approach for unidirectional ABS materials showed good correlation with experimental values of moduli and strength within $10 \%$ error. Similar study was conducted by Somireddy et al. [11] in which RVE model captured the influence of orientation, printing direction and layer thickness on the mechanical performance of the printed parts. To investigate this, a RVE was built in FE which simulates the horizontal and vertical plane taken from the mesostructured of the specimens. The RVE of the horizontal plane is taken only from the single layer of the specimen and then the constitutive matrix of the layer is computed using homogenization. The stresses, $\sigma_{\mathrm{ij}}$ and strains $\varepsilon_{\mathrm{ij}}$, are the local fields at any point in the RVE. The L-bracket structure was then manufactured via FFF with the following process parameters: lines infill pattern, $100 \%$ infill density, raster angle of $0^{\circ}$ and $90^{\circ}$ from the $\mathrm{x}$-axis, layer thickness of $0.317 \mathrm{~mm}$, and $10 \%$ overlap between the adjacent extrudates. The RVE is defined in local coordinate system $\mathrm{x}_{1}, \mathrm{x}_{2}$ and $\mathrm{x}_{3}$, which are aligned in the 
direction of length, width and thickness of the specimens, respectively. Three-dimensional hexahedron elements with eight nodes, C3D8, were used in the RVEs modeling. FE modeling was performed in Hypermesh (Altair Engineering) and the homogenization is completed using the micromechanics plugin in Abaqus. Since the RVE is subject to six different strains, six different load cases were prepared to determine the unknown elements in the constitutive matrix, $\mathrm{C}$. Then the FE simulation for homogenization of the material was carried out and the 9 unknown elements of the orthotropic constitutive matrix were calculated. The results obtained using numerical homogenization were compared with the elastic moduli of the experiments conducted by various literature. The variation of elastic moduli was between $12 \%-17 \%$ which were conducted by the researchers. They discussed the various reasons for the variation in the present analysis results and experimental. One was due to that the mesostructure represented in the FE model which was not the exact replication of the mesostructure in the test coupons. Furthermore, it was assumed that the bonding between the adjacent extrudates was prefect, which does not correspond to the ideal scenario in printed coupons. The maximum stress in all cases occurred at the interface of the extrudates since less material was present at the interface. Therefore, the weakest section in the mesostructure was the interface and was more prone to initiation of cracks during loading. Based on homogenization, some researchers found the coupons printed in the upright or on-edge orientation cannot be characterized using CLT. The computed stiffness value of constitutive matrix from the analysis was different from that of experiment for upright and flat build orientation of the part of same thickness. It was found that with an increase in the part thickness printed in the upright and on-edge build orientation their material behavior changes from orthotropic to transversely isotropic.

Another example of 3D FEA modeling was studied by Maidin et al. [12] of an additive manufactured textile for stab resistant vest. They took 5 different cross-sectional designs for the stab resistant textile made of ABS material and designed it in SolidWorks. FEA models were built for these five designs on an $85 \times 88 \mathrm{~mm}$ plate with tetra mesh and Ansys software was used for the simulation. An impact force hitting on the textile material with different cross section was simulated. Model 5 with lowest maximum total deformation of $3.8 \mathrm{~mm}$ was found to be the safest design for the wearer to be protected from injury on their bodies.

In all the above research works, researchers have assumed that the bonding between extrudates is perfect. Few researchers have shown how the bonding between the extrudates can be affected due to 
the nozzle extrudates deposition strategy and how it affects the mechanical property of the part. Li et al. [19] have proposed a various strategies of infill density of extrudates which controls the strength of the part. They proposed set of equations in which the density of the gap between the extrudates can be calculated for both positive and negative gaps. The input dimension parameters of the gap between the extrudates are captured in a microscope. Based on the gap density between the extrudates, the strength and modulus can be calculated. Different deposition densities, orientations and their combinations were studied in the paper to study their effect properties. The results were compared with the experimental data and the proposed set of equations were validated. The results showed good correlation between theoretical and experimental values with a maximum of $12 \%$ difference. Similar to the above, Gurrala et al. [21] have created a mathematical model for necking growth (the gap between filaments) by considering the surface tension, Newtonian flow and viscosity of filaments. All these equations are dependent based of the filaments deposited on the build plate from the nozzle. The bonding between extrudates in intra-layer and inter-layer bonding are studied based on combination of processes of molecular diffusion and cross-linking of polymeric chains of the material. Samples have been 3D printed with unidirectional ply layup with both 0 and 90 degree and tensile testing has been performed to determine the average tensile strength of the part. Variation of the dimensionless neck radius between the extrudates as a function of the dimensionless time is plotted. The mathematical model predicted dimensionless neck radius value of 1.41 which is very close to 1.5 obtained by experimental results. The ultimate tensile load predicted by the mathematical model was slightly overestimated by $8 \%$ when compared with the experimental results.

Kulkarni [20] has studied variation of effective stiffness affected by the inter and intra layer bonding, void, diameter of the nozzle, layer thickness and volume fraction of voids with respect to the extrudate deposition on the part. He used classical laminate theory and included void factor in the mathematical model for the inter-layer and intra layer in the stiffness calculation. Models were created with various raster angles and a tensile test is performed to determine the stiffness of each coupon. In addition, the effect of Poison's ratio with an imperfect bonding between adjacent extrudates is also studied. Although the printing speed was kept constant at $0.7 \mathrm{in} / \mathrm{sec}$, the spiral path was much faster since the indexing of the nozzle to start multiple contours was eliminated. The stiffness obtained from the composite laminate analysis showed higher (15\%) error when compared to experimental results. The correlation became better with less than $5 \%$ error as the void factor was included in the calculation with respect to the experimental tests. However, it is informed that these effects were limited to elastic 
analysis for a part made of polymers and was only valid for small deformations. Zhang et al. [14] have discussed extrudates width, layer thickness and nozzle speed parameters affecting the residual stress in an FFF generated part. Three levels (low, medium, and high) of each factor were used: 0.25, 0.5 , and $1.0 \mathrm{~mm}$ for the extrudate width, $0.127,0.254$, and $0.508 \mathrm{~mm}$ for the layer thickness, and 32 , 64, and $96 \mathrm{~mm} / \mathrm{s}$ for the nozzle speed have been studied. A combination of the effects has been studied and 3D FEA model in ANSYS is used for simulation. The simulations indicated that the residual stress accumulations increased with an increase in the extrudate width and the layer thickness by about 30\%. Similarly, Bellini et al. [18] have studied tool path, such as contour, raster or hybrid style affecting the mechanical properties of the FFF part. Zhang [15] and Cattenone [22] have shown how thermal loads due to extrudates placement from nozzle head affect the residual stresses with respect to different tool path in FFF process. They focused on the simulation of the meso/macroscopic structure of the FFF process using ABAQUS software. The effect of mesh size, material model, and time step interval has been discussed along with experimental validation. It was observed that the time step has a large influence on the local temperature distribution during the printing process, while it has a minor influence on the mechanical analysis with Von mises stress results. A finer meshing strategy was suggested in a case of small models to investigate local effects, while a coarser mesh was recommended in a case of larger models in which local effects can be neglected. They concluded that the proposed procedure in the present work can capture the deformed shape of the printed component and obtain an acceptable agreement with experimental data.

Researchers in some works used Nastran as the software to predict the strength of composites made using traditional techniques. Tang [23] shows how progressive failure analysis for composite laminate model is incorporated in commercial software's. The paper discusses about the code and its incorporation in MSC, ABAQUS and ANSYS software which is used by major industries. Reddy et al. [26], Pal et al. [27] and Ramesh et al. [28] have simulated the progressive failure approach using Nastran software with different models and loading conditions. Authors have discussed the intralaminar failure is mainly due to delamination, while the inter-laminar failure is governed by various mechanisms like matrix cracking, fiber breakage or fiber-matrix debonding. The materials used in the above papers are the ones in which authors have details about fiber and matrix properties separately. Inputs are given with matrix and fiber failure with the usage of different failure theories like puck failure theory which uses slope deflection curves. There has been no study performed in the literature using progressive failure analysis in Nastran for 3D printed parts. An attempt has been made to 
simulate the analysis in this work based on Reddy et al. [26], Pal et al. [27] and Ramesh et al. [28], but complete success was not achieved. This could be due to non-availability of inputs which were considered in these papers. Another important notable point is that none of these research papers were validated with experimental results. Hence the accuracy of their models in real world simulation is not guaranteed. A detailed simulation of progressive analysis with 3d FEM will be our next scope of work.

The aim of this project is to describe the mechanical behavior of FFF parts by the classical laminate theory through FEA simulation. To reach this objective, a simplified FEA approach is developed to predict the mechanical behavior of ASTM D638 tensile coupons. Knowing unidirectional stiffness and strength properties (along and transverse to the extrudates, $0^{\circ}$ and $90^{\circ}$ ), an approach to determine the strength and stiffness of a quasi-isotropic laminate is developed. This approach is later used to simulate and validate the quasi-isotropic laminate with defects. The approach and its results are validated with the experimental results that are documented in Fayazbakhsh et al. [29]. The comparison between FEA simulation results and experimental data are discussed and areas for improvement are presented in section 5. The findings of this approach and area the improvements suggestions are documented in the report as a scope for future work.

There are differences between the proposed approach and the ones found in the literature as outlined below:

- Bayraktar et al. [6] considered melt temperature as one of the characteristic in their analytical model for simulation. Few researchers considered manufacturing process parameters, like acceleration, bed temperature, infill level and printing speed in their FEA or mathematical model simulation. The effect of these parameters are included in the characterization of tensile coupons along and transverse to the extrudates $\left(0^{\circ}\right.$ and $\left.90^{\circ}\right)$ and are used as input in the proposed methodology.

- Liu et al. [7] proposed two-stage approach to estimate effective material properties with a mesoscale geometry. The proposed methodology here is based on CLT and microstructure, and does not consider a detail mesoscale geometry for simulation.

- Researchers simulated the impact of varying manufacturing process parameters, e.g. extrudates width, on strength and stiffness of final parts. In these studies, manufacturing 
process and design parameters are kept constant and the impact of defects inclusion on mechanical performance in explored.

- Researchers like Espin et al. [8] and Rodrigues et al. [16] have considered L-bracket for FEA simulation. This limits the use of their results since it was obtained for a certain geometry. ASTM D638 tensile coupons are considered in the proposed approach and their material properties can be used in simulation of complex parts.

- There has been no study conducted using progressive failure analysis in Nastran for 3D printed parts. An attempt has been made to simulate the analysis in our study based on Reddy et al. [26], Pal et al. [27] and Ramesh et al. [28], but complete success was not achieved. This could be due to non-availability of inputs which were considered in these papers. Another important notable point is that none of these research papers were validated with experimental results. Hence the accountability of this procedure in real life simulation was not guaranteed that we will achieve our results. A detailed simulation of progressive analysis with 3d FEM will be our next scope of work. The step by step approach of the progressive failure is explained in the methodologies section in the report.

We have used PolyLactic Acid (PLA) as the material of interest in our study. PLA is one form of natural polymers which has many advantages compared to synthetic polymers, e.g. it is low weight recyclable, and biodegradable. They have relatively high strength, stiffness and are renewable also cause no skin irritations. One of the method to produce polylactic acid composites is by direct polycondensation of lactic acid as discussed by Nampoothiri et al [36]. Lactic acid is the starting material for PLA synthesis and can be produced by fermentation from a number of different renewable resources. Nampoothiri also discusses that PLA has high strength, thermal plasticity, and biocompatibility. However, PLA has its own limitations and one such property is its brittleness which limits its application. This property of PLA has been observed in our study as well, where different failure patterns were investigated. Tensile coupons per ASTM D638-14 manufactured using FFF 3D printing were considered in this study [35]. 


\subsection{ANALYSIS PROCEDURE}

This section describes the methodologies used to determine the strength of the 3D printed thermoplastic parts in our study.

\subsubsection{FIRST PLY FAILURE (FPF)}

First Ply Failure (FPF) is a universally used method for predicting a laminate's strength. The loads on the laminate are used and classical laminate theory (CLT) is used to determine the stresses in each ply. Failure criteria require stresses and strain of each lamina to be with respect to material coordinate system. Laminate coordinates usually do not match the main material axes of each ply. It is necessary to transform the stresses and strains from laminate coordinates to the laminate material coordinates. The stresses in material coordinates can be calculated in one of the two ways mentioned in the flowchart below:

(a)

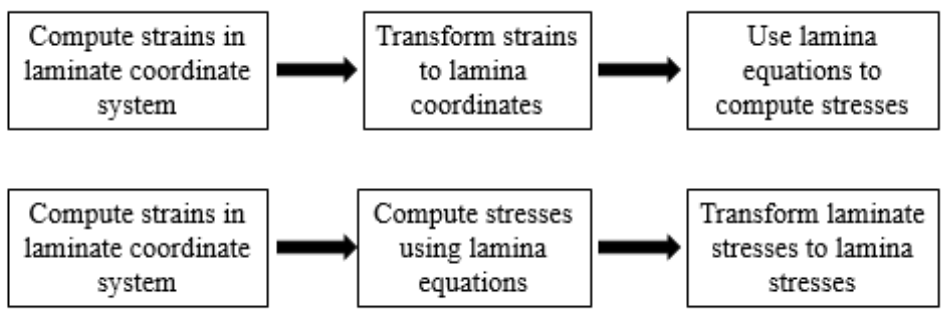

\section{Figure 2-1 Transformation of stresses and strains in element to material coordinate system.}

For our study the finite-element procedure is used to determine the stresses at any point of the laminate. Stresses in the element coordinate system is converted to material coordinate system. The lamina (i.e. material coordinate) stresses are then used in a chosen failure criterion to check if each finite element and each lamina has failed. If the failure criterion is satisfied in a ply of an element, then the individual contributions, called failure indices, of each stress component to the tensor polynomial are computed. The failure indices can be used to interpret the mode of failure. If the contributions of the $\sigma_{1}$ to the tensor polynomial is greater than the contribution of other stress components, the failure in the tension or compression in the 1 direction is assumed. The first-ply failure calculation requires to use an iterative procedure through the laminate thickness. The procedure involves solving the stress problem for an initial displacement. If one plies in an element fails, displacement is increased or reduced by a percentage of the initial displacement and the failure analysis is repeated. This iteration is continued until the failure index of any one ply is 1 . The 
corresponding average force divided by the laminate thickness is the strength of the laminate. The below flow chart is inspired from Prusty et al. [30].

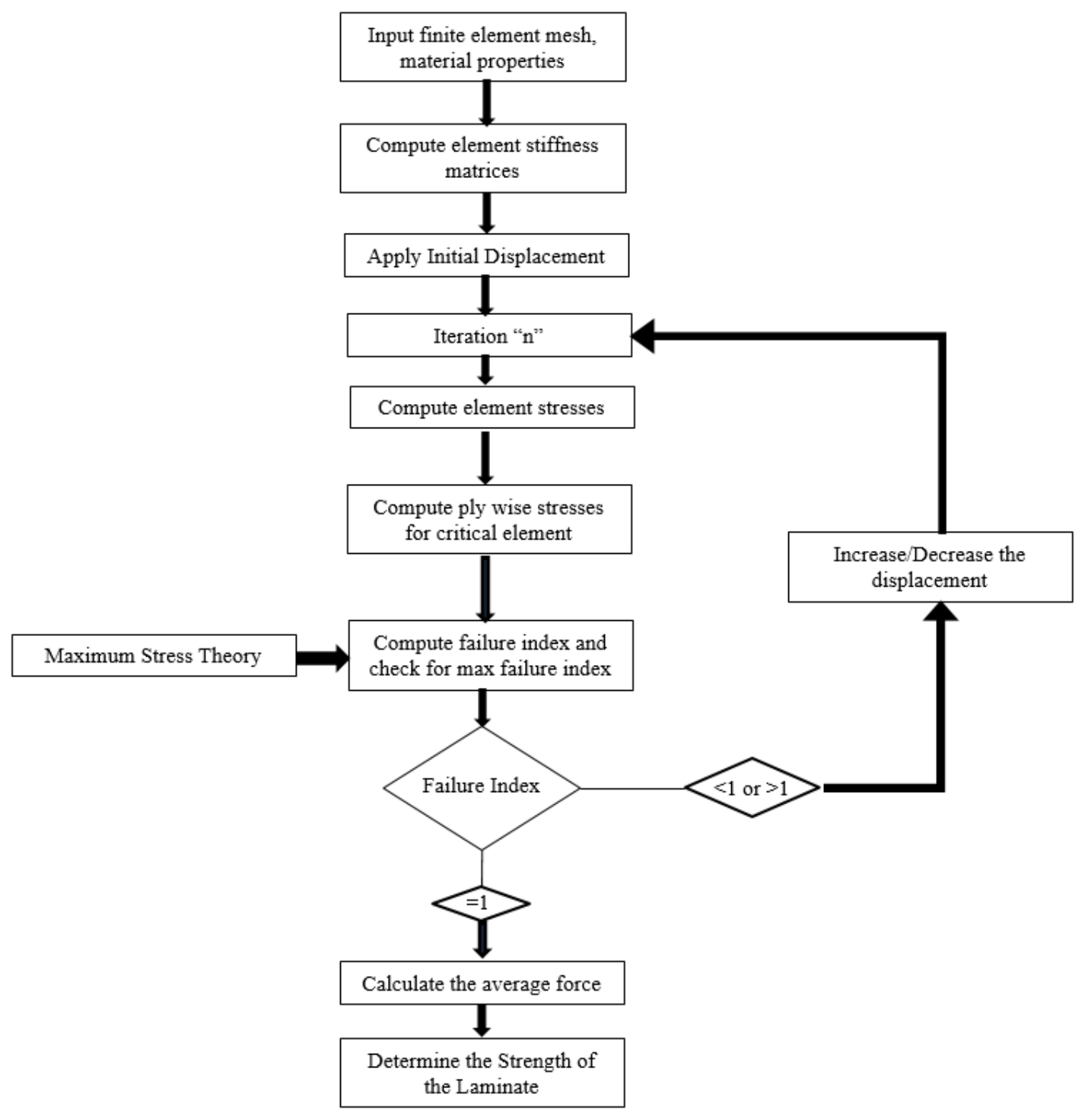

Figure 2-2 Flow Chart for First Ply Failure Analysis. 


\subsubsection{LAST PLY FAILURE (LPF)}

Last ply failure implements same procedure as First ply failure. The only difference is when the stress is known in each ply, a failure criterion is used to determine the load at which all plies fail in the layup. With LPF, the laminate is assumed to have failed when the last ply fails. This method is used so as to avoid using progressive ply failure analysis (Sol 400) which takes huge computational time. The below flow chart is inspired from Rahimi et al. [32].

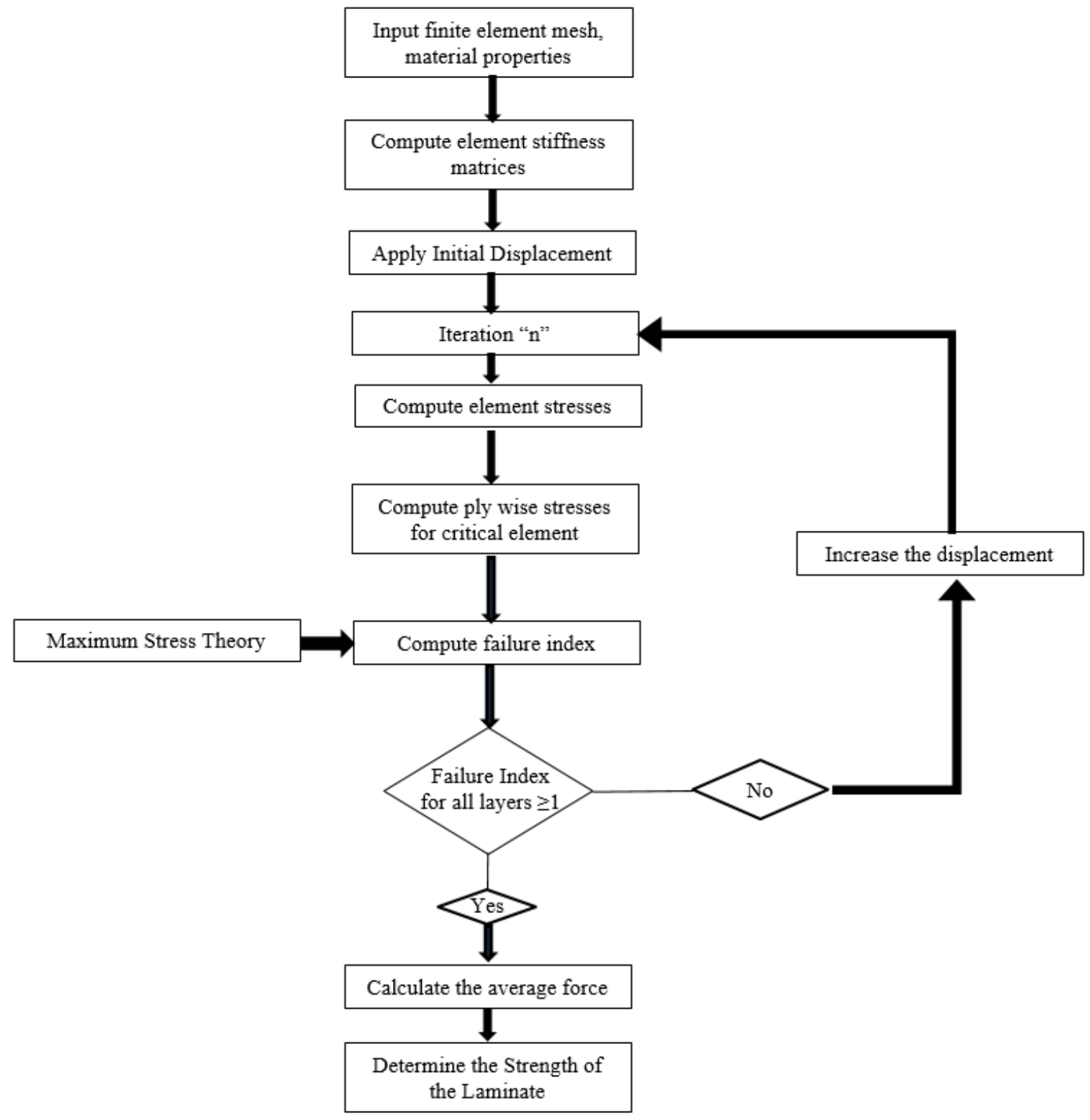

Figure 2-3 Flow Chart for Last Ply Failure Analysis. 


\subsubsection{PROGRESSIVE PLY FAILURE}

Progressive Ply Failure is another method which has been implemented in our study. This method allows to see what happens beyond first ply failure [24]. Like the first ply failure, CLT is used to evaluate each ply against a specified criterion for failure; however, the analysis does not stop at the first failure. At each integration point in a finite element model, the material stiffness is reduced to a fraction of the original stiffness after a failure criterion has been satisfied (one ply has failed). When the steadiness at an integration point is reduced, the amount of load that can be carried by the element is reduced and the loads are routed around the failed element into the intact elements around it. Since this process is carried out in a structure with multiple integration points, the result is a gradual weakening of the whole structure; as individual elements fail, loads are re- routed to surrounding elements that fail. This process continues until the composite structure's load carrying capacity is reduced to the point where the structure cannot carry anymore load, indicating ultimate failure. [Figure 2-4]. The process is inherently nonlinear because it degrades laminate stiffness and goes beyond the initiation of failure (linear elasticity ends) as discussed by Reddy et al. [26], Pal et al. [27] and Ramesh et al.[28] in their studies which is summarized in literature review.

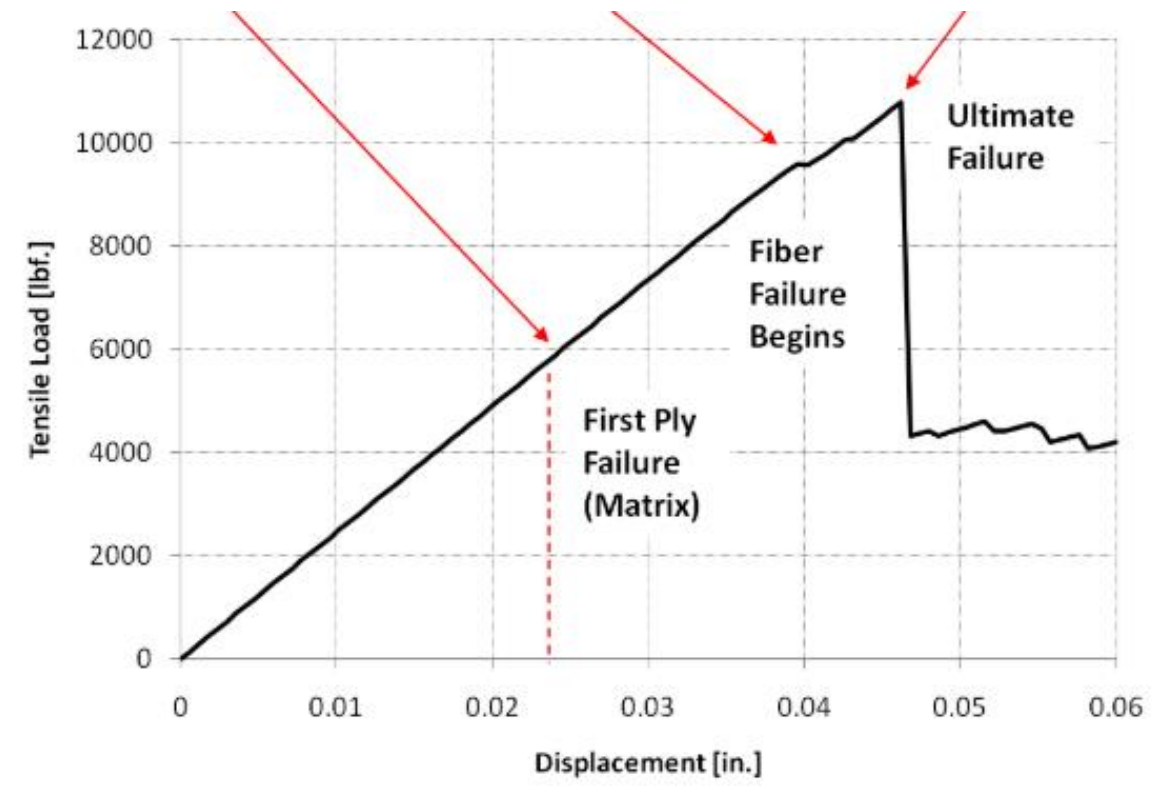

Figure 2-4 Example of progressive failure analysis [37].

In this study, progressive failure was implemented for some cases. However, this method had to be abandoned as the strength prediction was conservative and the 2D modeling approach was not suited for our scope of project. 
A simpler method, Stiffness reduction was used instead of progressive failure analysis and is discussed in the next section.

\subsubsection{STIFFNESS REDUCTION METHOD}

Based on the maximum stress failure criterion, stresses at the midpoint of each element are used to determine the failure and the degradation of the material moduli in the failed plies. If the stress component in the fiber direction $\left(\sigma_{1}\right)$ of a reaches its limit value (fiber failure mode), all the moduli ( $E_{1}$ and $E_{2}$ ) of the ply at that integration point are set to zero. On the other hand, if the matrix fracture in a ply occurs at an element integration point (matrix failure mode), the crack is assumed to span the entire length of the ply to form a crack line and the transverse modulus $\left(\mathrm{E}_{2}\right)$ of the ply is treated as zero at all element integration points of the elements passed through the crack line. The effects of transverse shear stresses on thin plates are small and therefore are not included in the stiffness reduction model. The updated layer-wise material moduli are then used to modify the element stiffness matrices of the damaged laminated composite plate. A schematic sketch of the stiffness reduction model is shown in Figure 2-5.

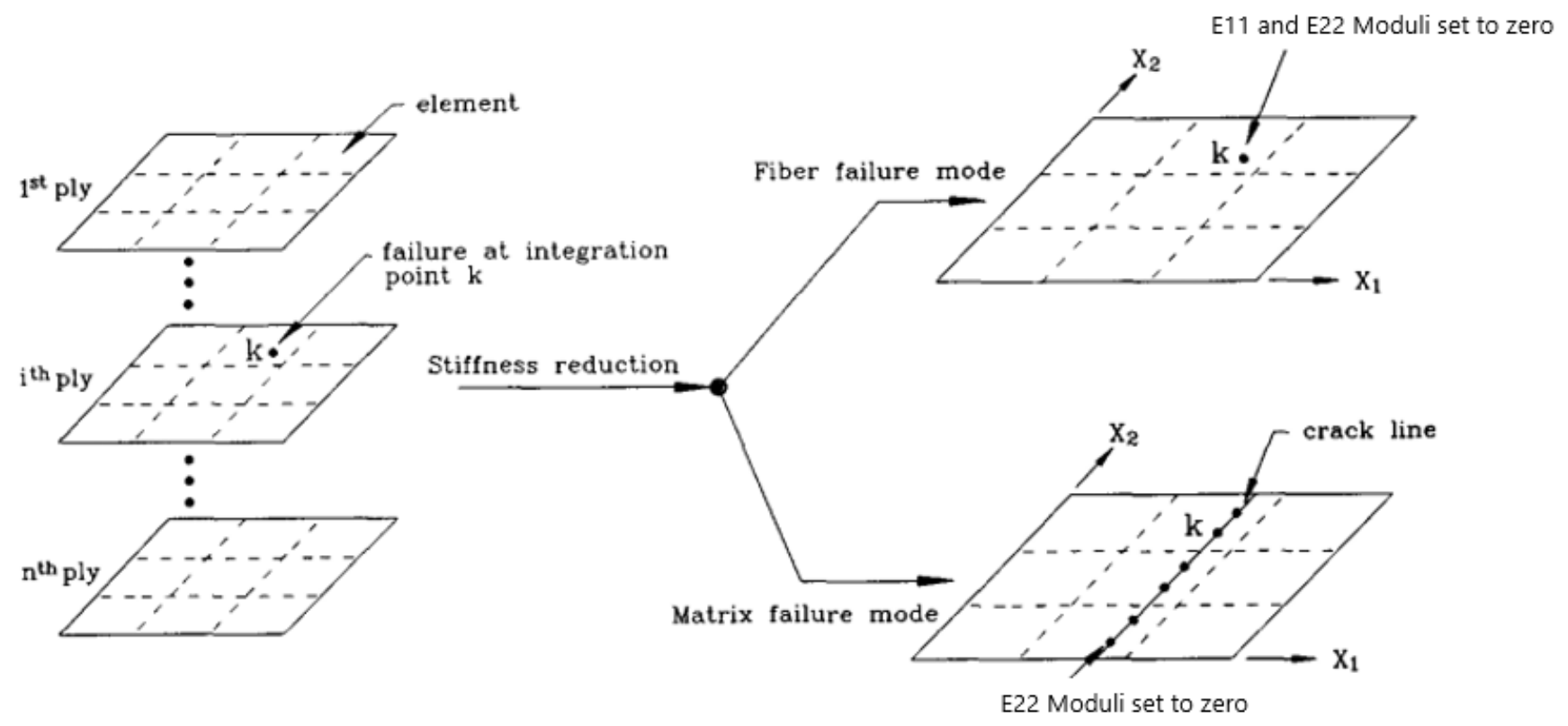

Figure 2-5 Stiffness Reduction Method [33]. 


\section{FINITE ELEMENT DESCRIPTION}

This section describes the FE modeling of ASTM D638 coupons [35] manufactured using FFF 3D printing. MSc Patran and Hypermesh is used for finite element modeling of the coupon. The finite element model is used to determine and validate the mechanical performance of the coupon, e.g. tensile modulus, strength, and failure strain. A finite element model representation of the coupon standard test specimen is shown in Figure 3-1. Points are created based on the global coordinate system show in Figure 3-1. Curves and transition regions are created based on these points to form a surface representing a coupon. Mesh seed is used to control and refine the mesh based on the geometry.
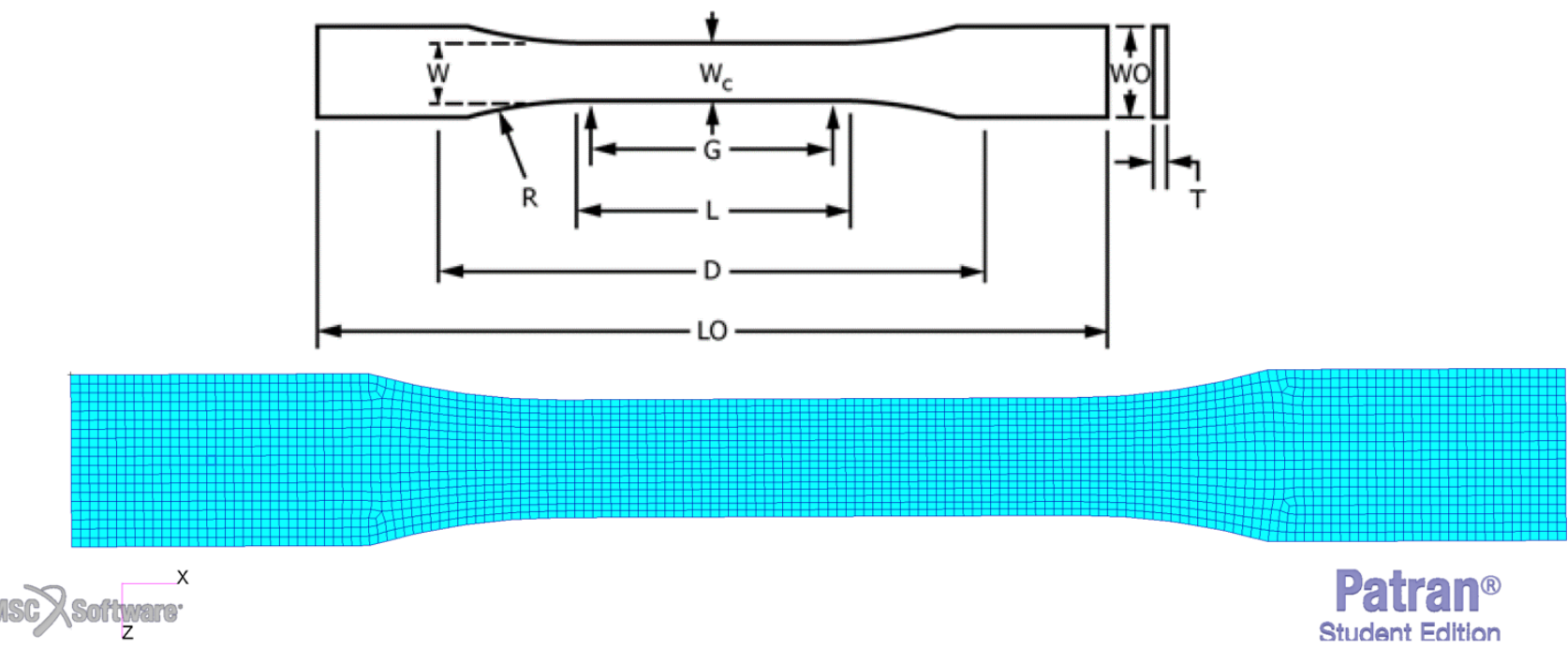

\begin{tabular}{|c|c|}
\hline \multirow{2}{*}{$\begin{array}{c}\text { Dimensions (see drawing) } \\
\text { (ASTM D638-14) [35] }\end{array}$} & $7(0.28)[\mathrm{mm}(\mathrm{in})]$ \\
\hline & Type I \\
\hline W-Width of narrow section $E, F$ & $13(0.50)$ \\
\hline L-Length of narrow section & $57(2.25)$ \\
\hline WO - Width overall, $\min ^{G}$ & $19(0.75)$ \\
\hline WO - Width overall, $\min ^{G}$ & - \\
\hline LO-Length overall, $\min ^{H}$ & $165(6.5)$ \\
\hline G-Gage length ${ }^{l}$ & $50(2.00)$ \\
\hline G-Gage length ${ }^{l}$ & 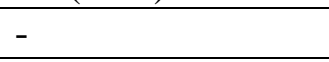 \\
\hline D-Distance between grips & $115(4.5)$ \\
\hline$R$-Radius of fillet & $76(3.00)$ \\
\hline
\end{tabular}

Figure 3-1 Finite element model representation of coupon with ASTM standard test specimen (ASTM D638-14 [35]). 
The geometry of ASTM coupon is almost rectangular. Since the coupon is quite flat and has thin surface, the finite element model is represented by CQUAD4s linear shell elements. Shell elements support five (5) degrees of freedom per node with degree of freedom based on rigidity in the out-ofplane degree of freedom of rotation [37]. CQUAD4 is the most frequently used element for plates, shells and membranes in NX Nastran. It is a flat quadrilateral plate connecting four grid points representing in-plane, bending, and transverse shear behavior. CQUADs remove the modeling prejudice associated with triangular elements and hence CQUADs are chosen instead of CTRIAs as it gives more accurate results for the same mesh size. Under certain conditions, for the same mesh size, quadrilateral elements give considerably less accurate results than triangular elements. An attempt is made to keep quadrilateral elements roughly square as possible because their accuracy tends to deteriorate with an increase in their aspect ratio.

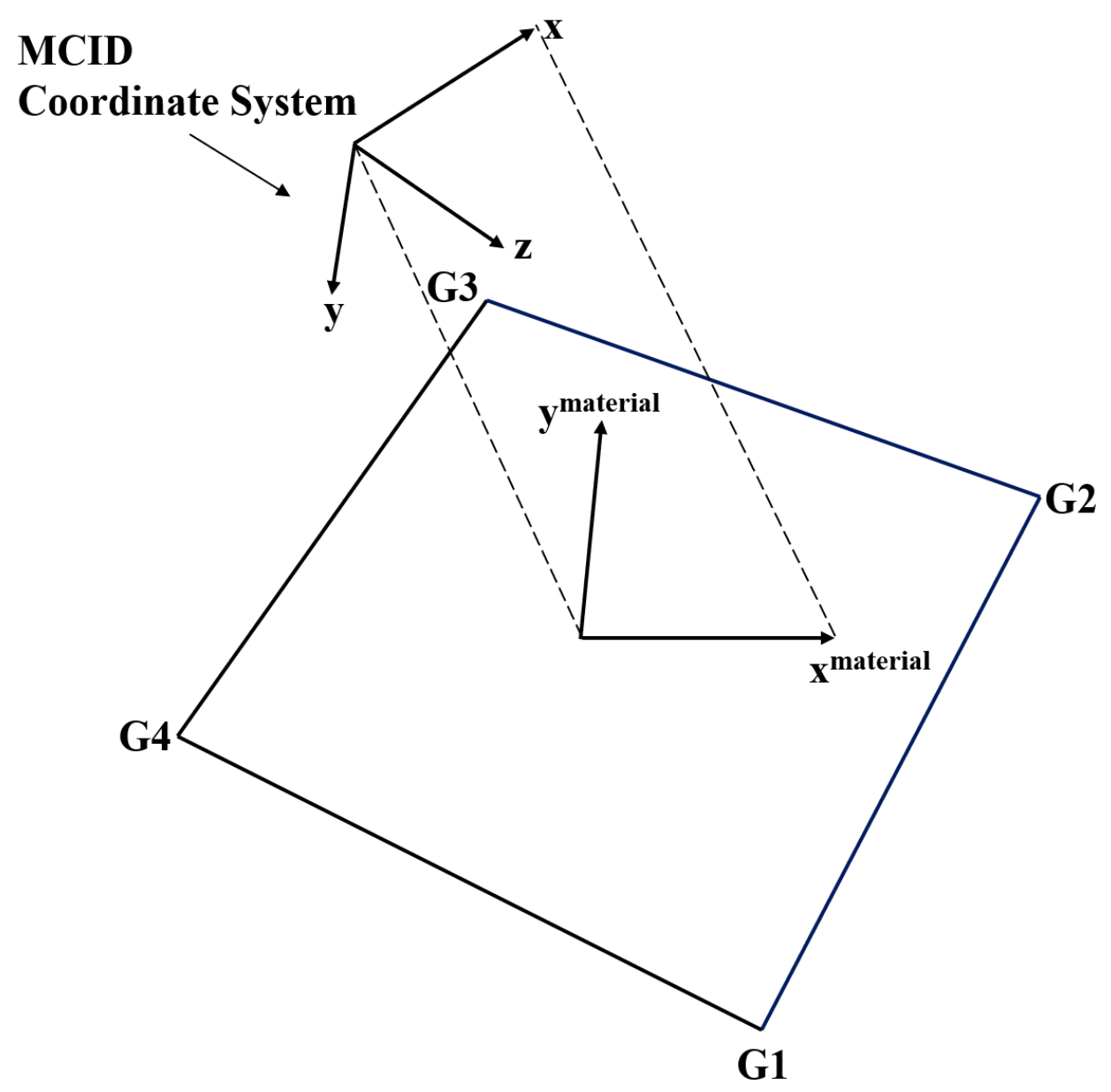

Figure 3-2 Nastran 2D CQUAD4 element [37]. 
The material orientation follows such that the positive $\mathrm{Z}$ direction points outward (outboard) and the $\mathrm{X}$ direction is fore-aft. The connectivity order for the grid points determines the orientation of the element coordinate system. The z-axis, often referred to as the positive normal of an element, is determined using the right-hand rule. Therefore, any change in the grid point's connectivity order could also reverse the direction of this positive normal. This rule is important when viewing the forces or stresses of the element. Element stress contours often seem strange when viewed in a postprocessor, as the normal of the adjacent elements may be inconsistent. In the element coordinate system NX Nastran always outputs components of forces, moments and element stresses. Therefore, it becomes mandatory to align all the element coordinate system with one system.

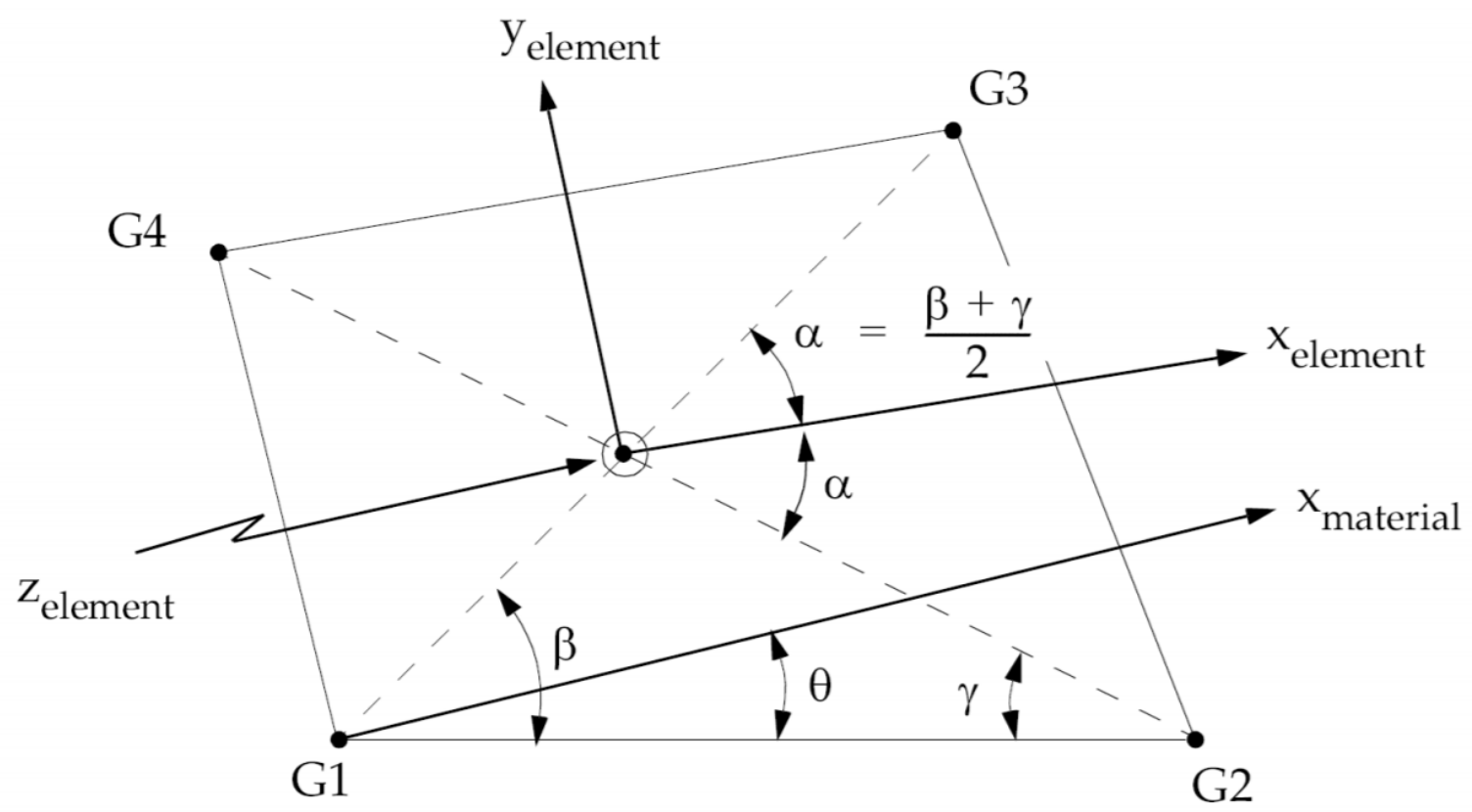

Figure 3-3 CQUAD4 Element Geometry and Coordinate Systems [37].

Each of the elements that represent the coupon contains a NASTRAN PCOMP card which defines the material and lay-ups for the skins. With regards to the lay-up orientation, the 0-direction is foreaft, the 90-direction is transverse, and the +45 -direction is split between the 0 and 90 directions as shown in Figure 3-4. 
Transverse $\left(90^{\circ}\right) \uparrow$

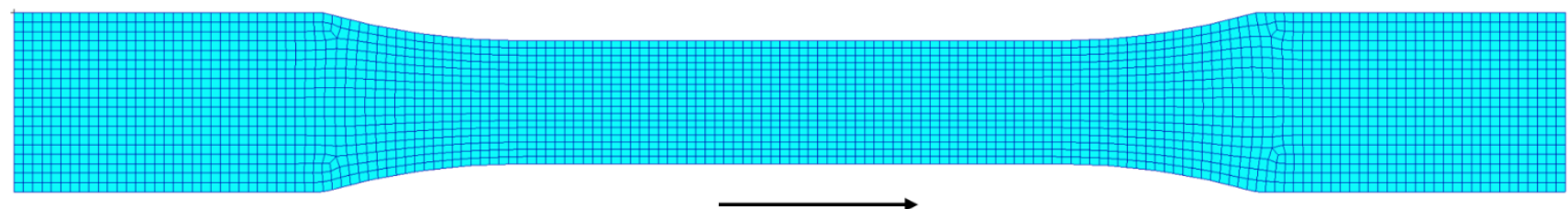

Fore-aft $\left(0^{\circ}\right)$

NSC) 2 seftwonz $z$

Patran $^{\circledast}$

Student Edltion

Figure 3-4 Finite element model orientations.

Elements are positioned at the Global Coordinate System. The use of the material coordinate system is required due to the varying size and shape of the elements used in the FEM of the coupon. For the ease of analysis both element and material coordinate systems have been modeled same. With regards to the lay-up orientation, the 0-direction is fore-aft and is oriented in $\mathrm{x}$-direction as shown in Figure 3-5

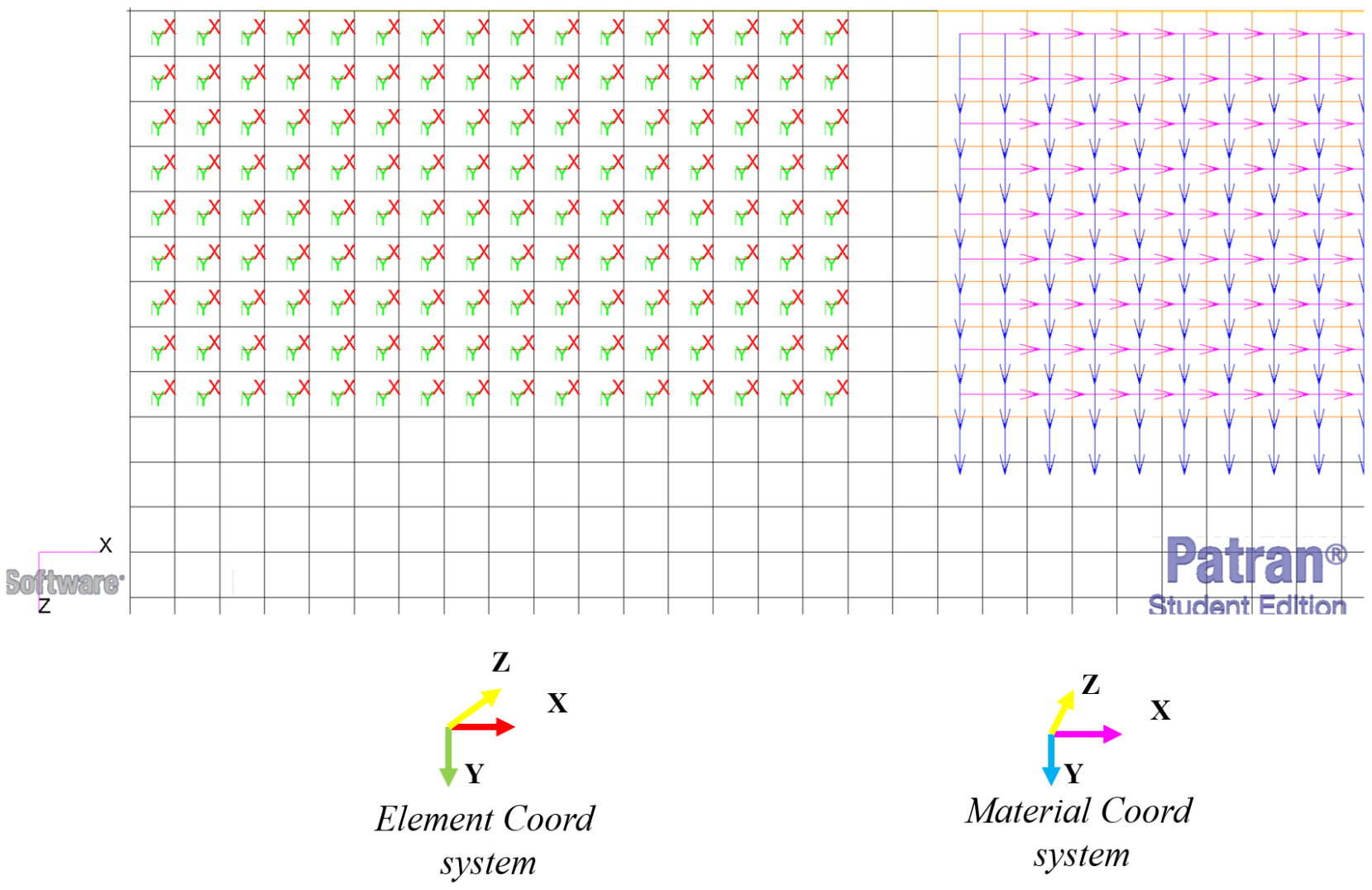

Figure 3-5 Finite element model: Element and Material Orientations. 


\subsection{PCOMP MODELING}

Tensile coupons have 24 plies of [45/0/90/-45] $]_{3 s}$ layup sequence with each ply thickness being $0.146 \mathrm{~mm}$ (total thickness $3.504 \mathrm{~mm}$ ). FEM is modeled on the midplane to simulate equal thickness on both sides. Pcomp layup sequence in FEM is shown in Figure 3-6.

\section{Pcomp layup sequence in FEM}

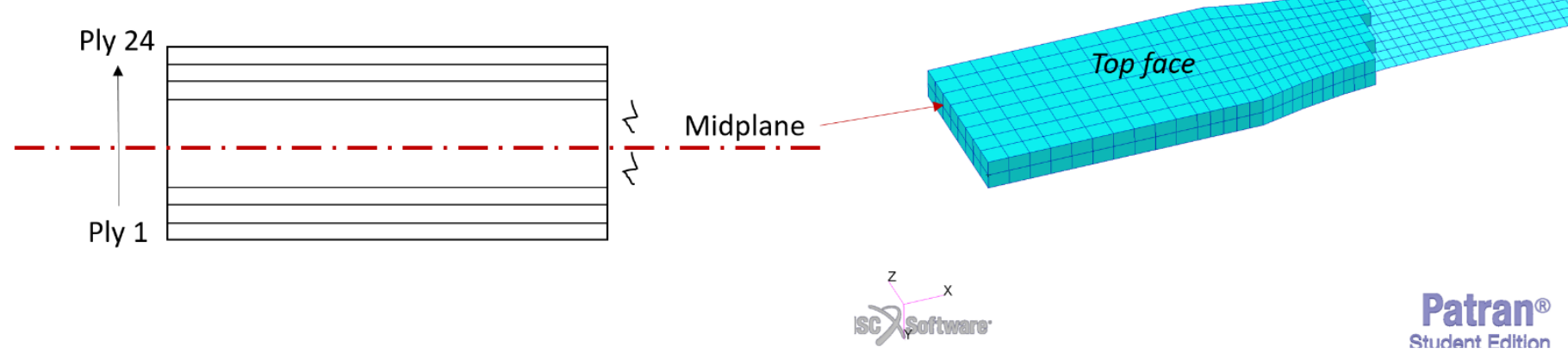

Figure 3-6 Finite element model: 2D model and thickness representation.

The Pcomp card in Nastran. bdf file shows stacking sequence, layer thickness and material id in the below Figure 47.

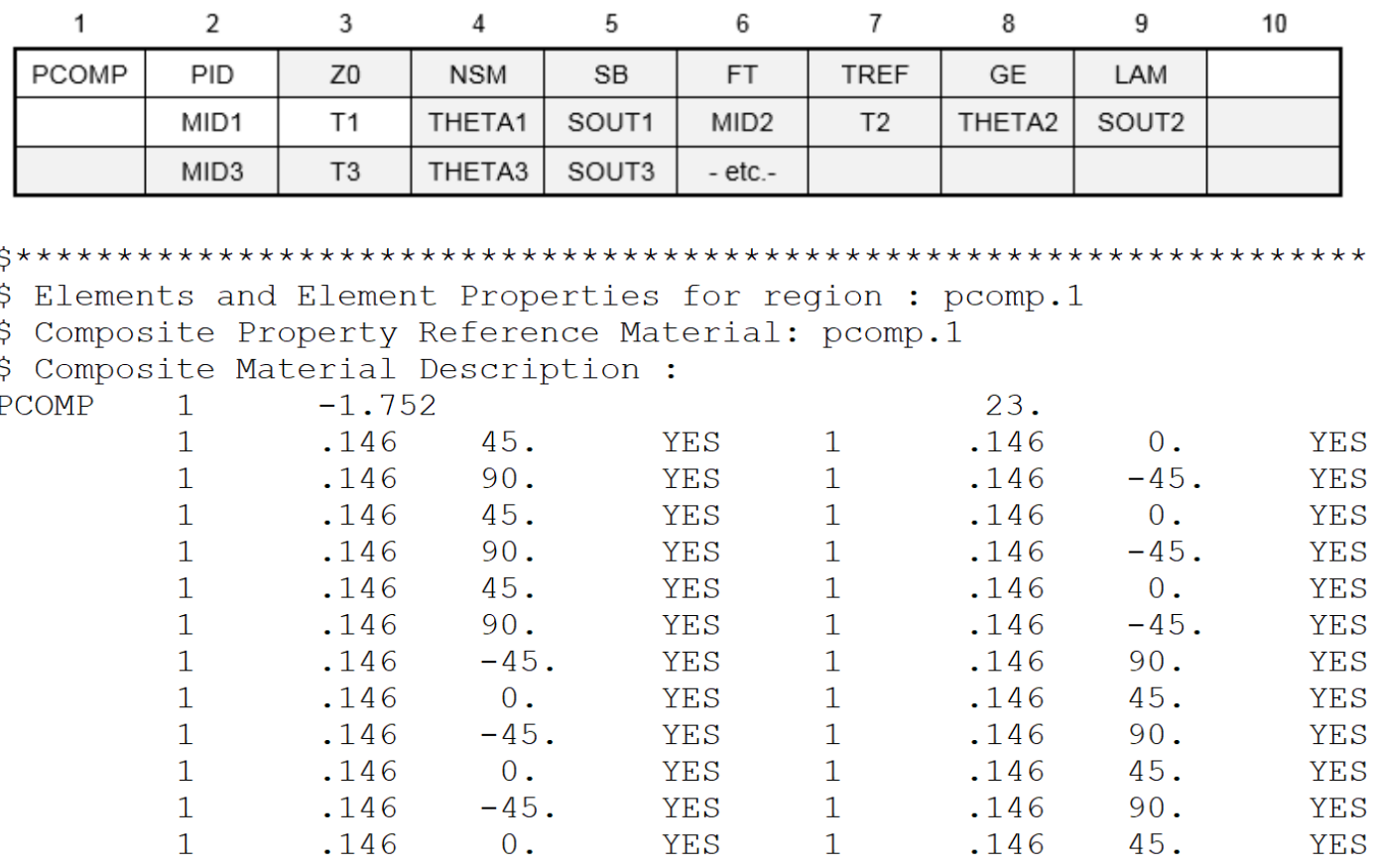

Figure 3-7 PCOMP Representation. 


\subsection{MATERIAL PROPERTIES}

For composite material, Nastran requires input data for material properties as follows:

Table 3.2-1 Material Property [29]

\begin{tabular}{|l|l|}
\hline Material Property & \\
\hline Elastic modulus in fiber direction (E11) & $3130 \mathrm{MPa}$ \\
\hline Elastic modulus in transverse direction (E22) & $2900 \mathrm{MPa}$ \\
\hline Shear Modulus (G12) & $1204 \mathrm{MPa}$ \\
\hline Poisson's ratio (v) & 0.3 \\
\hline Density & 1.24 \\
\hline
\end{tabular}

Note: Since the geometry is modeled in " $\mathrm{mm}$ " the material properties are given in $\mathrm{MPa}\left(\mathrm{N} / \mathrm{mm}^{2}\right)$ Elastic modulus is experimentally determined in uniaxial tension test by loading along and transverse to the extrudates. Shear modulus is theoretically determined by the relationship between elastic, shear modulus and Poisson's ratio. Poisson's ratio and density are assumed for simulation of analysis.

The material property consisting of elastic modulus, shear modulus, density and poisson's ratio are the inputs for MAT8 card which is shown below. Thermal expansion co-efficient and reference temperature are given as $1.0 \mathrm{e}^{-6}$ and $23^{\circ} \mathrm{C}$ respectively.

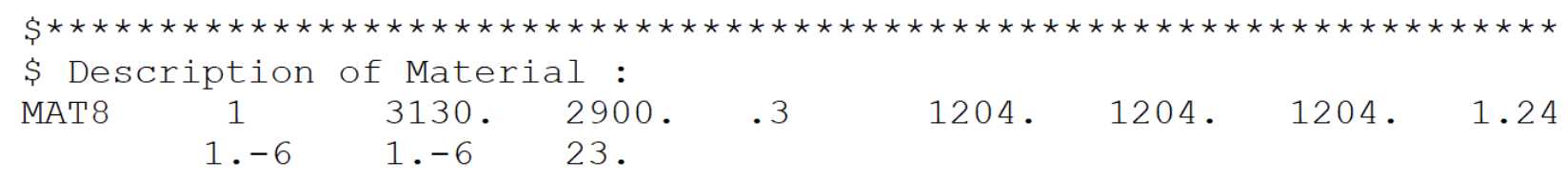

Figure 3-8 Material Properties input for MAT8. 


\subsection{BOUNDARY CONDITION}

This study simulates a uni-axial testing performed on ASTM D638 coupons in Aerospace Stress Analysis Laboratory in Aerospace Engineering Department. The bottom-end of the specimen is fixed and the top-end was subjected to an axial tensile displacement as shown in Figure 3-9.

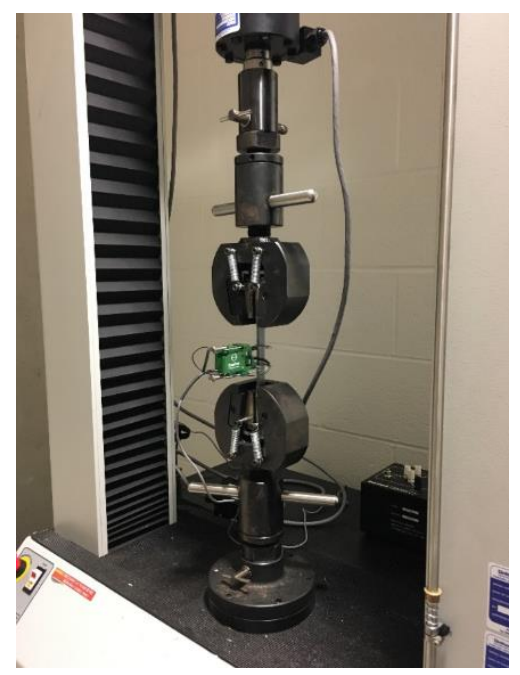

Figure 3-9 Uniaxial tensile testing machine.

The boundary conditions applied on the model are shown in Figure 3-10. The left-edge of the coupon is constrained in 1, 2, 3, 4, 5 and 6 (all DOF) directions and on the other end displacement load is applied.

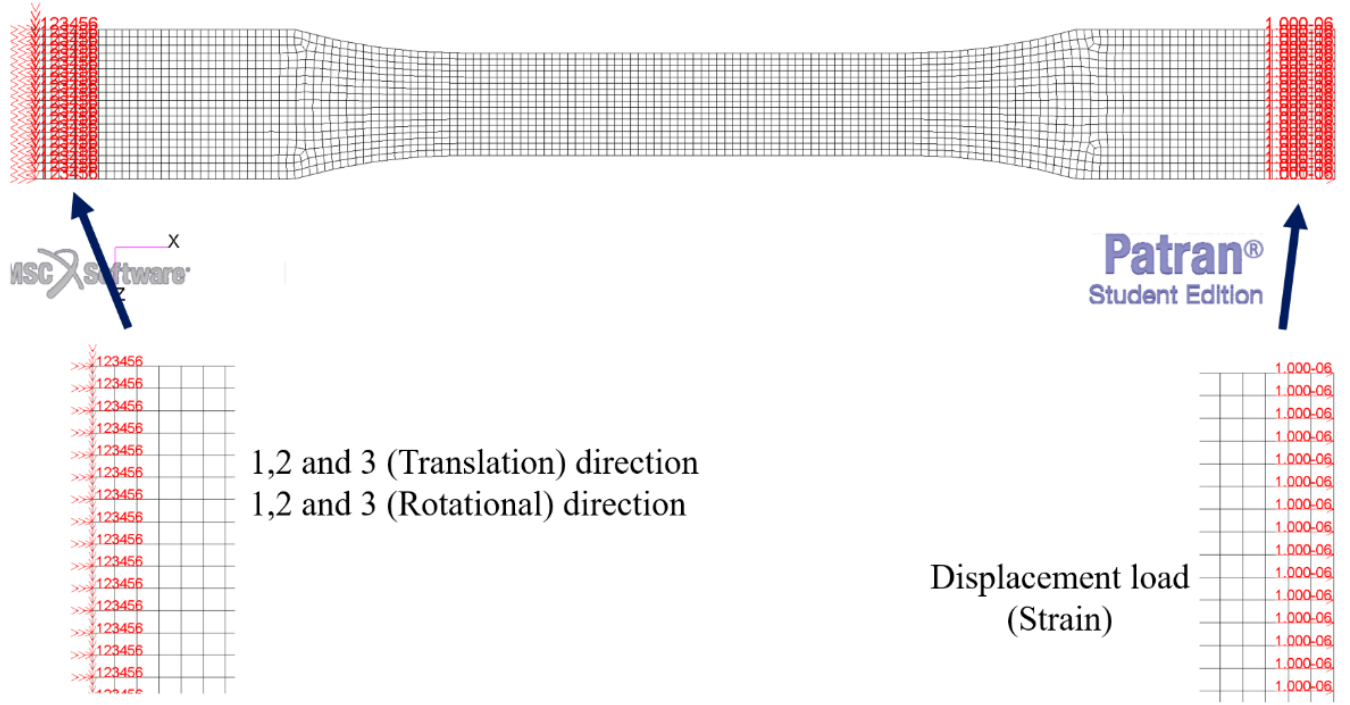

Figure 3-10 Boundary Conditions. 


\subsection{MODEL CHECK}

After a finite element model is created and before results are used from that model, standard validity checks on the model needs to be conducted. Based on MSc guidelines [38], Model check is conducted on the parameters shown in Table 3.4-1.

Table 3.4-1 Model Verification Checklist [38].

\begin{tabular}{|c|c|c|c|}
\hline \multicolumn{4}{|c|}{ QUALITY ASSURANCE OF FEM } \\
\hline Checkout Task & Passing Criteria & Pass/Fail & Comments \\
\hline Material and Property Cards & Correct Units are used & Pass & $\begin{array}{l}\text { Model is in mm and stiffness is in Mpa } \\
(\mathrm{N} / \mathrm{mm} 2)\end{array}$ \\
\hline \multicolumn{4}{|l|}{ Geometry Checks } \\
\hline Coincident Nodes & No unintended coincident nodes & Pass & Checked \\
\hline Coincident Elements & No unintended coincident elements & Pass & Checked \\
\hline Free Edge & $\mathrm{N} / \mathrm{A}$ & Pass & Checked \\
\hline Element Normals & Consistent Directions & Pass & Checked \\
\hline Element Orientation & Important for Orthotropic Materials & Pass & Checked \\
\hline Material Orientation & Important for Orthotropic Materials & Pass & Checked \\
\hline Aspect Ratio & $>10$ & Pass & 1.84 \\
\hline Taper & $0.8<$ Taper $<1.0$ & Pass & 0.02 \\
\hline Warping & $<0.05$ & Pass & 0.0617 \\
\hline Skew & 30 deg $<$ Skew & Pass & 12.51 \\
\hline \multicolumn{4}{|l|}{ Nastran Parameters } \\
\hline Max Ratio & Max Ratio < $10^{7}$ & Pass & $2.08 \mathrm{E}+03$ \\
\hline Epsilon & $10^{-9}$ (Target), $10^{-6}$ (Threshold) & Pass & $-2.05 E-15$ \\
\hline
\end{tabular}

\subsection{MESH CONVERGENCE STUDY}

A finer mesh typically results in a more accurate solution in finite element modeling. However, computation time increases as mesh size increases. To evaluate the mesh that balances accuracy and computing resources satisfactorily, a mesh convergence study is carried out.

The following steps determines the mesh convergence study that has been carried out on the coupon.

- A mesh is created with least, reasonable number of elements and is analyzed with arbitrary load.

- The mesh is reconstructed with a denser element distribution to re-analyze and the results are compared to those of the previous mesh.

- The mesh density is increased and re-analyzed until the results converge satisfactorily. 
Once the samples have been created, Von Mises stress contours is plotted to show a graphical illustration of the stepped variations in results from one element to the next. This contour is used to determine the effect of the mesh on accuracy and, if necessary, to guide the areas that need localized mesh refining.

The above- mentioned process of mesh convergence study allows us to obtain a precise solution with a mesh that is dense enough and not too demanding of computer resources.
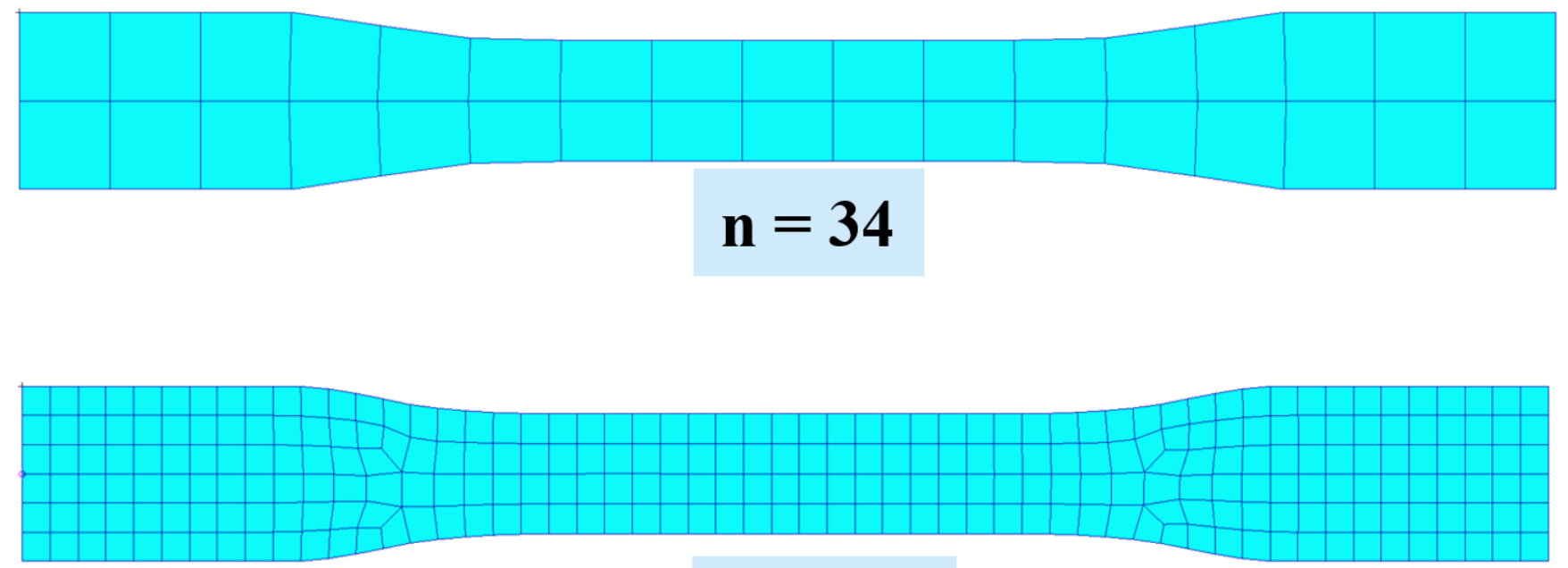

$$
\mathbf{n}=\mathbf{2 7 2}
$$

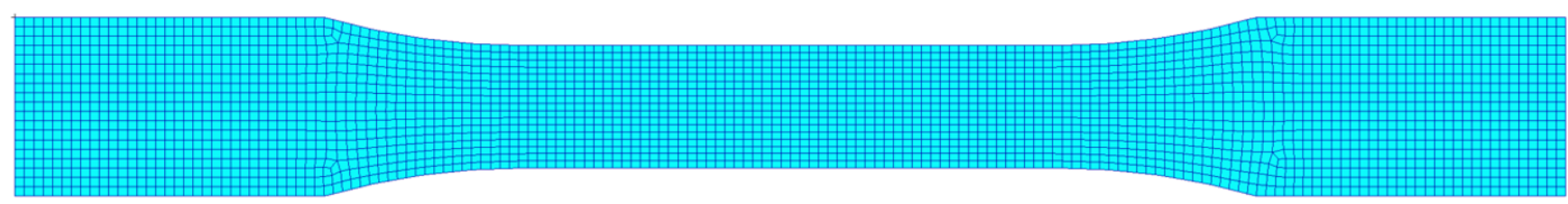

\section{$\mathbf{n}=\mathbf{2 9 2 9}$}

Figure 3-11 Example of meshes in the convergence study.

Figure 3-11 shows some of the sample FE models used to perform the convergence study. The stress results of the plate model converged to a solution (24.25 MPa) as the mesh density increased. Hence the number of elements preferred for our study is selected as 2929 elements. 
The maximum Von Mises stresses with respect to number of elements are as follows:

Table 3.5-1 Mesh convergence with different element density.

\begin{tabular}{|ccc|}
\hline Elements & $\begin{array}{c}\text { Von Mises Stress } \\
(\mathrm{MPa})\end{array}$ & Error \% \\
34 & 20.6 & - \\
84 & 22.5 & 8.4 \\
272 & 23.6 & 4.7 \\
730 & 24.02 & 1.7 \\
2929 & 24.25 & 0.9 \\
\hline
\end{tabular}

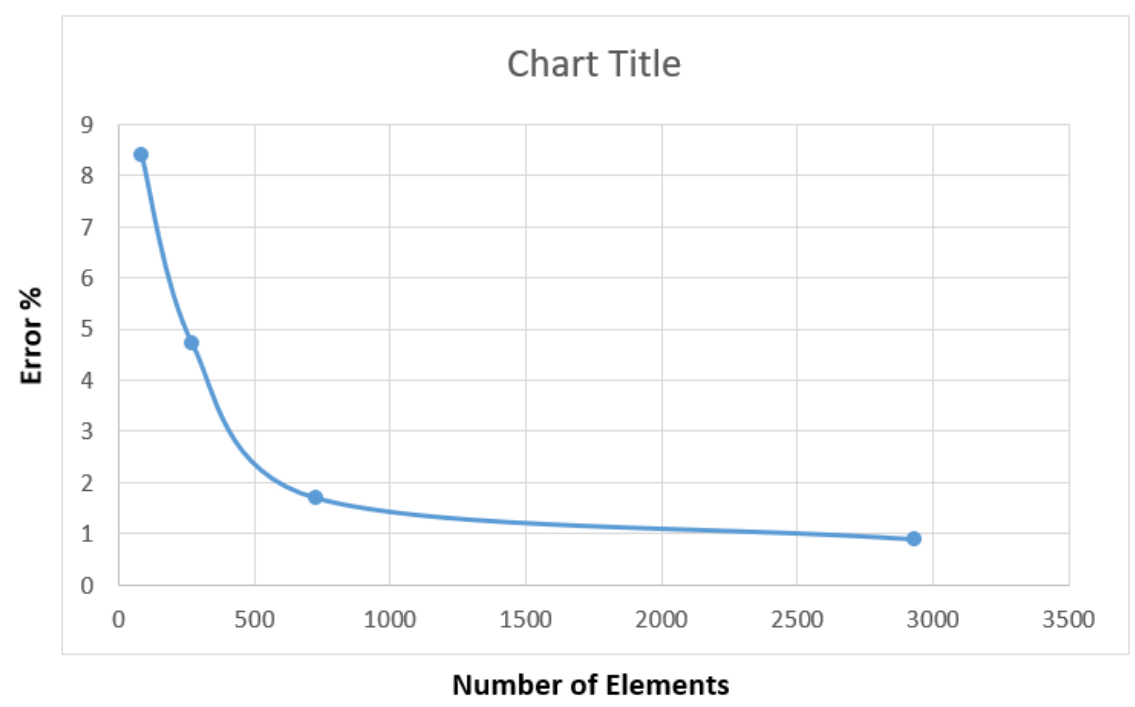

Figure 3-12 A plot of Von Mises stress versus $n$ shows the changes in stress results for the different mesh densities. 


\subsection{FAILURE THEORY FOR STRENGTH PREDICTION}

The strength of a unidirectional composite lamina can be characterized by five material parameters:

- Longitudinal tensile strength, $\sigma_{\mathrm{Lu} 1}$

- Longitudinal compressive strength, $\sigma_{\mathrm{Lu} 1}{ }^{\prime}$

- Transverse tensile strength, $\sigma_{\mathrm{Tu} 2}$

- Transverse compressive strength, $\sigma_{\mathrm{Tu} 2}{ }^{\prime}$

- In-plane shear strength, $\tau_{\mathrm{u} 12}$

In the present study, maximum stress failure theory is used to predict the strength of the laminate.

\subsubsection{MAXIMUM STRESS THEORY}

The failure occurs if one of the stresses in the material axes $(1,2)$ exceeds the corresponding allowable stress. To avoid failure, the material must satisfy the following inequalities:

$$
\begin{aligned}
& \sigma_{1}>\sigma_{\mathrm{Lu} 1} \text { if } \sigma_{1}>0 \\
& \sigma_{1}>\sigma_{\mathrm{Lu} 1} \text { if } \sigma_{1}<0 \\
& \sigma_{2}>\sigma_{\mathrm{Tu} 2} \text { if } \sigma_{2}>0 \\
& \sigma_{2}>\sigma_{\mathrm{Tu} 2} \text { if } \sigma_{2}<0 \\
& \left|\tau_{12}\right|>\tau_{\mathrm{u} 12}
\end{aligned}
$$

Transformation equations are shown below;

$$
\sigma_{u 1}=\sigma_{x} \cos ^{2} \theta \& \sigma_{u 2}=\sigma_{x} \sin ^{2} \theta
$$

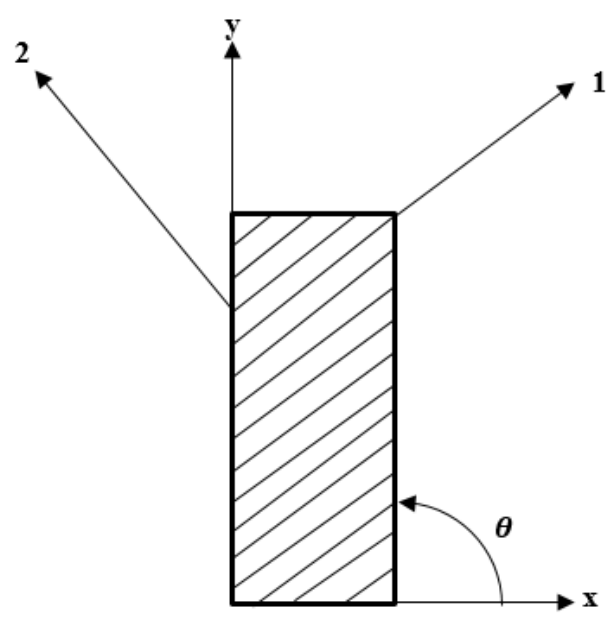

Figure 3-13 Laminae material and element co-ordinate system [34]. 


\section{RESULTS AND DISCUSSIONS}

Numerical results presented below the outcomes of the strength prediction simulations performed in Nastran (MSc Software). The strength of laminate for different stacking sequences are then compared with experimental results which are discussed in Section 5.

\subsection{STRENGTH OF UNIDIRECTIONAL LAMINATE}

\subsection{1 $0^{\circ}$ DEGREE COUPON}

The FEA section described in section 3 is used to model unidirectional ( $0^{\circ}$ ply) laminate. This model is implemented to predict the strength of the laminate using the first ply failure approach. On one edge of the coupon SPCD (enforced displacement) is applied, whereas the other end is fixed. The SPCD is increased until the first ply is failed. The corresponding average nodal force is determined to predict the strength of the laminate.

Patran 2017.0.2 (Student Edition) 25-Jun-18 23:20:34

Vector: COMPOSITES.SC1, A1:Static Subcase, Constraint Forces, Translational, , (NON-LAYERED)

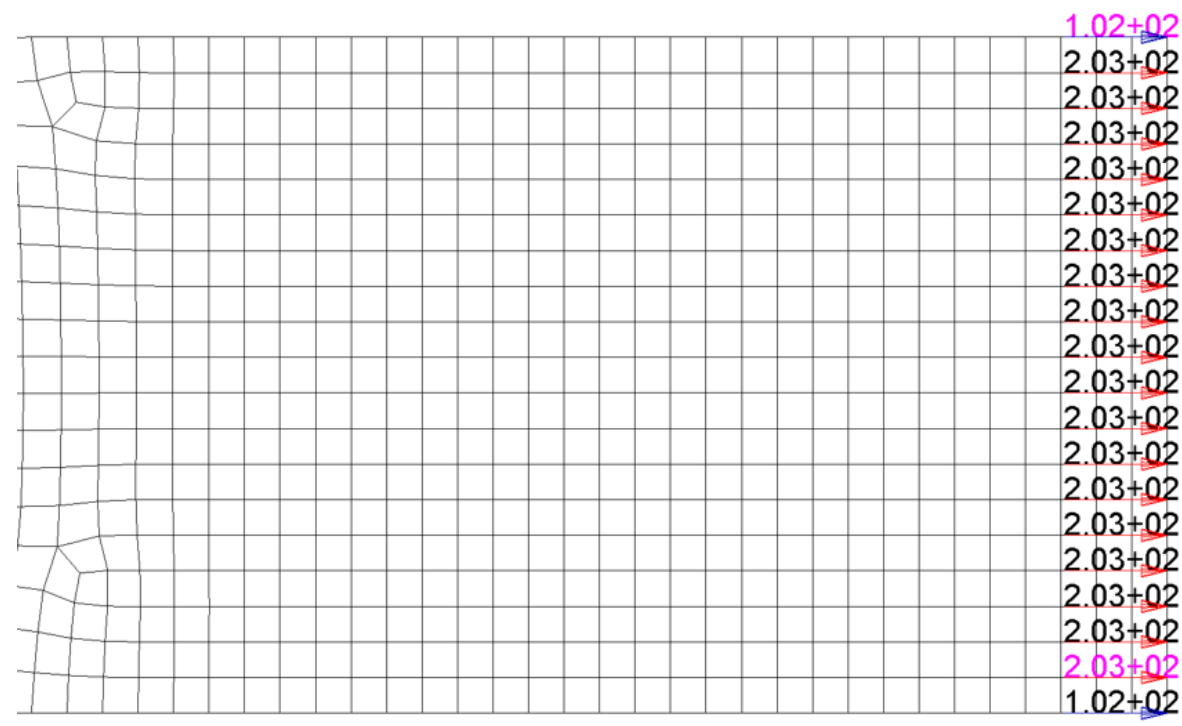

$1.02+02$

$2.03+02$

$2.03+02$

$2.03+02$

$2.03+02$

$2.03+02$

$2.03+02$

$2.03+02$

$2.03+02$

$2.03+02$

$2.03+02$

$3+0$

$2.03+02$

$2.03+02$

$1.02+02$
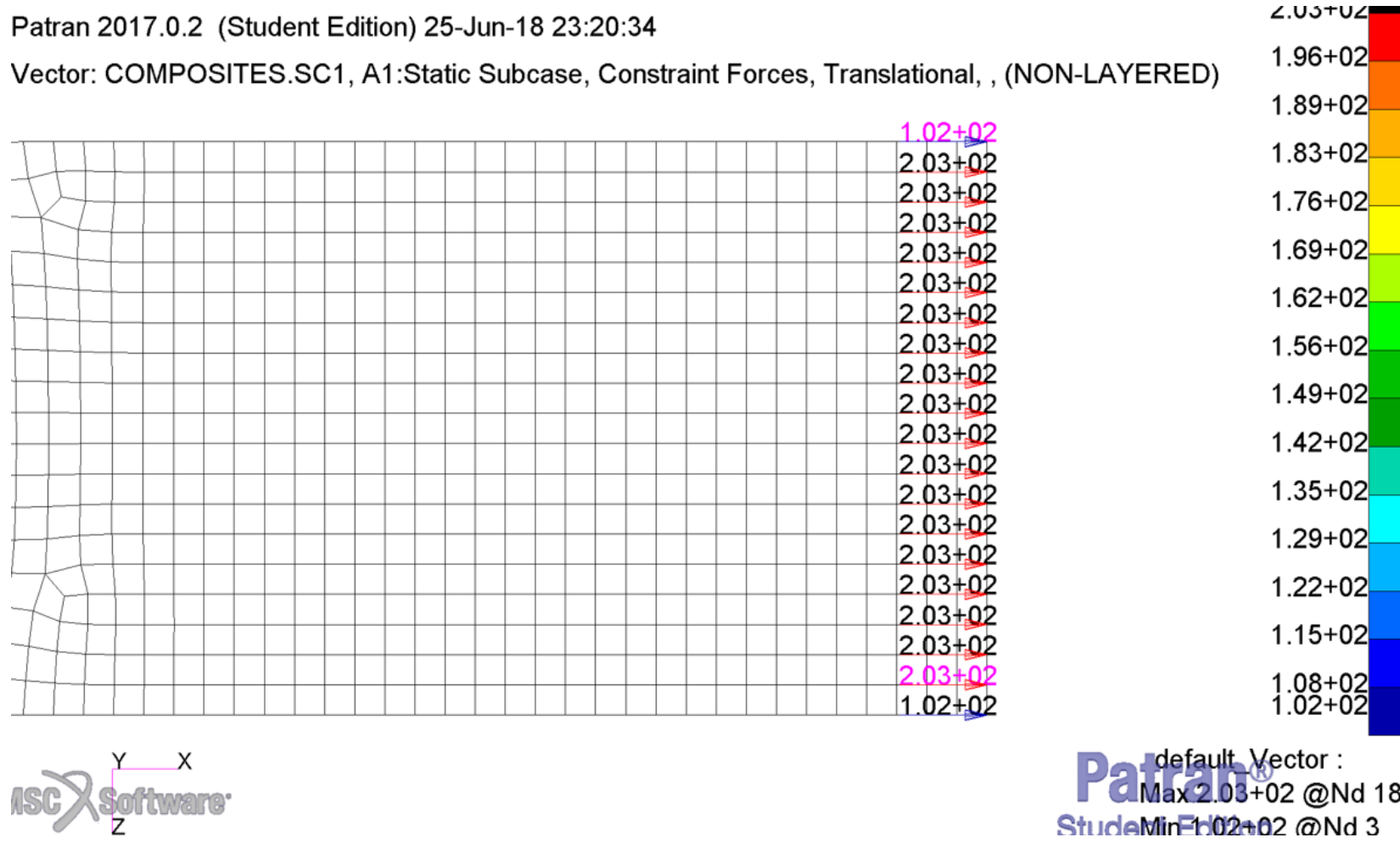

D. default Vector:

Figure 4-1 FEA Results - Constraint forces for unidirectional ( $\left(0^{\circ} \mathrm{ply}\right)$ laminate (N/mm). 
Table 4.1-1 Ply-wise Stresses and their Failure Index for $\left(0^{\circ} \mathrm{ply}\right)$ laminate

\begin{tabular}{|c|c|c|c|c|c|}
\hline Ply Id & Sigma L (MPa) & Sigma T (MPa) & Sigma LT (MPa) & Ply & FI @ $\mathbf{~}$ \\
\hline 1 & 57.9149 & 0.017662 & $-1 \mathrm{E}-05$ & 0 & 1.003 \\
\hline 2 & 57.9149 & 0.017636 & $-9.4 \mathrm{E}-06$ & 0 & 1.003 \\
\hline 3 & 57.9149 & 0.017609 & $-8.5 \mathrm{E}-06$ & 0 & 1.003 \\
\hline 4 & 57.9149 & 0.017583 & $-7.7 \mathrm{E}-06$ & 0 & 1.003 \\
\hline 5 & 57.9149 & 0.017556 & $-6.9 \mathrm{E}-06$ & 0 & 1.003 \\
\hline 6 & 57.9149 & 0.01753 & $-6.1 \mathrm{E}-06$ & 0 & 1.003 \\
\hline 7 & 57.9149 & 0.017504 & $-5.3 \mathrm{E}-06$ & 0 & 1.003 \\
\hline 8 & 57.9149 & 0.017477 & $-4.5 \mathrm{E}-06$ & 0 & 1.003 \\
\hline 9 & 57.9149 & 0.017451 & $-3.7 \mathrm{E}-06$ & 0 & 1.003 \\
\hline 10 & 57.9149 & 0.017424 & $-2.9 \mathrm{E}-06$ & 0 & 1.003 \\
\hline 11 & 57.9149 & 0.017398 & $-2.1 \mathrm{E}-06$ & 0 & 1.003 \\
\hline 12 & 57.9149 & 0.017372 & $-1.3 \mathrm{E}-06$ & 0 & 1.003 \\
\hline 13 & 57.9149 & 0.017345 & $-4.9 \mathrm{E}-07$ & 0 & 1.003 \\
\hline 14 & 57.9149 & 0.017319 & $3.14 \mathrm{E}-07$ & 0 & 1.003 \\
\hline 15 & 57.9149 & 0.017292 & $1.12 \mathrm{E}-06$ & 0 & 1.003 \\
\hline 16 & 57.9149 & 0.017266 & $1.93 \mathrm{E}-06$ & 0 & 1.003 \\
\hline 17 & 57.9149 & 0.01724 & $2.73 \mathrm{E}-06$ & 0 & 1.003 \\
\hline 18 & 57.9149 & 0.017213 & $3.54 \mathrm{E}-06$ & 0 & 1.003 \\
\hline 19 & 57.9149 & 0.017187 & $4.34 \mathrm{E}-06$ & 0 & 1.003 \\
\hline 20 & 57.9149 & 0.01716 & $5.15 \mathrm{E}-06$ & 0 & 1.003 \\
\hline 21 & 57.9149 & 0.017134 & $5.95 \mathrm{E}-06$ & 0 & 1.003 \\
\hline 22 & 57.9149 & 0.017108 & $6.76 \mathrm{E}-06$ & 0 & 1.003 \\
\hline 23 & 57.9149 & 0.017081 & $7.57 \mathrm{E}-06$ & 0 & 1.003 \\
\hline 24 & 57.9149 & 0.017055 & $8.37 \mathrm{E}-06$ & 0 & 1.003 \\
\hline
\end{tabular}

It is observed that at SPCD of $3.77 \mathrm{~mm}$ the plies start to fail as shown in Table 4.1-1. The nodal force distribution is as shown in Figure 4-1. The average force for the laminate at failure is found to be 203 $\mathrm{N} / \mathrm{mm}$. 
Hence the strength and strain at failure for the laminate is as shown below.

$$
\begin{aligned}
\sigma_{(0 \text { Laminate })} & =\frac{F_{\text {average }}}{\text { thickness of the laminate }} \\
\sigma_{(0 \text { Laminate })} & =\frac{203}{3.504} \\
\sigma_{(0 \text { Laminate })} & =57.92 \mathrm{MPa}
\end{aligned}
$$

Failure Strain:

$$
\varepsilon_{(\text {Failure })}=\frac{\Delta L}{L}=\frac{3.77}{165}=2.3 \%
$$

\subsubsection{0 ${ }^{\circ}$ DEGREE COUPON}

Similar procedure has been followed for $90^{\circ}$ laminate. FEA results for constraint forces at the loading region is shown below in Figure 4-2.

Patran 2017.0.2 (Student Edition) 27-Jun-18 14:28:00

Vector: SC1:, A1:Static Subcase, Shell Forces, Force Resultant, Component, (NON-LAYERED)
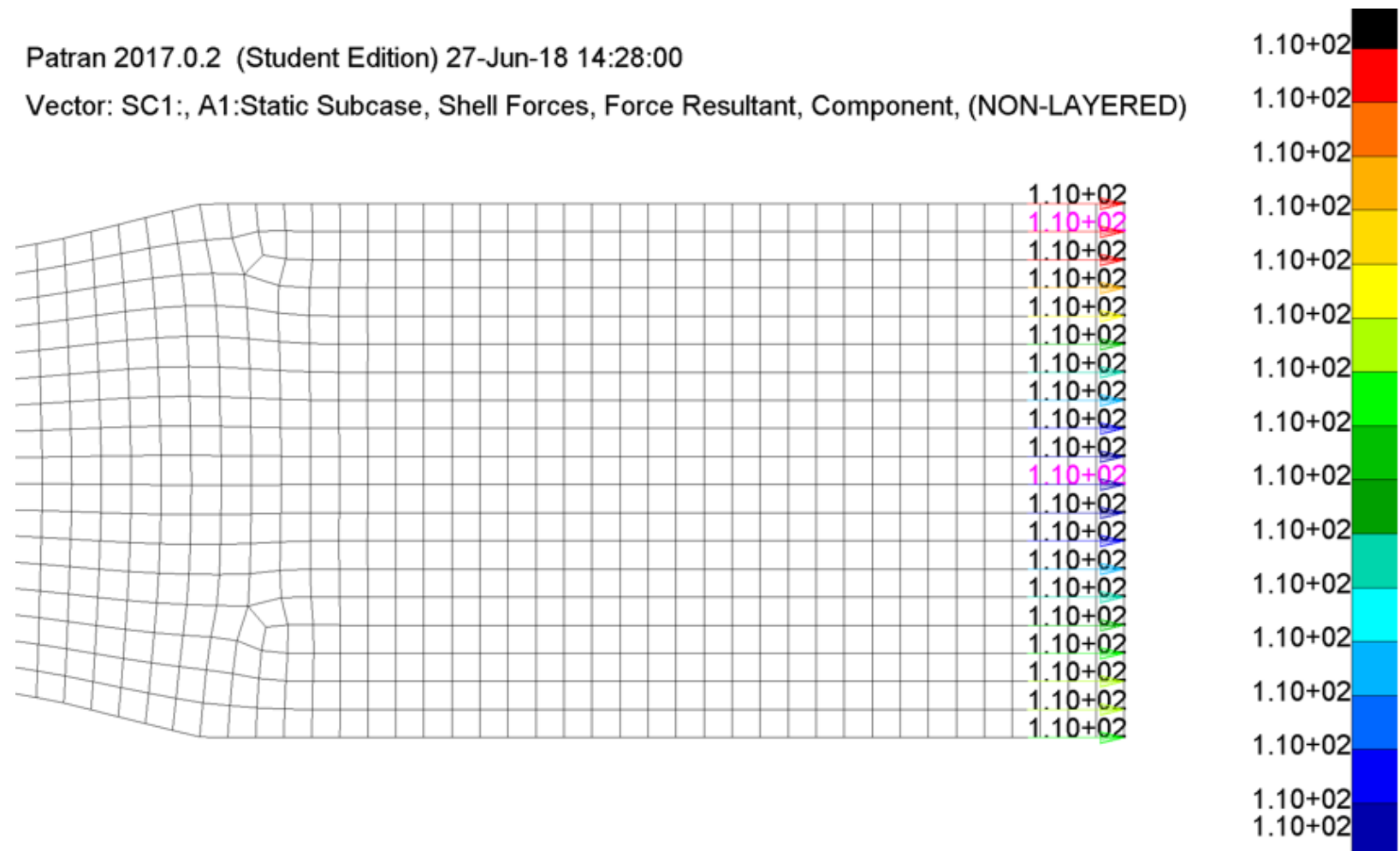

Figure 4-2 FEA Results - Constraint forces for unidirectional $\left(90^{\circ} \mathrm{ply}\right)$ laminate $(\mathrm{N} / \mathrm{mm})$. 
Table 4.1-2 Ply-Wise Stresses and their Failure Index for $\left(90^{\circ} \mathrm{ply}\right)$ laminate

\begin{tabular}{|l|l|l|l|l|l|}
\hline Ply Id & Sigma L (MPa) & Sigma T (MPa) & Sigma LT (MPa) & Ply & FI $@ \mathbf{x}$ \\
\hline 1 & 0.008169 & 31.3255 & $1.02 \mathrm{E}-05$ & 90 & 1.017 \\
\hline 2 & 0.008157 & 31.3255 & $9.91 \mathrm{E}-06$ & 90 & 1.017 \\
\hline 3 & 0.008145 & 31.3255 & $9.59 \mathrm{E}-06$ & 90 & 1.017 \\
\hline 4 & 0.008133 & 31.3255 & $9.27 \mathrm{E}-06$ & 90 & 1.017 \\
\hline 5 & 0.008121 & 31.3255 & $8.95 \mathrm{E}-06$ & 90 & 1.017 \\
\hline 6 & 0.008109 & 31.3255 & $8.63 \mathrm{E}-06$ & 90 & 1.017 \\
\hline 7 & 0.008096 & 31.3255 & $8.31 \mathrm{E}-06$ & 90 & 1.017 \\
\hline 8 & 0.008084 & 31.3255 & $7.99 \mathrm{E}-06$ & 90 & 1.017 \\
\hline 9 & 0.008072 & 31.3255 & $7.68 \mathrm{E}-06$ & 90 & 1.017 \\
\hline 10 & 0.00806 & 31.3255 & $7.36 \mathrm{E}-06$ & 90 & 1.017 \\
\hline 11 & 0.008048 & 31.3255 & $7.04 \mathrm{E}-06$ & 90 & 1.017 \\
\hline 12 & 0.008036 & 31.3255 & $6.72 \mathrm{E}-06$ & 90 & 1.017 \\
\hline 13 & 0.008024 & 31.3255 & $6.4 \mathrm{E}-06$ & 90 & 1.017 \\
\hline 14 & 0.008012 & 31.3255 & $6.08 \mathrm{E}-06$ & 90 & 1.017 \\
\hline 15 & 0.007999 & 31.3255 & $5.76 \mathrm{E}-06$ & 90 & 1.017 \\
\hline 16 & 0.007987 & 31.3255 & $5.44 \mathrm{E}-06$ & 90 & 1.017 \\
\hline 17 & 0.007975 & 31.3255 & $5.13 \mathrm{E}-06$ & 90 & 1.017 \\
\hline 18 & 0.007963 & 31.3255 & $4.81 \mathrm{E}-06$ & 90 & 1.017 \\
\hline 19 & 0.007951 & 31.3255 & $4.49 \mathrm{E}-06$ & 90 & 1.017 \\
\hline 20 & 0.007939 & 31.3255 & $4.17 \mathrm{E}-06$ & 90 & 1.017 \\
\hline 21 & 0.007927 & 31.3255 & $3.85 \mathrm{E}-06$ & 90 & 1.017 \\
\hline 22 & 0.007915 & 31.3255 & $3.53 \mathrm{E}-06$ & 90 & 1.017 \\
\hline 23 & 0.007902 & 31.3255 & $3.21 \mathrm{E}-06$ & 90 & 1.017 \\
\hline 24 & 0.00789 & 31.3255 & $2.9 \mathrm{E}-06$ & 90 & 1.017 \\
\hline
\end{tabular}

It is observed that at SPCD of $2.20 \mathrm{~mm}$ the plies start to fail as shown in Table 4.1-2. The nodal force distribution is as shown in Figure 4-2. The average force for the laminate at failure is found to be 110 $\mathrm{N} / \mathrm{mm}$. 
Hence the strength and strain at failure for the laminate is as shown below.

$$
\begin{aligned}
\sigma_{(0 \text { Laminate })} & =\frac{F_{\text {average }}}{\text { thickness of the laminate }} \\
\sigma_{(0 \text { Laminate })} & =\frac{110}{3.504} \\
\sigma_{(0 \text { Laminate })} & =31 \mathrm{MPa}
\end{aligned}
$$

Failure Strain:

$$
\varepsilon_{(\text {Failure })}=\frac{\Delta L}{L}=\frac{2.20}{165}=1.3 \%
$$

\subsection{STRENGTH OF QUASI-ISOTROPIC LAMINATE}

Similar procedure was followed for quasi-isotropic laminate. FEA results for constraint forces at the loading region is shown below in Figure 4-2.

Patran 2017.0.2 (Student Edition) 25-Jun-18 23:35:56

Vector: COMPOSITES.SC1, A1:Static Subcase, Constraint Forces, Translational, , (NON-LA A2

$1.05+02$

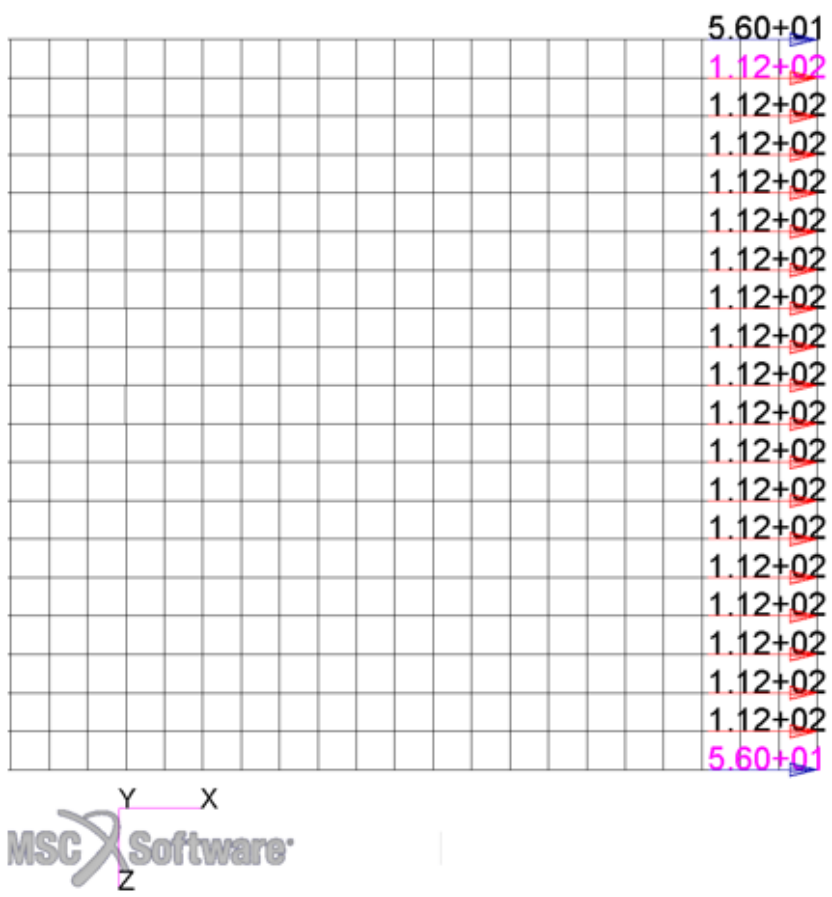

$1.01+02$

$9.71+01$

$9.34+01$

$8.96+01$

$8.59+01$

$8.22+01$

7.84+01

$7.47+01$

$7.10+01$

$6.72+01$

$6.35+01$

$5.98+01$

$5.60+01$

Do default -Vector : Max 1912+02@Nd 17C StudMint50ton@Nd 4

Figure 4-3 FEA Results - Constraint forces for quasi-isotropic laminate - FPF - (N/mm). 
Table 4.2-1 Ply-Wise Stresses and their Failure Index for quasi-isotropic laminate - FPF.

\begin{tabular}{|c|c|c|c|c|c|c|}
\hline Ply Id & Sigma L (MPa) & Sigma T (MPa) & Sigma LT (MPa) & Ply & FI @ $\mathbf{x}$ & FI @ $\mathbf{~}$ \\
\hline 1 & 16.46 & 15.52 & -16.21 & 45 & 0.570 & 1.007 \\
\hline 2 & 33.06 & 0.61 & 0.00 & 0 & 0.573 & - \\
\hline 3 & -0.13 & 30.42 & 0.00 & 90 & - & 0.988 \\
\hline 4 & 16.46 & 15.52 & 16.21 & -45 & 0.570 & 1.007 \\
\hline 5 & 16.46 & 15.52 & -16.21 & 45 & 0.570 & 1.007 \\
\hline 6 & 33.06 & 0.61 & 0.00 & 0 & 0.573 & - \\
\hline 7 & -0.13 & 30.42 & 0.00 & 90 & - & 0.988 \\
\hline 8 & 16.46 & 15.52 & 16.21 & -45 & 0.570 & 1.007 \\
\hline 9 & 16.46 & 15.52 & -16.21 & 45 & 0.570 & 1.007 \\
\hline 10 & 33.06 & 0.61 & 0.00 & 0 & 0.573 & - \\
\hline 11 & -0.13 & 30.42 & 0.00 & 90 & - & 0.988 \\
\hline 12 & 16.46 & 15.52 & 16.21 & -45 & 0.570 & 1.007 \\
\hline 13 & 16.46 & 15.52 & 16.21 & -45 & 0.570 & 1.007 \\
\hline 14 & -0.13 & 30.42 & 0.00 & 90 & - & 0.988 \\
\hline 15 & 33.06 & 0.61 & 0.00 & 0 & 0.573 & - \\
\hline 16 & 16.46 & 15.52 & -16.21 & 45 & 0.570 & 1.007 \\
\hline 17 & 16.46 & 15.52 & 16.21 & -45 & 0.570 & 1.007 \\
\hline 18 & -0.13 & 30.42 & 0.00 & 90 & - & 0.988 \\
\hline 19 & 33.06 & 0.61 & 0.00 & 0 & 0.573 & - \\
\hline 20 & 16.46 & 15.52 & -16.21 & 45 & 0.570 & 1.007 \\
\hline 21 & 16.46 & 15.52 & 16.21 & -45 & 0.570 & 1.007 \\
\hline 22 & -0.13 & 30.42 & 0.00 & 90 & - & 0.988 \\
\hline 23 & 33.06 & 0.61 & 0.00 & 0 & 0.573 & - \\
\hline 24 & 16.46 & 15.52 & -16.21 & 45 & 0.570 & 1.007 \\
\hline & & & & & & \\
\hline
\end{tabular}

It is observed that at SPCD of $2.14 \mathrm{~mm}$ the first ply $\left(45^{\circ}\right)$ starts to fail as shown in Table 4.2-1. The nodal force distribution for first ply failure is as shown in Figure 4-3. Stiffness of $45^{\circ}$ ply was reduced to simulate failure to carry any further load. However, this reduced the overall stiffness of the coupon thus not able to carry any further load than the first ply failure load. Failure to simulate this behavior was due to the restrictions in the solver - SOL 101 Linear static analysis. Material non-linearity or geometry discontinuity did not feature in SOL 101 solver.

The other alternative for this problem was to perform progressive failure analysis which was also discarded as the ultimate strength of the laminate with 2D model showed a very conservative approach 
in Nastran software with Sol 400 analysis. However, the behavior of the model showed very close relationship with the experimental results as shown below in Figure 4-4.

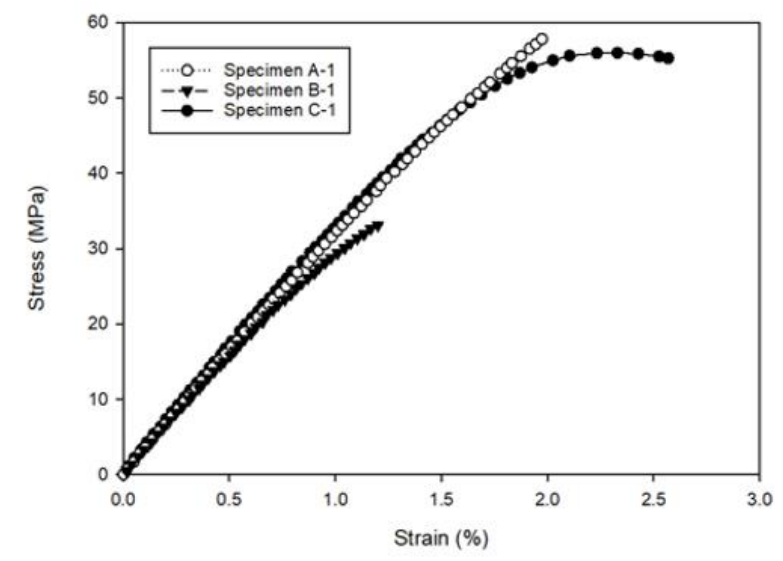

(a)

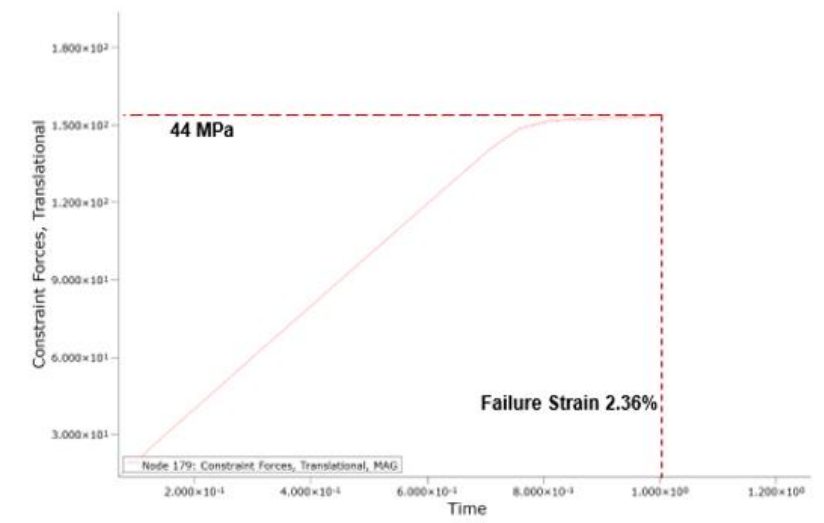

(b)

Figure 4-4 Tensile test results: (a) Experimental results for $0^{\circ}, 9^{\circ}$ and quasi-isotropic laminate [29] (b) FE results for quasi-isotropic laminate.

Hence, only Last ply failure method was implemented to determine the strength of quasi-isotropic laminate. In this procedure, the failure criterion is used to determine the load at which all the plies in the layup fails.

Figure 4-5 below shows all the plies have failed in both $\mathrm{x}$ and $\mathrm{y}$ direction. The corresponding average load is determined to find out the strength of the laminate.

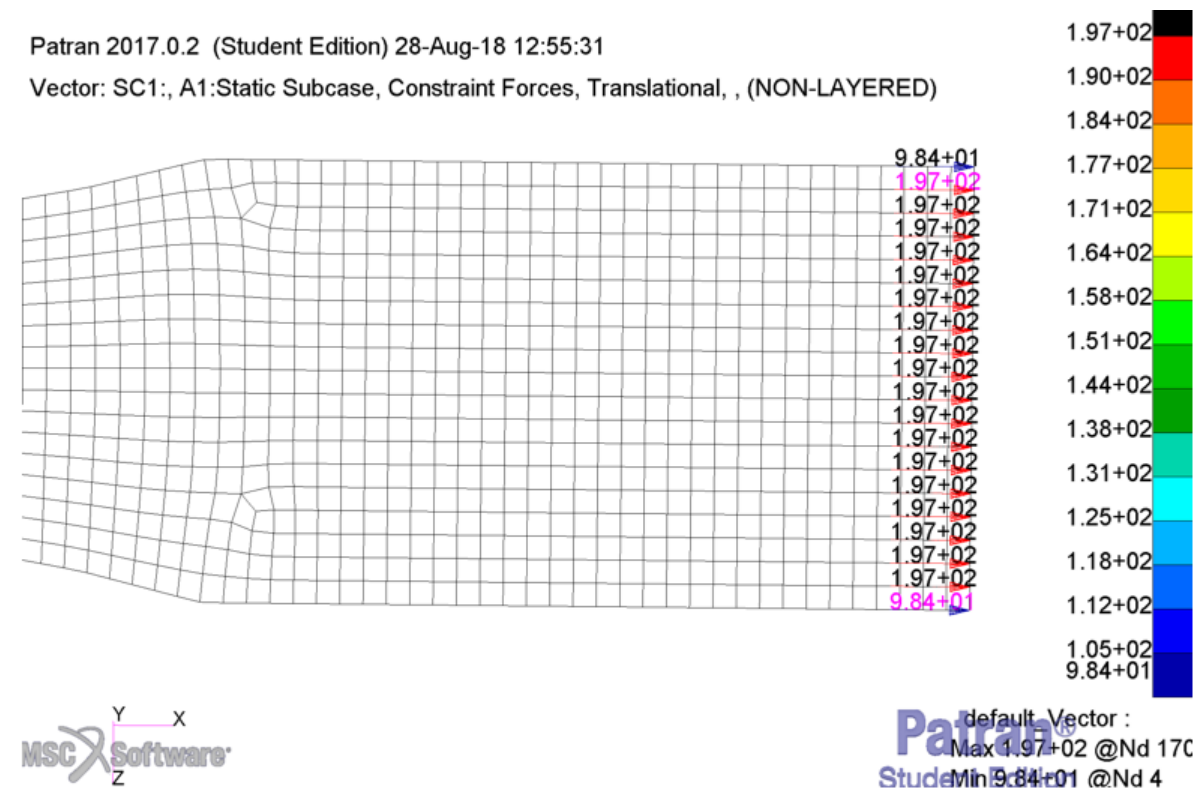

Figure 4-5 FEA Results - Constraint forces for quasi-isotropic laminate - LPF - (N/mm). 
Table 4.2-2 Ply-wise Stresses and their Failure Index for quasi-isotropic laminate - LPF.

\begin{tabular}{|c|c|c|c|c|c|c|}
\hline Ply Id & Sigma L (MPa) & Sigma T (MPa) & Sigma LT (MPa) & Ply & FI @ & FI @ $\mathbf{~}$ \\
\hline 1 & 28.92 & 27.26 & -28.48 & 45 & 1.002 & 1.770 \\
\hline 2 & 58.08 & 1.07 & 0.00 & 0 & 1.006 & - \\
\hline 3 & -0.24 & 53.45 & 0.00 & 90 & - & 1.735 \\
\hline 4 & 28.92 & 27.26 & 28.48 & -45 & 1.002 & 1.770 \\
\hline 5 & 28.92 & 27.26 & -28.48 & 45 & 1.002 & 1.770 \\
\hline 6 & 58.08 & 1.07 & 0.00 & 0 & 1.006 & - \\
\hline 7 & -0.24 & 53.45 & 0.00 & 90 & - & 1.735 \\
\hline 8 & 28.92 & 27.26 & 28.48 & -45 & 1.002 & 1.770 \\
\hline 9 & 28.92 & 27.26 & -28.48 & 45 & 1.002 & 1.770 \\
\hline 10 & 58.08 & 1.07 & 0.00 & 0 & 1.006 & - \\
\hline 11 & -0.24 & 53.45 & 0.00 & 90 & - & 1.735 \\
\hline 12 & 28.92 & 27.26 & 28.48 & -45 & 1.002 & 1.770 \\
\hline 13 & 28.92 & 27.26 & 28.48 & -45 & 1.002 & 1.770 \\
\hline 14 & -0.24 & 53.45 & 0.00 & 90 & - & 1.735 \\
\hline 15 & 58.08 & 1.07 & 0.00 & 0 & 1.006 & - \\
\hline 16 & 28.92 & 27.26 & -28.48 & 45 & 1.002 & 1.770 \\
\hline 17 & 28.92 & 27.26 & 28.48 & -45 & 1.002 & 1.770 \\
\hline 18 & -0.24 & 53.45 & 0.00 & 90 & - & 1.735 \\
\hline 19 & 58.08 & 1.07 & 0.00 & 0 & 1.006 & - \\
\hline 20 & 28.92 & 27.26 & -28.48 & 45 & 1.002 & 1.770 \\
\hline 21 & 28.92 & 27.26 & 28.48 & -45 & 1.002 & 1.770 \\
\hline 22 & -0.24 & 53.45 & 0.00 & 90 & - & 1.735 \\
\hline 23 & 58.08 & 1.07 & 0.00 & 0 & 1.006 & - \\
\hline 24 & 28.92 & 27.26 & -28.48 & 45 & 1.002 & 1.770 \\
\hline
\end{tabular}

It is observed that at SPCD of $3.76 \mathrm{~mm}$ the plies start to fail as shown in Table 7.2-2. The nodal force distribution is as shown in Figure 4-5. The average force for the laminate at failure is found to be $187.14 \mathrm{~N} / \mathrm{mm}$. 
Hence, the strength and strain at failure for the laminate is as shown below.

$$
\begin{aligned}
\sigma_{(0 \text { Laminate })} & =\frac{F_{\text {average }}}{\text { thickness of the laminate }} \\
\sigma_{(0 \text { Laminate })} & =\frac{187.14}{3.504} \\
\sigma_{(0 \text { Laminate })} & =53.41 \mathrm{MPa}
\end{aligned}
$$

Failure Strain:

$$
\varepsilon_{(\text {Failure })}=\frac{\Delta L}{L}=\frac{3.76}{165}=2.27 \%
$$




\subsection{STRENGTH OF QUASI-ISOTROPIC LAMINATE WITH DEFECT}

\subsubsection{0-DEFREE DEFECT}

In the quasi-isotropic coupon, [45/0/90/-45] $]_{3 s}$, intentional defects were placed in the laminate in every $0^{\circ}$ layer along the coupon length, a missing extrudate. The nozzle diameter in $3 \mathrm{D}$ printer is $0.4 \mathrm{~mm}$ and the measured width is $0.48 \mathrm{~mm}$ due to nozzle pushing on the extrudates. To simulate this defect for quasi-isotropic model the nodes are adjusted to the defect width based on the actual manufactured part in the 3D printing as shown in Figure 4-6.

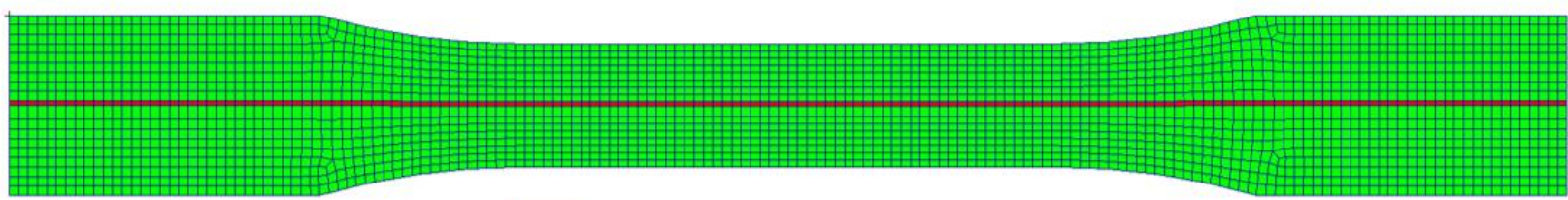

Defect width $=0.48 \mathrm{~mm}$

Figure 4-6 Quasi-isotropic laminate with 0ºfect.

The material stiffness of the defect ply is created in a different Mat8 card with low stiffness. This is as shown below in Figure 4-7. As shown the defected $0^{\circ}$ ply is assigned to Mat8-2 card, which has very low stiffness.

\begin{tabular}{|c|c|c|c|c|c|c|c|c|}
\hline \multicolumn{9}{|c|}{$\begin{array}{l}\text { \$ Elements and Element Properties for region : pcomp.3 } \\
\$ \text { Composite Property Reference Material: pcomp.3 } \\
\text { \$ Composite Material Description : }\end{array}$} \\
\hline \multirow[t]{13}{*}{ PCOMP } & 3 & -1.752 & & .01 & TSAI & 23. & & \\
\hline & 1 & .146 & 45 . & YES & 2 & .146 & 0 . & YES \\
\hline & 1 & .146 & 90. & YES & 1 & .146 & -45 & YES \\
\hline & 1 & .146 & 45. & YES & 2 & .146 & 0 . & YES \\
\hline & 1 & .146 & 90. & YES & 1 & .146 & -45 & YES \\
\hline & 1 & .146 & 45. & YES & 2 & .146 & 0. & YES \\
\hline & 1 & .146 & 90. & YES & 1 & .146 & -45 & YES \\
\hline & 1 & .146 & -45 & YES & 1 & .146 & 90. & YES \\
\hline & 2 & .146 & 0 & YES & 1 & .146 & 45. & YES \\
\hline & 1 & .146 & -45 & YES & 1 & .146 & 90. & YES \\
\hline & 2 & .146 & 0. & YES & 1 & .146 & 45. & YES \\
\hline & 1 & .146 & -45. & YES & 1 & .146 & 90. & YES \\
\hline & 2 & .146 & 0. & YES & 1 & .146 & 45. & YES \\
\hline \multirow[t]{2}{*}{ MAT8 } & 1 & 3130. & 2900. & 3 & 1204. & 1204. & 1204. & 1.24 \\
\hline & 1. -6 & 1. -6 & 23 & 57.72 & 30.8 & 30.8 & 30.8 & 30.8 \\
\hline \multicolumn{9}{|l|}{$\$$} \\
\hline \multirow[t]{2}{*}{ MAT8 } & 2 & 10. & 10. & .3 & 1204. & 1204. & 1204. & 1.24 \\
\hline & 1. -6 & 1. -6 & 23. & 57.72 & 30.8 & 30.8 & 30.8 & 30.8 \\
\hline
\end{tabular}

Figure 4-7 0 Defect model simulation.

At first, strength prediction with LPF method was used and it is summarized below. 
In this procedure, the failure criterion is used to determine the load at which all the plies in the layup fails. Stiffness of $0^{\circ}$ ply was modified to simulate ply failure as shown in Figure 4-7. Table 4.3-1 below shows all the plies have failed in y direction.

Table 4.3-1 Ply-Wise Stresses and Failure Index for quasi-isotropic laminate - $0^{\circ}$ Defect, LPF.

\begin{tabular}{|c|c|c|c|c|c|c|}
\hline Ply Id & Sigma L (MPa) & Sigma T (MPa) & Sigma LT (MPa) & Ply & FI @ & FI @ $\mathbf{~}$ \\
\hline 1 & 16.80 & 15.83 & -16.33 & 45 & 0.582 & 1.028 \\
\hline 2 & 0.11 & 0.00 & 0.00 & 0 & 0.002 & - \\
\hline 3 & 0.07 & 30.85 & 0.00 & 90 & - & 1.002 \\
\hline 4 & 16.80 & 15.83 & 16.33 & -45 & 0.582 & 1.028 \\
\hline 5 & 16.80 & 15.83 & -16.33 & 45 & 0.582 & 1.028 \\
\hline 6 & 0.11 & 0.00 & 0.00 & 0 & 0.002 & - \\
\hline 7 & 0.07 & 30.85 & 0.00 & 90 & - & 1.002 \\
\hline 8 & 16.80 & 15.83 & 16.33 & -45 & 0.582 & 1.028 \\
\hline 9 & 16.80 & 15.83 & -16.33 & 45 & 0.582 & 1.028 \\
\hline 10 & 0.11 & 0.00 & 0.00 & 0 & 0.002 & - \\
\hline 11 & 0.07 & 30.85 & 0.00 & 90 & - & 1.002 \\
\hline 12 & 16.80 & 15.83 & 16.33 & -45 & 0.582 & 1.028 \\
\hline 13 & 16.80 & 15.83 & 16.33 & -45 & 0.582 & 1.028 \\
\hline 14 & 0.07 & 30.85 & 0.00 & 90 & - & 1.002 \\
\hline 15 & 0.11 & 0.00 & 0.00 & 0 & 0.002 & - \\
\hline 16 & 16.80 & 15.83 & -16.33 & 45 & 0.582 & 1.028 \\
\hline 17 & 16.80 & 15.83 & 16.33 & -45 & 0.582 & 1.028 \\
\hline 18 & 0.07 & 30.85 & 0.00 & 90 & - & 1.002 \\
\hline 19 & 0.11 & 0.00 & 0.00 & 0 & 0.002 & - \\
\hline 20 & 16.80 & 15.83 & -16.33 & 45 & 0.582 & 1.028 \\
\hline 21 & 16.80 & 15.83 & 16.33 & -45 & 0.582 & 1.028 \\
\hline 22 & 0.07 & 30.85 & 0.00 & 90 & - & 1.002 \\
\hline 23 & 0.11 & 0.00 & 0.00 & 0 & 0.002 & - \\
\hline 24 & 16.80 & 15.83 & -16.33 & 45 & 0.582 & 1.028 \\
\hline
\end{tabular}

The corresponding average load is determined to find out the strength of the laminate. 
Patran 2017.0.2 (Student Edition) 29-Sep-18 17:59:45

Vector: COMPOSITES.SC1, A1:Static Subcase, Constraint Forces, Translational, , (NON-LAYEREG4) 02
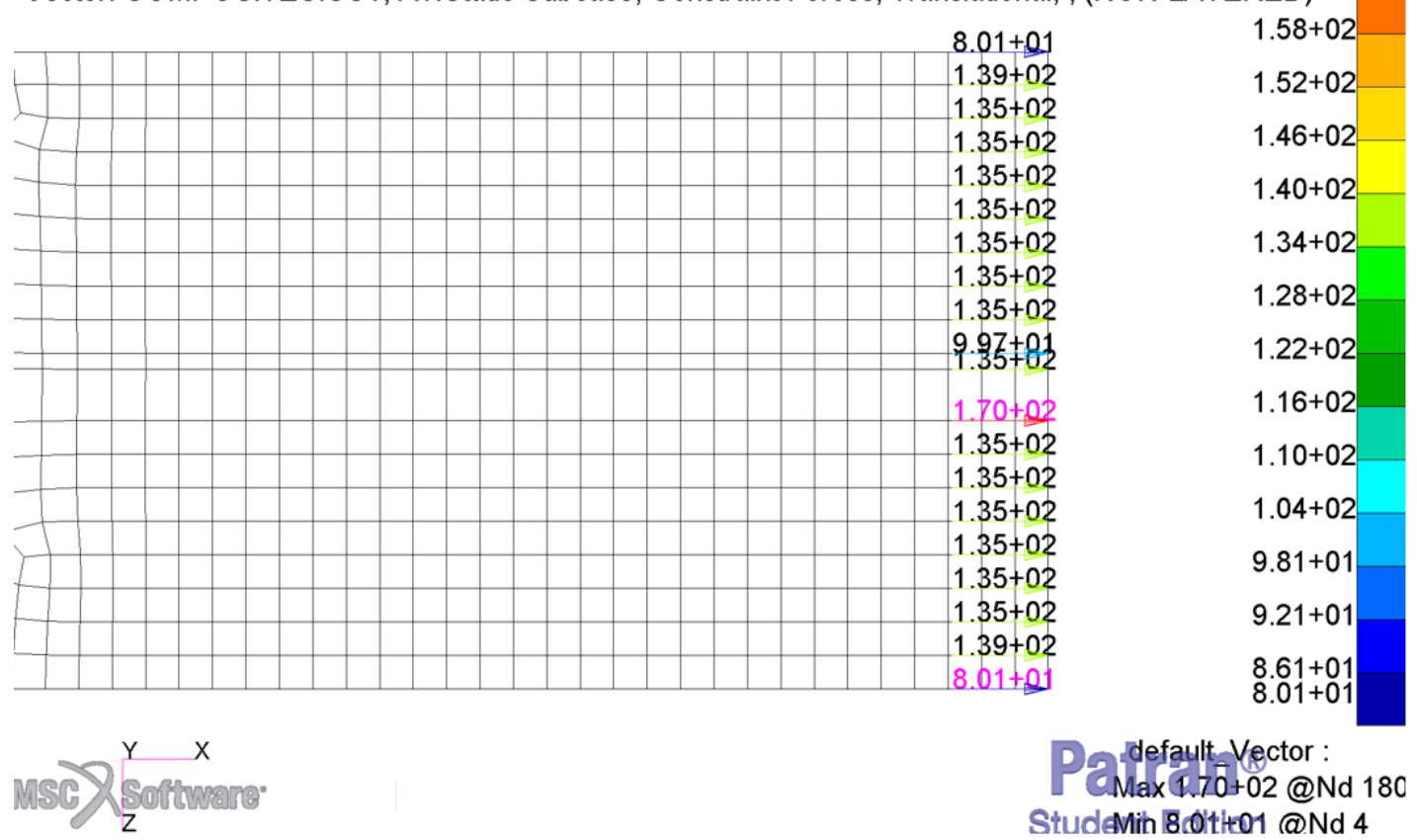

Figure 4-8 FEA Results - Constraint forces for quasi-isotropic laminate - $0^{\circ}$ Defect, LPF -

$(\mathbf{N} / \mathbf{m m})$.

It is observed that at SPCD of $2.17 \mathrm{~mm}$ all the plies of the first critical element have failed and the ply-wise element stresses for the first critical element is as shown in Table 4.3-1. The nodal force distribution is as shown in Figure 4-8. The average force with this method was found to fail at 108 $\mathrm{N} / \mathrm{mm}$.

$$
\begin{aligned}
\sigma_{(0 \text { Laminate })} & =\frac{F_{\text {average }}}{\text { thickness of the laminate }} \\
\sigma_{(0 \text { Laminate })} & =\frac{108}{3.504} \\
\sigma_{(0 \text { Laminate })} & =30.82 \mathrm{MPa}
\end{aligned}
$$

Failure Strain:

$$
\varepsilon_{(\text {Failure })}=\frac{\Delta L}{L}=\frac{2.17}{165}=1.3 \%
$$

The above strength value does not match the experimental results; as a result, LPF with stiffness reduction method on all the edge elements were implemented. The summary of this is presented 
below. Last ply failure criterion with reduction in stiffness method is used to determine the load at which all the plies in the layup fails. Once the ply is failed for the initial load, the stiffness in the direction of failure is reduced as discussed in section 2.1.4. This then leads the same ply to carry the load in the other direction. Load is increased until all the elements in the constraint location fails. Example: Element 53 was the last element to fail in the region. Table 4.3-2 below shows all the plies have failed in both $\mathrm{x}$ direction only. This is because in the course of analysis the stiffness of $\mathrm{y}$ direction was reduced. The nodal force is shown in Figure 4-9.

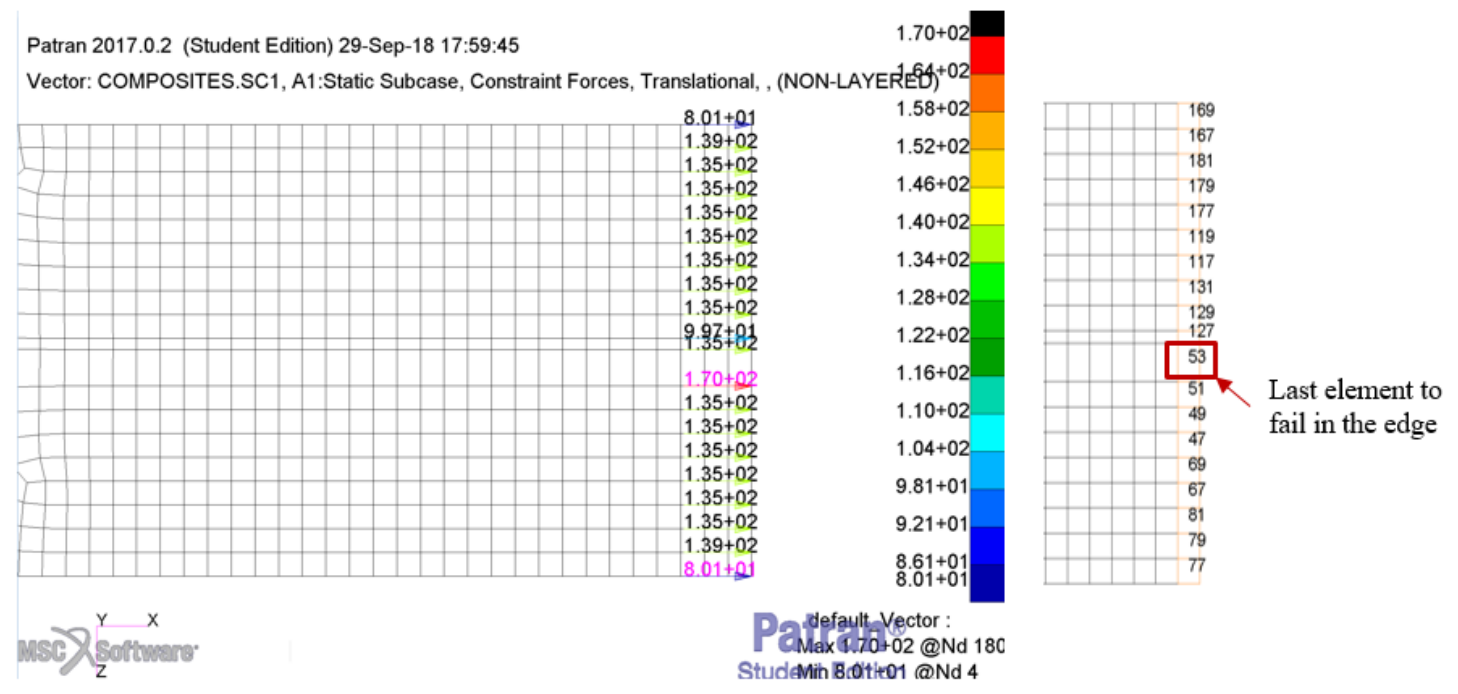

Figure 4-9 FEA Results - Constraint forces for quasi-isotropic laminate - $0^{\circ}$ Defect - (N/mm).

\section{Averaging methodology}

The defect element 127 fails first as the $0^{\circ}$ ply in this element is considered to be failed. However, the stiffness in all the other edge element is intact. As load is increased it is noticed that one by one the element starts to fail. The last element that fails is element 53. Elemental solution in FEA is the results generated by nodal integration. Both nodal and elemental results are generated by nodal solution but in elemental solution results were averaged to nodal value. The strength of the coupon is determined only when all the elements have failed (as shown in Figure 4-10). Hence the nodal force of the last element to fail is considered for averaging.

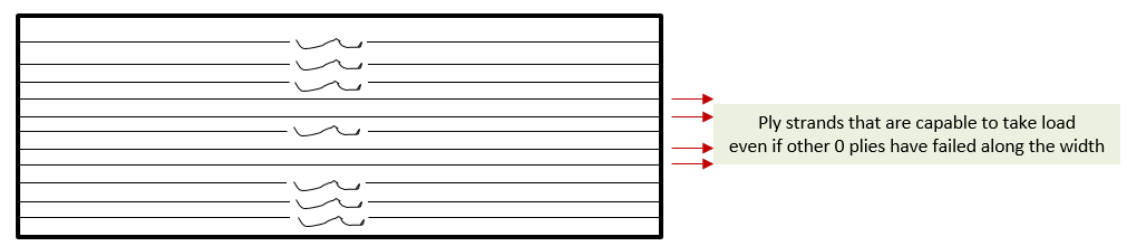

Figure 4-10 Load Averaging for $0^{\circ}$ Defect Coupon. 
Table 4.3-2 Ply-Wise Stresses and their Failure Index for quasi-isotropic laminate - $0^{\circ}$ Defect.

\begin{tabular}{|c|c|c|c|c|c|c|}
\hline Ply Id & Sigma L (MPa) & Sigma T (MPa) & Sigma LT (MPa) & Ply & FI @ $\mathbf{x}$ & FI @ $\mathbf{~}$ \\
\hline 1 & 28.95 & 0.12 & -28.99 & 45 & 1.003 & 0.008 \\
\hline 2 & 66.61 & 0.04 & 0.00 & 0 & 1.154 & - \\
\hline 3 & -8.69 & 0.20 & 0.00 & 90 & - & 0.007 \\
\hline 4 & 28.96 & 0.12 & 28.99 & -45 & 1.004 & 0.008 \\
\hline 5 & 28.95 & 0.12 & -28.99 & 45 & 1.003 & 0.008 \\
\hline 6 & 66.61 & 0.04 & 0.00 & 0 & 1.154 & - \\
\hline 7 & -8.69 & 0.20 & 0.00 & 90 & - & 0.007 \\
\hline 8 & 28.96 & 0.12 & 28.99 & -45 & 1.004 & 0.008 \\
\hline 9 & 28.95 & 0.12 & -28.99 & 45 & 1.003 & 0.008 \\
\hline 10 & 66.61 & 0.04 & 0.00 & 0 & 1.154 & - \\
\hline 11 & -8.69 & 0.20 & 0.00 & 90 & - & 0.007 \\
\hline 12 & 28.96 & 0.12 & 28.99 & -45 & 1.004 & 0.008 \\
\hline 13 & 28.96 & 0.12 & 28.99 & -45 & 1.004 & 0.008 \\
\hline 14 & -8.69 & 0.20 & 0.00 & 90 & - & 0.007 \\
\hline 15 & 66.61 & 0.04 & 0.00 & 0 & 1.154 & - \\
\hline 16 & 28.95 & 0.12 & -28.99 & 45 & 1.003 & 0.008 \\
\hline 17 & 28.96 & 0.12 & 28.99 & -45 & 1.004 & 0.008 \\
\hline 18 & -8.69 & 0.20 & 0.00 & 90 & - & 0.007 \\
\hline 19 & 66.61 & 0.04 & 0.00 & 0 & 1.154 & - \\
\hline 20 & 28.95 & 0.12 & -28.99 & 45 & 1.003 & 0.008 \\
\hline 21 & 28.96 & 0.12 & 28.99 & -45 & 1.004 & 0.008 \\
\hline 22 & -8.69 & 0.20 & 0.00 & 90 & - & 0.007 \\
\hline 23 & 66.61 & 0.04 & 0.00 & 0 & 1.154 & - \\
\hline 24 & 28.95 & 0.12 & -28.99 & 45 & 1.003 & 0.008 \\
\hline
\end{tabular}

It is observed that at SPCD of $3.79 \mathrm{~mm}$ all the plies have failed and the ply-wise element stresses for the last element to fail is as shown in Table 4.3-2. The nodal force distribution is as shown in Figure 
4-9. Based on the average force calculation explained above, the laminate is found to fail at 153 $\mathrm{N} / \mathrm{mm}$. Hence the strength and strain at failure for the laminate is as shown below.

$$
\begin{aligned}
\sigma_{(0 \text { Laminate })} & =\frac{F_{\text {average }}}{\text { thickness of the laminate }} \\
\sigma_{(0 \text { Laminate })} & =\frac{153}{3.504} \\
\sigma_{(0 \text { Laminate })} & =44 \mathrm{MPa}
\end{aligned}
$$

Failure Strain:

$$
\varepsilon_{(\text {Failure })}=\frac{\Delta L}{L}=\frac{3.79}{165}=2.30 \%
$$




\subsubsection{QUASI-ISOTROPIC LAMINATE WITH 90 ${ }^{\circ}$ DEFECT}

Quasi-isotropic coupon with $90^{\circ}$ defect is modeled similar to a $0^{\circ}$ defect shown in section 4.3.1.

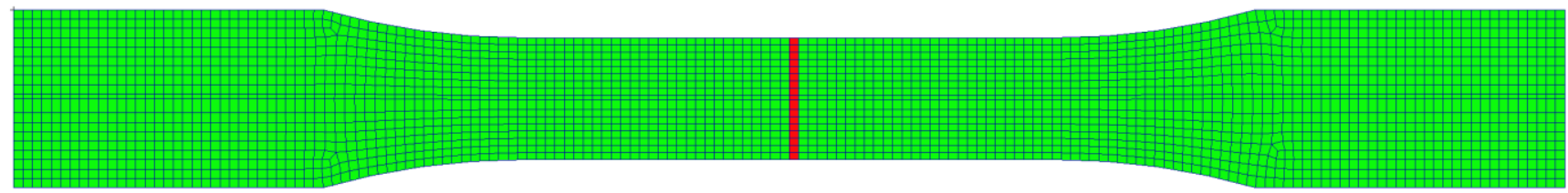

Figure 4-11 Quasi-isotropic laminate with $90^{\circ}$ Defect.

Similar procedure has been followed to determine the strength of quasi-isotropic laminate with $90^{\circ}$ defect. The varying nodal force is shown in Figure 4-12.

Patran 2017.0.2 (Student Edition) 30-Sep-18 13:25:33

Vector: COMPOSITES.SC1, A1:Static Subcase, Constraint Forces, Translational, , (NON-LAYERED)
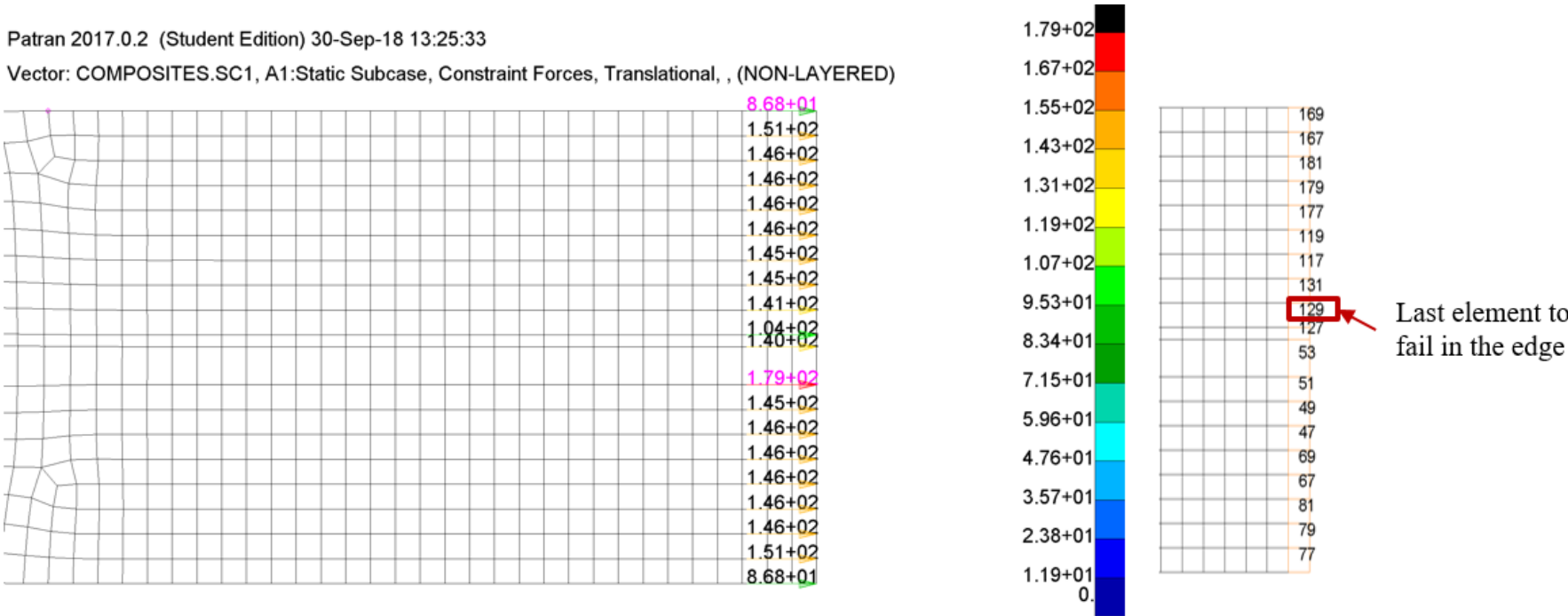

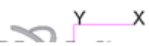

Patrdefault:iyector:

Figure 4-12 FEA Results - Constraint forces for quasi-isotropic laminate $-90^{\circ}$ Defect (N/mm). 
Table 4.3-3 Ply-Wise Stresses and their Failure Index for quasi-isotropic laminate - $90^{\circ}$ Defect.

\begin{tabular}{|c|c|c|c|c|c|c|}
\hline Ply Id & Sigma L (MPa) & Sigma T (MPa) & Sigma LT (MPa) & Ply & FI @ $\mathbf{~}$ & FI @ $\mathbf{~}$ \\
\hline 1 & 33.107 & 0.125 & -29.364 & 45 & 1.147 & 0.008 \\
\hline 2 & 69.282 & 0.044 & 1.515 & 0 & 1.200 & - \\
\hline 3 & -7.003 & 0.215 & -1.515 & 90 & - & 0.007 \\
\hline 4 & 29.172 & 0.134 & 29.364 & -45 & 1.011 & 0.009 \\
\hline 5 & 33.107 & 0.125 & -29.364 & 45 & 1.147 & 0.008 \\
\hline 6 & 69.282 & 0.044 & 1.515 & 0 & 1.200 & - \\
\hline 7 & -7.003 & 0.215 & -1.515 & 90 & - & 0.007 \\
\hline 8 & 29.172 & 0.134 & 29.364 & -45 & 1.011 & 0.009 \\
\hline 9 & 33.107 & 0.125 & -29.364 & 45 & 1.147 & 0.008 \\
\hline 10 & 69.282 & 0.044 & 1.515 & 0 & 1.200 & - \\
\hline 11 & -7.003 & 0.215 & -1.515 & 90 & - & 0.007 \\
\hline 12 & 29.172 & 0.134 & 29.364 & -45 & 1.011 & 0.009 \\
\hline 13 & 29.172 & 0.134 & 29.364 & -45 & 1.011 & 0.009 \\
\hline 14 & -7.003 & 0.215 & -1.515 & 90 & - & 0.007 \\
\hline 15 & 69.282 & 0.044 & 1.515 & 0 & 1.200 & - \\
\hline 16 & 33.107 & 0.125 & -29.364 & 45 & 1.147 & 0.008 \\
\hline 17 & 29.172 & 0.134 & 29.364 & -45 & 1.011 & 0.009 \\
\hline 18 & -7.003 & 0.215 & -1.515 & 90 & - & 0.007 \\
\hline 19 & 69.282 & 0.044 & 1.515 & 0 & 1.200 & - \\
\hline 20 & 33.107 & 0.125 & -29.364 & 45 & 1.147 & 0.008 \\
\hline 21 & 29.172 & 0.134 & 29.364 & -45 & 1.011 & 0.009 \\
\hline 22 & -7.003 & 0.215 & -1.515 & 90 & - & 0.007 \\
\hline 23 & 69.282 & 0.044 & 1.515 & 0 & 1.200 & - \\
\hline 24 & 33.107 & 0.125 & -29.364 & 45 & 1.147 & 0.008 \\
\hline
\end{tabular}

It is observed that at SPCD of $2.85 \mathrm{~mm}$ all the plies have failed and the ply-wise element stresses for the last element to fail is as shown in Table 4.3-3. The nodal force distribution is as shown in Figure 
4-12. Based on the average force calculation explained above, the laminate is found to fail at 147 $\mathrm{N} / \mathrm{mm}$. Hence the strength and strain at failure for the laminate is as shown below.

$$
\begin{aligned}
\sigma_{(0 \text { Laminate })} & =\frac{F_{\text {average }}}{\text { thickness of the laminate }} \\
\sigma_{(0 \text { Laminate })} & =\frac{147}{3.504} \\
\sigma_{(0 \text { Laminate })} & =41.95 \mathrm{MPa}
\end{aligned}
$$

Failure Strain:

$$
\varepsilon_{(\text {Failure })}=\frac{\Delta L}{L}=\frac{2.85}{165}=1.7 \%
$$




\subsubsection{QUASI-ISOTROPIC LAMINATE WITH $0^{\circ}$ AND $90^{\circ}$ DEFECT}

Quasi-isotropic with $0^{\circ}$ and $90^{\circ}$ defect is modeled as a combination of $0^{\circ}$ and $90^{\circ}$ defects and is shown in section 4.3.1.

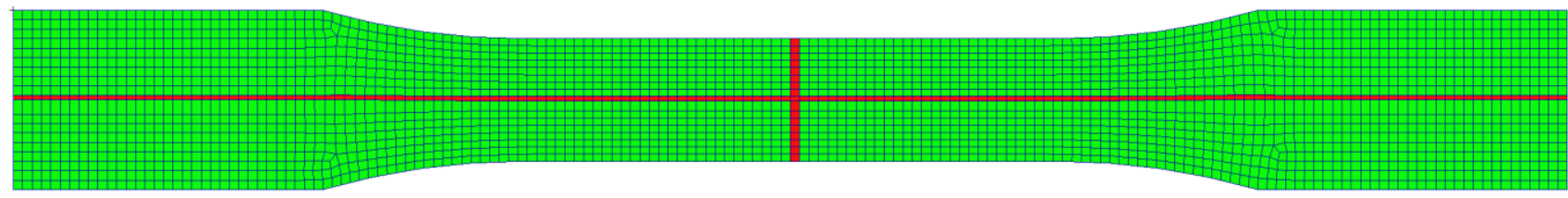

Figure 4-13 Quasi-isotropic laminate with $0^{\circ}$ and $90^{\circ}$ Defect.

Similar procedure has been followed to determine the strength of quasi-isotropic laminate with $0^{\circ}$ and $90^{\circ}$ defect. The varying nodal force is shown in Figure 4-14.

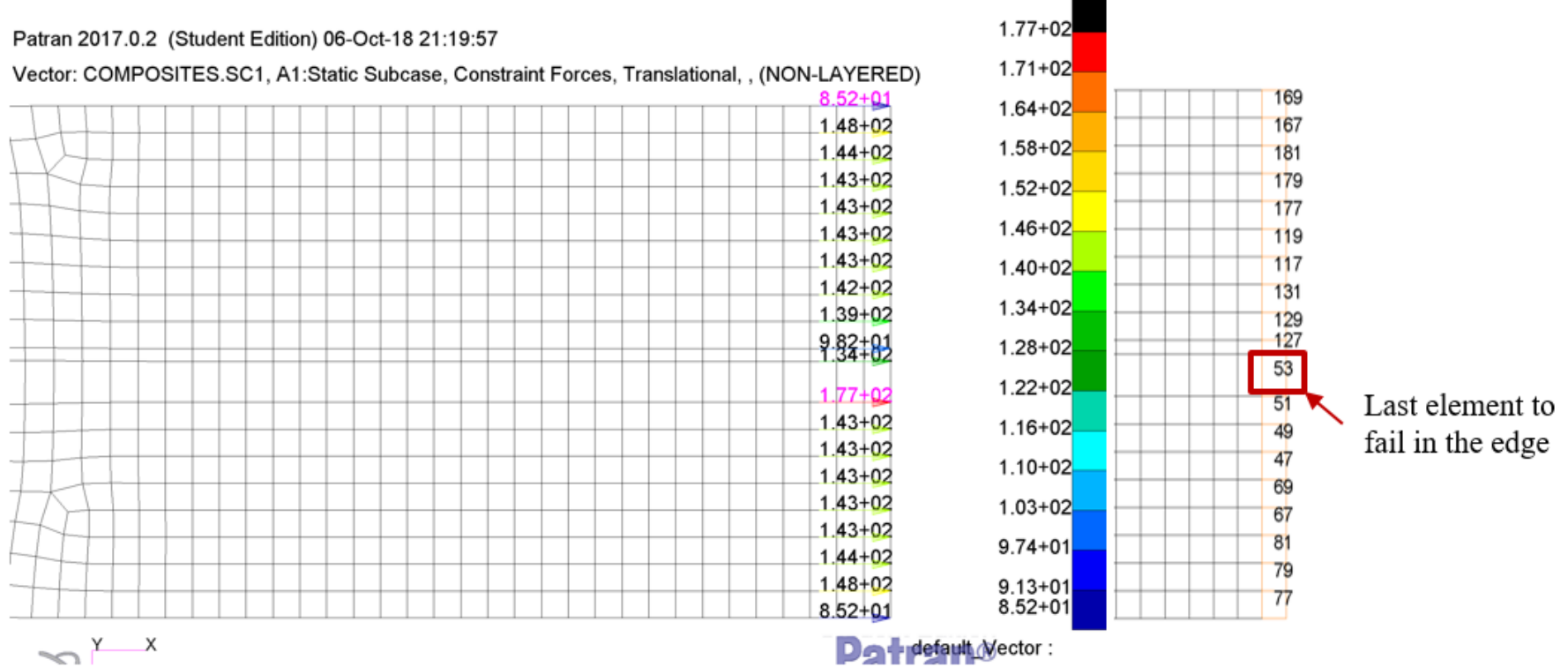

Figure 4-14 FEA Results - Constraint forces for quasi-isotropic laminate $-0^{\circ}$ and $90^{\circ}$ Defect $(\mathbf{N} / \mathbf{m m})$.

It is observed that at SPCD of $2.80 \mathrm{~mm}$ all the plies have failed and the ply-wise element stresses for the last element to fail is as shown in Table 7.3-4 
Table 4.3-4 Ply-Wise Stresses and Failure Index for quasi-isotropic laminate - $0^{\circ}$ and $90^{\circ}$ Defect.

\begin{tabular}{|c|c|c|c|c|c|c|}
\hline Ply Id & Sigma L (MPa) & Sigma T (MPa) & Sigma LT (MPa) & Ply & FI @ $\mathbf{x}$ & FI @y \\
\hline 1 & 29.73 & 0.13 & -29.46 & 45 & 1.030 & 0.009 \\
\hline 2 & 69.36 & 0.04 & -1.04 & 0 & 1.202 & - \\
\hline 3 & -7.17 & 0.21 & 1.04 & 90 & - & 0.007 \\
\hline 4 & 32.45 & 0.13 & 29.46 & -45 & 1.124 & 0.008 \\
\hline 5 & 29.73 & 0.13 & -29.46 & 45 & 1.030 & 0.009 \\
\hline 6 & 69.36 & 0.04 & -1.04 & 0 & 1.202 & - \\
\hline 7 & -7.17 & 0.21 & 1.04 & 90 & - & 0.007 \\
\hline 8 & 32.45 & 0.13 & 29.46 & -45 & 1.124 & 0.008 \\
\hline 9 & 29.73 & 0.13 & -29.46 & 45 & 1.030 & 0.009 \\
\hline 10 & 69.36 & 0.04 & -1.04 & 0 & 1.202 & - \\
\hline 11 & $\begin{array}{l}-7.17 \\
\end{array}$ & 0.21 & 1.04 & 90 & - & 0.007 \\
\hline 12 & 32.45 & 0.13 & 29.46 & -45 & 1.124 & 0.008 \\
\hline 13 & 32.45 & 0.13 & 29.46 & -45 & 1.124 & 0.008 \\
\hline 14 & $\begin{array}{l}-7.17 \\
\end{array}$ & 0.21 & 1.04 & 90 & - & 0.007 \\
\hline 15 & 69.36 & 0.04 & $\begin{array}{l}-1.04 \\
\end{array}$ & 0 & 1.202 & - \\
\hline 16 & 29.73 & 0.13 & -29.46 & 45 & 1.030 & 0.009 \\
\hline 17 & 32.45 & 0.13 & 29.46 & -45 & 1.124 & 0.008 \\
\hline 18 & -7.17 & 0.21 & 1.04 & 90 & - & 0.007 \\
\hline 19 & 69.36 & 0.04 & $\begin{array}{l}-1.04 \\
\end{array}$ & 0 & 1.202 & - \\
\hline 20 & 29.73 & 0.13 & -29.46 & 45 & 1.030 & 0.009 \\
\hline 21 & 32.45 & 0.13 & 29.46 & -45 & 1.124 & 0.008 \\
\hline 22 & -7.17 & 0.21 & 1.04 & 90 & - & 0.007 \\
\hline 23 & 69.36 & 0.04 & $\begin{array}{l}-1.04 \\
\end{array}$ & 0 & 1.202 & - \\
\hline 24 & 29.73 & 0.13 & -29.46 & 45 & 1.030 & 0.009 \\
\hline
\end{tabular}


The nodal force distribution is as shown in Figure 4-14. Based on the average force calculation, the laminate is found to fail at $158 \mathrm{~N} / \mathrm{mm}$. Hence the strength and strain at failure for the laminate is as shown below.

$$
\begin{aligned}
\sigma_{(0 \text { Laminate })} & =\frac{F_{\text {average }}}{\text { thickness of the laminate }} \\
\sigma_{(0 \text { Laminate })} & =\frac{158}{3.504} \\
\sigma_{(0 \text { Laminate })} & =45.09 \mathrm{MPa}
\end{aligned}
$$

Failure Strain:

$\varepsilon_{(\text {Failure })}=\frac{\Delta L}{L}=\frac{2.80}{165}=1.69 \%$ 


\section{COMPARISON WITH EXPERIMENTAL RESULTS}

As mentioned, experimental data is available for six different tests [29] as outlines below:

- Unidirectional 0-degree ply coupon without defects

- Unidirectional 90 degree ply coupon without defects

- Quasi-isotropic coupon without defects

- Quasi-isotropic Laminate with $0^{\circ}$ Defect

- Quasi-isotropic Laminate with $90^{\circ}$ Defect

- Quasi-isotropic Laminate with $0^{\circ}$ and $90^{\circ}$ Defect

Tensile tests on $0^{\circ}$ coupons captures the mechanical response of a 3D-printed part that mainly depends on the mechanical behavior of the extrudates. Conversely, tensile tests at $90^{\circ}$ are suitable for retrieving the mechanical characteristics of 3D-printed parts which primarily depend on the bonding process, i.e. on inter-extrudate properties.

The comparison between the experimental and FEA results of the previously described are tabulated below in Table 4.3-1, Table 7.3-2 and Table 4.3-3.From the results reported it can be concluded that strength modeling through maximum stress theory yielding criterion is sufficiently accurate to describe $0^{\circ}$ coupon behavior.

Table 4.3-1 FEA and Experimental Result Comparison- Unidirectional laminate.

\begin{tabular}{|l|l|l|l|}
\hline Mechanical Property & \multicolumn{1}{|c|}{$\begin{array}{c}\text { FEA } \\
\text { Results }\end{array}$} & \multicolumn{1}{|c|}{$\begin{array}{c}\text { Experimental } \\
\text { Results }\end{array}$} & $\begin{array}{c}\text { \% } \\
\text { Difference }\end{array}$ \\
\hline Young's modulus $(\mathrm{E})$ & $3.14 \mathrm{GPa}$ & $3.13 \mathrm{GPa}$ & 0.3 \\
\hline Shear Modulus $\left(\mathrm{G}_{12}\right)$ & $1.20 \mathrm{GPa}$ & Not available & - \\
\hline Poisson's ratio & 0.282 & Not available & - \\
\hline Laminae strength of $0^{\circ}$ & $57.92 \mathrm{MPa}$ & $57.72 \mathrm{MPa}$ & 0.3 \\
\hline Failure Strain & 2.30 & 1.96 & 17.3 \\
\hline
\end{tabular}


Table 4.3-2 FEA and Experimental Result Comparison- Unidirectional laminate.

\begin{tabular}{|l|l|l|l|}
\hline \multicolumn{1}{|c|}{ Mechanical Property } & FEA Results & Experimental Results & \% Difference \\
\hline Young's modulus (E) & $2.90 \mathrm{GPa}$ & $2.90 \mathrm{GPa}$ & 0.1 \\
\hline Shear Modulus $\left(\mathrm{G}_{12}\right)$ & $1.20 \mathrm{GPa}$ & Not available & - \\
\hline Poisson's ratio & 0.282 & Not available & - \\
\hline Laminae strength of $90^{\circ}$ & $31 \mathrm{MPa}$ & $30.8 \mathrm{MPa}$ & 0.6 \\
\hline Failure Strain & 1.3 & 1.15 & 13.0 \\
\hline
\end{tabular}

Table 4.3-3 FEA and Experimental Result Comparison- Quasi-Isotropic laminate.

\begin{tabular}{|l|c|c|c|}
\hline Mechanical Property & FEA Results & Experimental Results & $\begin{array}{c}\% \\
\text { Difference }\end{array}$ \\
\hline Young's modulus (E) & $3.05 \mathrm{GPa}$ & $3.11 \mathrm{GPa}$ & 1.92 \\
\hline Shear Modulus $\left(\mathrm{G}_{12}\right)$ & $1.19 \mathrm{GPa}$ & Not available & - \\
\hline Poisson's ratio & 0.282 & Not available & - \\
\hline $\begin{array}{l}\text { Laminate strength of } \\
(45 / 0 / 90 /-45) 3 \mathrm{~s}\end{array}$ & $53.41 \mathrm{MPa}$ & $53.48 \mathrm{MPa}$ & 0.1 \\
\hline Failure Strain & 2.27 & & 4.6 \\
\hline
\end{tabular}

Fiber orientation significantly affects tensile yield strength: longitudinal specimens have a much higher yield strength (almost double) than transverse specimens. However, the quasi-isotropic strength is in between longitudinal and transverse direction laminate but more towards the longitudinal directional laminate. Laminate elastic modulus and strength validation data shows a good consistency with FEA modeling estimation for all 3 configurations. The error percentage difference is less than 5\% for all 3 specimens. Although, in the beginning first ply failure analysis did not match the experimental data but maximum stress theory with last ply failure analysis shows a good correlation with the experimental data. The failure strain data for along and transverse direction testing $\left(0^{\circ}\right.$ and $90^{\circ}$ coupons $)$ shows an error of $17 \%$ and $13 \%$, respectively. This might be because of the brittle nature of the laminate in both along and transverse printing directions, where the failure happened suddenly. For quasi-isotropic laminate the failure in ductile in nature and the percent error between the experiment and FEA is $4.6 \%$. 
The comparison between the experimental and FEA results for the coupons with defects are tabulated below in Table 4.3-4, Table 4.3-5 and Table 4.3-6. The percent error for $0^{\circ}$ defect strength is $7.4 \%$, while the error for $90^{\circ}$ defect and $0^{\circ} / 90^{\circ}$ defect is $1.25 \%$ and $2.21 \%$, respectively. The best strength comparisons for the coupons with defects were computed by using last ply failure with maximum stress failure theory, stiffness reduction methodology and nodal force averaging. The prediction of strength is considering when parameters such as bonding is considered perfect. With intentional defects, bonding between the filaments or void content due to defect, is not captured in FEA and if any of these parameters exists in the specimen the results can vary drastically.

Table 4.3-4 FEA and Experimental Result Comparison- $0^{\circ}$ Defect.

\begin{tabular}{|l|l|l|l|}
\hline Mechanical Property & FEA Results & Experimental Results & \% Difference \\
\hline Young's modulus ( $\left.\mathrm{E}_{\text {eff }}\right)$ & $2.85 \mathrm{GPa}$ & $2.92 \mathrm{GPa}$ & 2.39 \\
\hline Shear Modulus $\left(\mathrm{G}_{12}\right)$ & $1.12 \mathrm{MPa}$ & Not available & - \\
\hline $\begin{array}{l}\text { Laminate strength of } \\
(45 / 0 / 90 /-45) 3 \mathrm{~s} \text { with } 0 \\
\text { defect }\end{array}$ & $44 \mathrm{MPa}$ & $47.50 \mathrm{MPa}$ & 7.4 \\
\hline Failure Strain & 2.30 & 2.88 & 20.1 \\
\hline
\end{tabular}

Table 4.3-5 FEA and Experimental Result Comparison-90 Defect.

\begin{tabular}{|l|l|l|l|}
\hline Mechanical Property & FEA Results & Experimental Results & \% Difference \\
\hline Young's modulus (E $\left.\mathrm{E}_{\mathrm{eff}}\right)$ & $2.82 \mathrm{GPa}$ & $2.81 \mathrm{GPa}$ & 0.4 \\
\hline Shear Modulus $\left(\mathrm{G}_{12}\right)$ & $1.12 \mathrm{GPa}$ & Not available & - \\
\hline $\begin{array}{l}\text { Laminate strength of } \\
(45 / 0 / 90 /-45) 3 \mathrm{~s} \text { with } \\
90^{\circ} \text { defect }\end{array}$ & $42 \mathrm{MPa}$ & $42.53 \mathrm{MPa}$ & 1.25 \\
\hline Failure Strain & 1.70 & 2.08 & 18.2 \\
\hline
\end{tabular}


Table 4.3-6 FEA and Experimental Result Comparison- $0^{\circ}$ and $90^{\circ}$ Defect.

\begin{tabular}{|l|l|l|l|}
\hline Mechanical Property & FEA Results & Experimental Results & \% Difference \\
\hline Young's modulus $\left(\mathrm{E}_{\text {eff }}\right)$ & $2.83 \mathrm{MPa}$ & $2.88 \mathrm{MPa}$ & 1.7 \\
\hline Shear Modulus $\left(\mathrm{G}_{12}\right)$ & $1.12 \mathrm{GPa}$ & Not available & - \\
\hline $\begin{array}{l}\text { Laminate strength of } \\
(45 / 0 / 90 /-45) 3 \mathrm{~s} \text { with } \\
0^{\circ} \& 90^{\circ} \text { defect }\end{array}$ & $45.09 \mathrm{MPa}$ & $46.11 \mathrm{MPa}$ & 2.21 \\
\hline Failure Strain & 1.69 & 2.06 & 17.9 \\
\hline
\end{tabular}




\section{CONCLUSION AND FUTURE WORK}

Mechanical characterization of PLA 3D printed coupons are simulated in FEM to obtain their stiffness, strength, and failure strain. Coupons with and without defects are considered and unidirectional $\left(0^{\circ}\right.$ and $\left.90^{\circ}\right)$ and quasi-isotropic stacking sequences are explored. First ply, last ply failure, and stiffness reduction iterative approach has been implemented on a 2D shell model with MSC Software to simulate the analysis. This simulation is then extended to predict strength and stiffness of a quasi-isotropic coupon with defects. The analysis is also extended to implement progressive failure analysis to predict the ultimate strength of the laminate. For coupons without defects, FE models estimated test results of stiffness and strength within $1 \%$ error, while the error for estimating failure strain is higher. For coupons with defects, the error in calculating stiffness and strength is below $8 \%$, while it is higher for failure strain. Although the stress-strain curve from FE simulation follows the same trend as the experimental results, it is found that progressive failure analysis is necessary for obtaining failure strain values with acceptable error percentage.

The result comparison without defects has less variations in strength and failure strain predictions. However, as soon as the defects are introduced the non-linearity in the model is increased and the prediction shows higher error percentage. The approach is limited to slight non-linearity in the model only.

The procedure mentioned in the analysis section is based on an iterative process. The process involves increasing/decreasing the load and reducing the stiffness of ply until the last ply fails. This requires good knowledge on the process and the software for an analyst. An attempt was made to eliminate this complex iteration process by using a non-linear implicit progressive analysis approach. But complete success was not achieved. The ultimate strength and failure strain of the laminate was not matched with the experimental results. The ultimate strength showed 18\% error, which is a huge number when compared to the results obtained by linear static analysis. However, stress-strain curve from FE simulation follows the same trend as the experimental results, which is shown in Figure 4-4. The reason for this can be due to the modelling approach, which was a simple 2D shell model. As a future scope of work, the detailed 3D modeling approach can be implement to predict the stiffness and strength of the 3D printed part. Secondly, for this study, maximum stress criterion was considered. The strength prediction can vary with failure criterion used in the study. A detail research of how strength of the part effects with the usage of different failure criterion and which one gives the closed results can be considered in the future work. 
On the third point, other commercial software in the industry for FEA simulations can be used. Researchers used Ansys and Abaqus software for simulation and can be considered as alternatives. Although all FEA packages perform on a similar way, but the capabilities and approaches used can be slightly different. MSc Nastran does not have the flexibility of editing the code by the analyst to perform the analysis they are require. On the other hand, Abaqus has this capability that can be investigated in future work. 


\section{REFERENCES}

1. Carneiro, OS., et al. (2015). Fused deposition modeling with polypropylene. Materials \& Design. 83: 768-776.

2. Berman, B. (2012). 3-D printing: The new industrial revolution. Business horizons, 55(2), 155-162.

3. Huang, B., \& Singamneni, S. (2015). Raster angle mechanics in fused deposition modelling. Journal of Composite Materials, vol.49(3), 363-383

4. Frenkel J. Viscous flow of crystalline bodies under the action of surface tension. $J$ Phys (USSR) 1945; 9:385-91.

5. Eshelby JD. Seminar on the kinetics of sintering. Transactions of the American Institute of Mining and Metallurgical Engineers 1949; 185(11): 796-813

6. Bayraktar, Ö., Uzun, G., Çakiroğlu, R., \& Guldas, A. (2017). Experimental study on the 3Dprinted plastic parts and predicting the mechanical properties using artificial neural networks. Polymers for Advanced Technologies, vol.28(8), 1044-1051

7. Xingchen Liu, V. S. (2016). Homogenization of material properties in additively manufactured. Computer-Aided Design, vol 78, 71-82

8. Domingo-Espin, M., Puigoriol-Forcada, J. M., Garcia-Granada, A., Llumà, J., Borros, S., \& Reyes, G. (2015). Mechanical property characterization and simulation of fused deposition modeling polycarbonate parts. Materials \& Design, vol.83, 670-677

9. Casavola, C., Cazzato, A., Moramarco, V., \& Pappalettere, C. (2016). Orthotropic mechanical properties of fused deposition modelling parts described by classical laminate theory. Materials \& Design, vol.90, 453-458

10. Alaimo, G., Marconi, S., Costato, L., \& Auricchio, F. (2017). Influence of meso-structure and chemical composition on FDM 3D-printed parts. Composites Part B: Engineering, vol.113, $371-380$

11. M Somireddy, A. C.-M. (2018). Development of constitutive material model of 3D printed structure via FDM. Materials Today Communications vol.15, 143-152

12. S.Maidin, C. S. (2016). Finite element analysis of Additive Manufactured textiles for stab resistant. ARPN Journal of Engineering and Applied Sciences, vol.11 no.3, 1529-1535

13. Brensons, I., \& Polukoshko, S. (2013). Fused deposition modelling as rapid prototyping for structural material improvement: Analytical solution, Latvian Journal of Physics and Technical Sciences, 50(5), 4 
14. Y Zhang, K. C. (2008). A parametric study of part distortions in fused deposition modelling using three-dimensional finite element analysis. Mechanical Engineering Department, University of Alabama, Tuscaloosa, Alabama, USA, 959-967

15. Zhang, Y. Y. (2006). Three-dimensional finite element analysis simulations of the fused deposition modelling process. Proceedings of the Institution of Mechanical Engineers. Part B, Journal of engineering manufacture, vol:220, 1663-1671

16. Rodríguez, J. F., Thomas, J. P., \& Renaud, J. E. (2001). Mechanical behavior of acrylonitrile butadiene styrene (ABS) fused deposition materials experimental investigation. Rapid Prototyping Journal, vol.7(3), 148-158

17. Nemat-Nasser, S., \& Hori, M. (2013). Micromechanics: overall properties of heterogeneous materials (Vol. 37). Elsevier.

18. Bellini, A., \& Güçeri, S. (2003). Mechanical characterization of parts fabricated using fused deposition modeling. Rapid Prototyping Journal, vol. 9(4), 252-264

19. Li, L., Sun, Q., Bellehumeur, C., \& Gu, P. (2002). Composite modeling and analysis for fabrication of FDM prototypes with locally controlled properties. Journal of Manufacturing Processes, vol. 4(2), 129-141

20. P.Kulkarni, D. (1999). Deposition Strategies and Resulting Part Stiffnesses in Fused Deposition Modeling. Journal of Manufacturing Science and Engineering, vol.121, 93-103

21. Pavan Kumar Gurrala \& Srinivasa Prakash Regalla (2014) Part strength evolution with bonding between filaments in fused deposition modelling, Virtual and Physical Prototyping, 9:3, 141-149

22. A Cattenone, S. M. (2019). Finite Element Analysis of Additive Manufacturing Based on Fused Deposition Modeling: Distortions Prediction and Comparison with Experimental Data. Journal of Manufacturing Science and Engineering, Vol.141.

23. P.Y.Tang. (1989). Development of a Progressive failure model for strength of a laminated composites, NOSC TD 1687

24. Butler, T. G., \& Michel, D. (1971). NASTRAN-A summary of the functions and capabilities of the NASA structural analysis computer system.

25. Field, E. I., Herting, D. N., \& Morgan, M. J. (1979). NASTRAN user's guide (Level 17.5). 
26. Reddy, Y. S. N., Moorthy, C. M. D., \& Reddy, J. N. (1995). Non-linear progressive failure analysis of laminated composite plates. International Journal of Non-Linear Mechanics, 30(5), 629-649

27. Pal, P., \& Ray, C. (2002). Progressive failure analysis of laminated composite plates by finite element method. Journal of Reinforced Plastics and Composites, 21(16), 1505-1513

28. Ramesh V. Bammankatti, Lakshminarayana H. V, Kiran Kumar. (2014). Stress Analysis and Ultimate Strength Prediction of Laminated Composite Panels With Cutouts, International Journal of Engineering Research \& Technology (IJERT), vol.3, Issue 8, 174-180

29. Fayazbakhsh, K., Movahedi, M., \& Kalman, J. (2019). The impact of defects on tensile properties of 3D printed parts manufactured by fused filament fabrication. Materials Today Communications, 18, 140-148.

30. Prusty, B. G., Ray, C., \& Satsangi, S. K. (2001). First ply failure analysis of stiffened panelsa finite element approach. Composite structures, 51(1), 73-81.

31. T.Y.Kam, H. (1996). Predictions of Deflection and First-ply Failure Load of Thin Laminated Composite Plates via The Finite Element Approach. Int. J. Solids Sructures vol 33.no. 3, 375398

32. Norzihan Rahimi, A. K. (2012). Capability Assessment of Finite Element Software in Predicting the Last Ply Failure of Composite Laminates. Procedia Engineering 41, 1647 1653

33. Berthelot J-M. Composite materials mechanical behavior and structural analysis. Mechanical engineering series. Springer; 1999

34. Jones, R. M., \& Bert, C. W. (1975). Mechanics of composite materials.

35. ASTM D638-14 Standard Test Method for Tensile Properties of Plastics.,1-13

36. Nampoothiri, K. M., Nair, N. R., \& John, R. P. (2010). An overview of the recent developments in polylactide (PLA) research. Bioresource technology, 101(22), 8493-8501.

37. Nastran, M. S. C. (2004). Quick Reference Guide: MSC. Nastran Corporation.

38. Stockwell, A. E. (1995). A verification procedure for msc/nastran finite element models 


\section{APPENDIX A}

The present finite element formulation is based on a classical laminate theory mentioned in [33] and [34]. The solution algorithms employed are based on the classical lamination theory (CLT) with the formation of the $[\mathrm{A}],[\mathrm{B}]$ and $[\mathrm{D}]$ stiffness matrices to provide the constitutive relationship of the laminate. FEA needs the definition of basic composite material properties at the ply level, definition and orientation of stacking sequences and definition of loadings or constriants.

\section{Classical Lamination Theory}

\section{Assumptions:}

- Laminates are assumed to be infinitely long and wide such that edge effects can be ignored.

- Laminates are assumed to be in a state of plane stress whereby there is no stress through the thickness of the laminate.

- Each lamina is perfectly bonded to neighboring laminas that comprise the laminate, such that there is no slippage between lamina.

- The laminate material is linearly elastic in response and its strains are small.

- Each lamina is of a uniformly, small thickness compared to its length and width.

- Thickness of the laminate remains unchanged during deformation.

- Mid-surface normals of the laminate remain normal after laminate deformation

\section{Constitutive Equations of a Lamina}

The generalized expression of Hooke's law for stresses, with respect to a rectangular coordinate system, at any point within a ply material under plane stress is given as

$$
\left[\begin{array}{c}
\sigma_{1} \\
\sigma_{2} \\
\sigma_{12}
\end{array}\right]=\left[\begin{array}{lll}
Q_{11} & Q_{12} & Q_{16} \\
Q_{12} & Q_{22} & Q_{26} \\
Q_{16} & Q_{26} & Q_{66}
\end{array}\right]\left[\begin{array}{c}
\varepsilon_{1} \\
\varepsilon_{2} \\
\varepsilon_{12}
\end{array}\right]
$$


Such that,

$$
\begin{aligned}
Q_{11} & =\frac{E_{11}}{1-\mu_{12} \mu_{21}} \\
Q_{22} & =\frac{E_{22}}{1-\mu_{12} \mu_{21}} \\
Q_{12} & =\frac{\mu_{12} E_{22}}{1-\mu_{12} \mu_{21}}=\frac{\mu_{21} E_{11}}{1-\mu_{12} \mu_{21}} \\
Q_{66} & =G_{12} \\
\mu_{21} & =\frac{\mu_{21} E_{11}}{E_{11}}
\end{aligned}
$$

While $\mathrm{Q}_{16}=\mathrm{Q}_{26}=0$

The equation (1) above describes the state of stress along the principal directions of the lamina (or ply) material and must be transformed to express states of stress for any ply not oriented to these. The matrix Q consisting of the Qij elements (for $\mathrm{i}, \mathrm{j}=1,2,6$ ) here, is the stiffness matrix with respect to the principal material directions. For a ply aligned to a different rectangular (x-y) coordinate system, oriented by angle with respect to axis 1 in Error! Reference source not found..

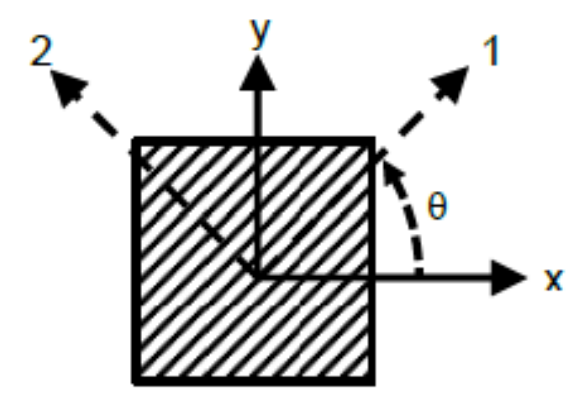

Figure 15 Sign Convention for In-Plane Transformation Angle $\theta$ [34]. 
The transformed state of stress is expressed below;

$$
\left[\begin{array}{c}
\sigma_{x} \\
\sigma_{y} \\
\sigma_{x y}
\end{array}\right]=\left[\begin{array}{lll}
\overline{Q_{11}} & \overline{Q_{12}} & \overline{Q_{16}} \\
\overline{Q_{12}} & \overline{Q_{22}} & \overline{Q_{26}} \\
\overline{Q_{16}} & \overline{Q_{26}} & \overline{Q_{66}}
\end{array}\right]\left[\begin{array}{c}
\varepsilon_{x} \\
\varepsilon_{y} \\
\varepsilon_{x y}
\end{array}\right]
$$

This is in accordance with the sign convention indicated per Error! Reference source not found., such that:

$$
\begin{aligned}
& \overline{Q_{11}}=Q_{11} \cos ^{4} \theta+2\left(Q_{12}+2 Q_{66}\right) \sin ^{2} \theta \cos ^{2} \theta+Q_{22} \sin ^{4} \theta \\
& \overline{Q_{22}}=Q_{11} \sin ^{4} \theta+2\left(Q_{12}+2 Q_{66}\right) \sin ^{2} \theta \cos ^{2} \theta+Q_{22} \cos ^{4} \theta \\
& \overline{Q_{12}}=\left(Q_{11}+Q_{22}-4 Q_{66}\right) \sin ^{2} \theta \cos ^{2} \theta+Q_{12}\left(\sin ^{4} \theta+\cos ^{4} \theta\right) \\
& \overline{Q_{16}}=\left(Q_{11}-Q_{12}-2 Q_{66}\right) \sin \theta \cos ^{3} \theta+\left(Q_{12}-Q_{22}+2 Q_{66}\right) \sin ^{3} \theta \cos \theta \\
& \overline{Q_{26}}=\left(Q_{11}-Q_{12}-2 Q_{66}\right) \sin ^{3} \theta \cos \theta+\left(Q_{12}-Q_{22}+2 Q_{66}\right) \cos ^{3} \theta \sin \theta \\
& \overline{Q_{66}}=\left(Q_{11}+Q_{22}-2 Q_{12}\right) \sin ^{2} \theta \cos ^{2} \theta+Q_{66}\left(\sin ^{2} \theta-\cos ^{2} \theta\right)^{2}
\end{aligned}
$$

\section{Constitutive Equation of the Laminate}

The state of strain of a laminate is expressed with respect to its mid-surface (or mid-plane) and is a function of the accumulated ply strain from each lamina. As such, lamina strains of the kth ply are expressed on the basis of this same datum per equation shown below,

$$
\left[\begin{array}{c}
\varepsilon_{x} \\
\varepsilon_{y} \\
\varepsilon_{x y}
\end{array}\right]_{k}=\left[\begin{array}{c}
\epsilon_{x}^{o} \\
\epsilon_{y}^{o} \\
\epsilon_{x y}^{o}
\end{array}\right]+z_{k}\left[\begin{array}{c}
k_{x} \\
k_{y} \\
k_{x y}
\end{array}\right]
$$

With,

$$
\left[\begin{array}{c}
\varepsilon_{x} \\
\varepsilon_{y} \\
\varepsilon_{x y}
\end{array}\right]_{k}=\left[\begin{array}{lll}
\overline{Q_{11}} & \overline{Q_{12}} & \overline{Q_{16}} \\
\overline{Q_{12}} & \overline{Q_{22}} & \overline{Q_{26}} \\
\overline{Q_{16}} & \overline{Q_{26}} & \overline{Q_{66}}
\end{array}\right]_{k}^{-1}\left[\begin{array}{c}
\sigma_{x} \\
\sigma_{y} \\
\sigma_{x y}
\end{array}\right]_{k}
$$

being the constitutive equation of the ply in a laminate.

Resultant forces and moments inducing laminate stresses per Eqn. (1) are calculated by integration of these stresses about the mid-surface as per equation shown below, 


$$
\begin{aligned}
& {\left[\begin{array}{l}
N_{x} \\
N_{y} \\
N_{x y}
\end{array}\right]=\left[\begin{array}{l}
\int_{\frac{-t}{2}}^{\frac{t}{2}} \sigma_{x} d z \\
\int_{\frac{-t}{2}}^{\frac{t}{2}} \sigma_{y} d z \\
\frac{t}{2} \\
\int_{\frac{-t}{2}}^{\frac{2}{2}} \sigma_{x y} d z
\end{array}\right]} \\
& {\left[\begin{array}{l}
M_{x} \\
M_{y} \\
M_{x y}
\end{array}\right]=\left[\begin{array}{l}
\int_{\frac{-t}{2}}^{\frac{t}{2}} \sigma_{x} z d z \\
\int_{\frac{-t}{2}}^{\frac{t}{2}} \sigma_{y} z d z \\
\int_{\frac{t}{2}}^{\frac{t}{2}} \sigma_{x y} z d z
\end{array}\right]}
\end{aligned}
$$

These equations algebraically combine to yield;

$$
\begin{aligned}
& {\left[\begin{array}{c}
N_{x} \\
N_{y} \\
N_{x y}
\end{array}\right]=\left[\begin{array}{lll}
A_{11} & A_{12} & A_{16} \\
A_{12} & A_{22} & A_{26} \\
A_{16} & A_{26} & A_{66}
\end{array}\right]\left[\begin{array}{c}
\epsilon_{x}^{o} \\
\epsilon_{y}^{o} \\
\epsilon_{x y}^{o}
\end{array}\right]+\left[\begin{array}{lll}
B_{11} & B_{12} & B_{16} \\
B_{12} & B_{22} & B_{26} \\
B_{16} & B_{26} & B_{66}
\end{array}\right]\left[\begin{array}{c}
k_{x} \\
k_{y} \\
k_{x y}
\end{array}\right]} \\
& {\left[\begin{array}{l}
M_{x} \\
M_{y} \\
M_{x y}
\end{array}\right]=\left[\begin{array}{lll}
B_{11} & B_{12} & B_{16} \\
B_{12} & B_{22} & B_{26} \\
B_{16} & B_{26} & B_{66}
\end{array}\right]\left[\begin{array}{c}
\epsilon_{x}^{o} \\
\epsilon_{y}^{o} \\
\epsilon_{x y}^{o}
\end{array}\right]+\left[\begin{array}{lll}
D_{11} & D_{12} & D_{16} \\
D_{12} & D_{22} & D_{26} \\
D_{16} & D_{26} & D_{66}
\end{array}\right]\left[\begin{array}{c}
k_{x} \\
k_{y} \\
k_{x y}
\end{array}\right]}
\end{aligned}
$$

where;

$$
\begin{aligned}
A_{i j} & =\sum_{k=1}^{N}\left(\overline{Q_{\imath \jmath}}\right)_{k}\left(z_{k}-z_{k-1}\right) \\
B_{i j} & =\frac{1}{2} \sum_{k=1}^{N}\left(\overline{Q_{\imath \jmath}}\right)_{k}\left(z_{k}^{2}-z_{k-1}^{2}\right) \\
D_{i j} & =\frac{1}{3} \sum_{k=1}^{N}\left(\overline{Q_{l \jmath}}\right)_{k}\left(z_{k}^{3}-z_{k-1}^{3}\right)
\end{aligned}
$$

The $[\mathrm{A}]$ matrix denotes coupling of shear and extensional deformations, the [B] matrix denotes coupling of flexural (bending) and extensional deformations while the [D] matrix denotes the coupling of bending and twisting deformations. 
Forces and moments identified adhere to the conventions indicated in Error! Reference source not found. as follows. Note the positive sense of moments Mx and My as depicted in Error! Reference source not found. is opposite in direction to the positive sense of such moments, as defined for CQUAD4 plate elements employed in NASTRAN.

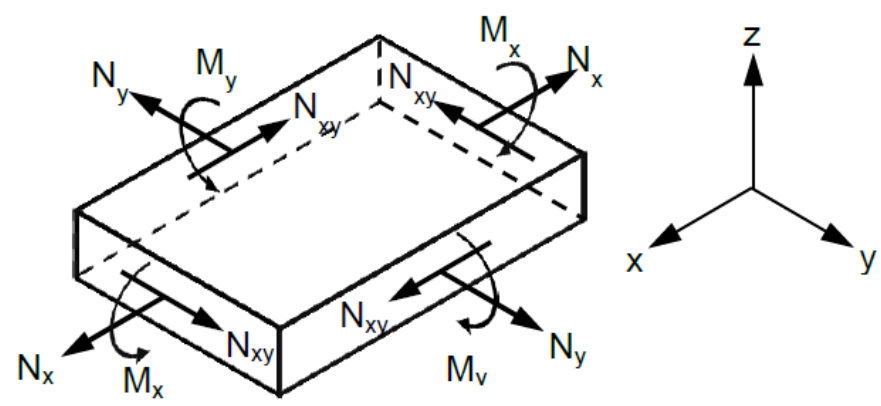

Figure 16 Force and Moment Sign Convention [34].

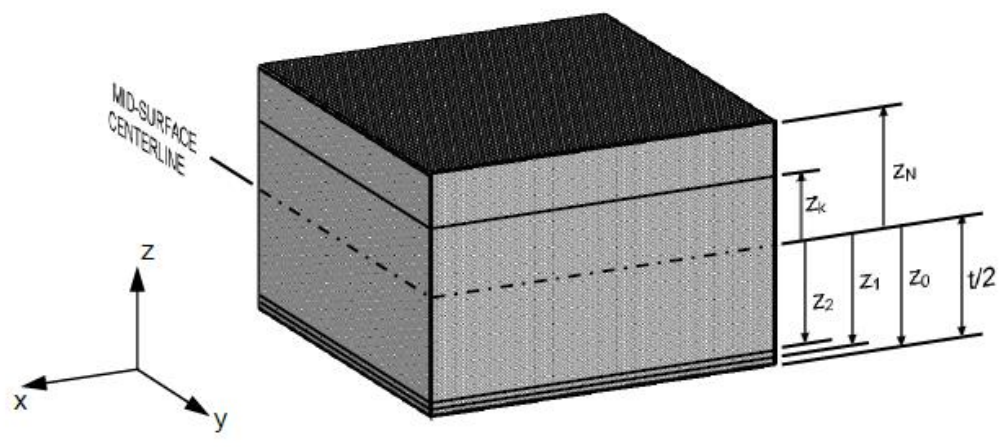

Figure 17 Z-Coordinates of a Laminate [34].

The outer most ply is considered as being a distance $Z_{0}$ from the mid-surface of the laminate such that:

$$
z_{0}=\frac{t}{2}
$$

Where is the thickness, $t$, of the laminate and is given by;

$$
t=\sum_{k=1}^{N} z_{k}-z_{k-1}=\sum_{k=1}^{N}\left(t_{k}\right)
$$

